Uma abordagem ciente de contexto e embasada por feedbacks para o gerenciamento de handovers em ambientes NGN 



\title{
Uma abordagem ciente de contexto e embasada por feedbacks para o gerenciamento de handovers em ambientes NGN
}

\section{Roberto Rigolin Ferreira Lopes}

Orientador: Prof. Dr. Edson dos Santos Moreira

\begin{abstract}
Tese apresentada ao Instituto de Ciências Matemáticas e de Computação - ICMC-USP, como parte dos requisitos para obtenção do título de Doutor em Ciências - Ciências de Computação e Matemática Computacional. VERSÃO REVISADA.
\end{abstract}

USP - São Carlos

Agosto de 2012 
Ficha catalográfica elaborada pela Biblioteca Prof. Achille Bassi e Seção Técnica de Informática, ICMC/USP, com os dados fornecidos pelo(a) autor(a)

\begin{tabular}{|c|c|}
\hline \multirow[t]{3}{*}{ L864a } & $\begin{array}{l}\text { Lopes, Roberto Rigolin Ferreira } \\
\text { Uma abordagem ciente de contexto e embasada por } \\
\text { feedbacks para o gerenciamento de handovers em } \\
\text { ambientes NGN / Roberto Rigolin Ferreira Lopes; } \\
\text { orientador Edson do Santos Moreira. -- São Carlos, } \\
2012 \text {. } \\
\quad 84 \mathrm{p} \text {. }\end{array}$ \\
\hline & $\begin{array}{l}\text { Tese (Doutorado - Programa de Pós-Graduação em } \\
\text { Ciências de Computação e Matemática Computacional) -- } \\
\text { Instituto de Ciências Matemáticas e de Computação, } \\
\text { Universidade de São Paulo, } 2012 \text {. }\end{array}$ \\
\hline & $\begin{array}{l}\text { 1. Gerenciamento de conectividade sem fio. } 2 . \\
\text { Serviços cientes de contexto. 3. Mídias sociais } \\
\text { baseadas em localização. I. Moreira, Edson do Santos, } \\
\text { orient. II. Título. }\end{array}$ \\
\hline
\end{tabular}




\section{Agradecimentos}

A minha mãe, a minha irmã e a tia Lúcia pela torcida.

A Profa. Agma (ICMC-USP) pelo apoio motivacional e financeiro.

Ao Prof. Bert-Jan (UTwente) por ter revisado e discutido todos os textos gerados nesta investigação, com exceção do presente.

Ao Prof. Azzedine (UOttawa) por ter lançado a investigação em direção a excelência. Não cheguei perto, mas valeu a intenção.

Ao Prof. Hélio (DC-UFSCar), meu orientador de mestrado, pelo exemplo de competência.

Aos professores G.A.R. Lima (UFMT) e Peter Zeilhofer (UFMT) pelo incentivo no início.

Aos professores Loureiro (DCC-UFMG), Marcondes (DC-UFSCar), Sichman (EP-USP) e Graça (ICMC-USP) pelas contribuições na banca.

Aos meus intrépidos amigos: Bruno Kimura, Bruno Tardiole, Danilo Coimbra, José Martins, Leandro Villas, Maycon Peixoto, Pablo Jaskowiak, Pedro Nobile, Roberto Sadao, e Tácito Trindade.

Por fim, a FAPESP e a Capes pelo apoio financeiro. 
Follow the path of the unsafe, independent thinker. Expose your ideas to the dangers of controversy. Speak your mind and fear less the label of 'crackpot' than the stigma of conformity. And on issues that seem important to you, stand up and be counted at any cost.

Thomas J. Watson (1874 - 1956) 

A evolução da computação móvel melhora a capacidade de comunicação e colaboração das pessoas. Os principais pilares desta transformação são: o desenvolvimento e a produção de dispositivos móveis com capacidade multimídia e equipados com duas ou mais interfaces de rede, a disponibilidade de conectividade sem fio ubíqua e a popularização de aplicações sociais online. As redes sociais online merecem destaque pelas funcionalidades que permitem a criação e o compartilhamento de conteúdo digital dentro de círculos sociais, tal conteúdo é também chamado de mídia social. Serviços na web anexam a localização geográfica do dispositivo ao conteúdo digital, criando as chamadas mídias sociais baseadas em localização. Equipadas com seus telefones e tablets, as pessoas estão criando e consumindo mídias sociais em qualquer lugar. Entretanto, é um desafio manter tais dispositivos móveis conectados nos ambientes de rede sem fio atuais e de próxima geração e.g., múltiplos provedores de acesso e múltiplas tecnologias de comunicação. Pesquisas recentes propõem componentes para o gerenciamento de conectividade sem fio que fazem uso simultâneo do contexto de conectividade atual e de um conjunto destes dados coletados no passado. Tais componentes são preditores de mobilidade, mecanismos de handover ou gerenciadores de mobilidade que utilizam dados de contexto de conectividade de forma particular para atingir seus propósitos. Na presente investigação, orquestramos um conjunto de métodos para gerenciamento de conectividade em um laço retro alimentado. Argumentamos que a coleta de dados de contexto de conectividade pode ser projetada como um sistema de sensoriamento, cujos sensores são as interfaces de rede sem fio. Como parte deste sistema de sensoriamento, os círculos sociais podem assistir o gerenciamento de conectividade, compartilhando dados de contexto de conectividade. A ideia central é utilizar serviços baseados em localização para compartilhar dados de contexto de conectividade dentro dos círculos sociais. Dessa forma, as redes sociais online adicionam escala para o sistema e permitem colaboração em volta de dados de contexto recentes, locais, personalizados e sociais. O objetivo é melhorar experiências de conectividade sem fio e.g., métricas de QoS (Quality of Service) como: vazão, latência e qualidade do sinal. Relatamos como os dados de contexto de conectividade são manipulados com um modelo baseado em grafos e métricas como intensidade do vértice e grau centralidade. Com isso, identificamos áreas com 
alta densidade de handovers, definimos a interação dos usuários e revelamos a cobertura das redes. Resultados de experimentos mostram que a colaboração pode melhorar métricas de QoS de $\sim 18$ a 30\% se comparado ao uso de um preditor de mobilidade ou um sistema operacional moderno, respectivamente. Esta discussão se desdobra com foco na viabilidade da solução em termos de sobrecarga de armazenamento e de consumo de energia. Os promissores resultados experimentais indicam que nossa solução pode melhorar experiências de conectividade sem fio de usuários móveis.

Palavras-chave: Dados de contexto de conectividade sem fio, gerenciamento de conectividade sem fio, mídias sociais baseadas em localização, redes sociais online, serviços cientes de contexto. 
7 he evolution of mobile computing improves communication and collaboration among people. The main pillars of this transformation are: the development and production of mobile devices with multimedia capabilities and equipped with two or more network interfaces, the availability of ubiquitous wireless connectivity and the popularity of online social applications. Online social networks noteworthy features that allow for the creation and sharing of digital content within social circles, also called Social Media. Web Services attach the geographic location of the device to the digital content, creating the so-called location-based social media. Equipped with their phones and tablets, people are creating and consuming social media anywhere. However, it is a challenge to keep such mobile devices connected in current and next generation wireless network environments e.g., multiple ISPs (Internet Service Provider) and multiple communication technologies. Recent researches proposes components for managing wireless connectivity that make simultaneous use of the current and past connectivity context data. Such components are mobility predictors, handovers mechanisms or mobility managers that use connectivity context data in a particular way to achieve its purposes. In this research, we orchestrated a set of methods for connectivity management in a feedback loop. We argue that the process of gathering connectivity context data can be designed as a sensing system, whose sensors are wireless network interfaces. As part of this sensing system, the social circles may assist the management of connectivity by sharing connectivity context data. The main idea is to use locationbased services to share connectivity context data within social circles. Thus, online social networks add scale to the system and enables collaboration around recent, local, and social context data. The goal is to enhance wireless connectivity experiences in terms of QoS (Quality of Service) metrics e.g., throughput, latency and signal quality. We report how this data is handled using complex networks metrics e.g., vertex's strength and centrality degree, to identify high density handover areas, define the mobile users' reputation and to reveal the networks coverage. Real experiments showed that collaboration can improve QoS metrics from $\sim 18$ to $~ 30 \%$ if compared to just use a mobility predictor or a modern operational system, respectively. The discussion unfolds with focus on the collaboration's efficiency as function of 
time, number of users, discovered area size and mobility patterns. The promising experimental results indicate that our solution can enhance mobile users wireless connectivity experiences.

Keywords: Context-aware services, location-based social media, online social networking, wireless connectivity management, wireless connectivity context data. 
$\begin{array}{lll}\text { Resumo } & \mathbf{v}\end{array}$

$\begin{array}{lll}\text { Abstract } & \text { vii }\end{array}$

Lista de abreviaturas $\quad$ xiii

Lista de figuras $\quad$ Xv

$\begin{array}{ll}\text { Lista de tabelas } & \text { xvii }\end{array}$

1 Introdução $\quad 1$

1.1 Hipótese . . . . . . . . . . . . . . . . . . . . . . . . . . 5

1.2 Desafios .............................. . . . 5

1.3 Objetivo .......................... 6

1.4 Contribuições .............................. . . 6

1.5 Estrutura da dissertação . . . . . . . . . . . . . . . . . . . . . . . . 7

2 Conceitos fundamentais 9

2.1 Cenário .............................. . . . 9

2.2 Computação móvel . . . . . . . . . . . . . . . . . . . . . . . . . 12

2.3 Redes sem fio de próxima geração . . . . . . . . . . . . . . . . 13

2.4 Algoritmo ideal para gerenciamento de conectividade . . . . . . . . . . . . . . 14

2.4.1 Preditor de mobilidade . . . . . . . . . . . . . . . . . . 16

2.4.2 Mecanismos de handover . . . . . . . . . . . . . . . . . 17

2.4.3 Gerenciador de mobilidade . . . . . . . . . . . . . . . . . 18

2.5 Gerenciamento de conectividade ciente de contexto . . . . . . . . . . . . . 20

2.5.1 Arquitetura SOHand .................... 20

2.5.2 Trabalhos relacionados .................... 22

2.6 Sensoriamento continuado . . . . . . . . . . . . . . . . . 25

2.7 Mídia social baseada em localização . . . . . . . . . . . . . . . . . . . . 27 
2.8 Considerações finais $\ldots \ldots \ldots \ldots \ldots \ldots \ldots \ldots$

3 Contexto de conectividade sem fio $\quad 29$

3.1 Dados de contexto de conectividade . . . . . . . . . . . . . . . . . . . . . 29

3.2 Modelo de dados . . . . . . . . . . . . . . . . . . . . 31

3.2 .1 Caminho de conectividade . . . . . . . . . . . . . . 31

3.2 .2 Grafo de conectividade . . . . . . . . . . . . . . . . . . . 32

3.2.3 Manipulando o grafo de conectividade . . . . . . . . . . . . . . 35

3.2 .4 Exemplo de aplicação . . . . . . . . . . . . . . . . . 37

3.3 Viabilidade . . . . . . . . . . . . . . . . . 38

3.3.1 Sobrecarga de armazenamento . . . . . . . . . . . . . . 39

3.3.2 Consumo de energia . . . . . . . . . . . . . . . . 40

3.3 .3 Economizando recursos . . . . . . . . . . . . . . . 41

3.4 Considerações finais . . . . . . . . . . . . . . . . . 43

4 Proposta $\quad 45$

4.1 Laço retroalimentado . . . . . . . . . . . . . . . . . . . . . . 45

4.1 .1 Coletar e combinar . . . . . . . . . . . . . . . 47

4.1 .2 Sumarizar . . . . . . . . . . . . . . . . . . 48

4.1 .3 Compartilhar . . . . . . . . . . . . . . . . 49

4.2 Desenvolvimento . . . . . . . . . . . . . . . . . . 50

4.2.1 Comunidade virtual especializada . . . . . . . . . . . . 50

4.2.2 Anexando contexto de conectividade a mídias sociais . . . . . . . . . . . 51

4.3 Considerações finais . . . . . . . . . . . . . . . . . . 54

5 Avaliação quantitativa $\quad \mathbf{5 5}$

5.1 Ambiente de experimentação . . . . . . . . . . . . . . . . 55

5.1 .1 Sistema de localização . . . . . . . . . . . . . . . . . 56

5.2 Experimentos . . . . . . . . . . . . . . . . . . . . . 59

5.2 .1 Descrição . . . . . . . . . . . . . . . . . . . . . 59

5.2.2 Mensurando as métricas de QoS . . . . . . . . . . . . . . . 60

5.3 Resultados . . . . . . . . . . . . . . . . . . . . . . 60

5.3 .1 Visão geral . . . . . . . . . . . . . . . . . . . 60 60

5.3.2 Analisando caminhos particulares . . . . . . . . . . . . . . 62

5.4 Padrões de mobilidade . . . . . . . . . . . . . . . . . . 64

5.5 Pontos positivos e negativos . . . . . . . . . . . . . 66

5.6 Considerações finais $\ldots \ldots \ldots \ldots \ldots$. . . . . . . . . . . . . . . 67

6 Conclusão e trabalhos futuros $\quad 69$

6.1 Contribuições . . . . . . . . . . . . . . . . . . 70

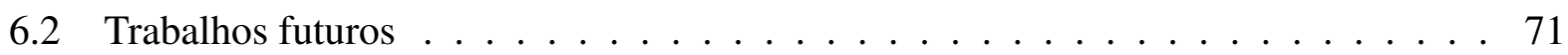


Referências 
AAA Authorization, Authentication and Accounting ..................... 14

ABC $\quad$ Always Best Connected ................................. 11

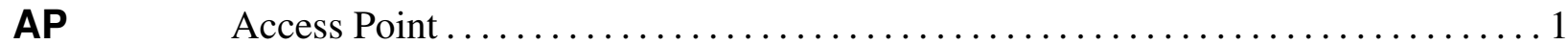

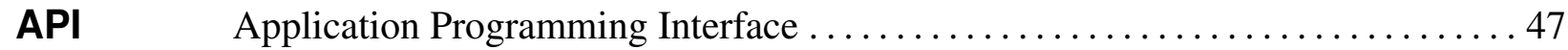

CRAWDAD Community Resource for Archiving Wireless Data At Dartmouth ........... 31

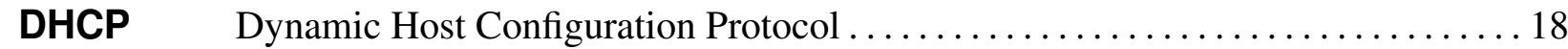

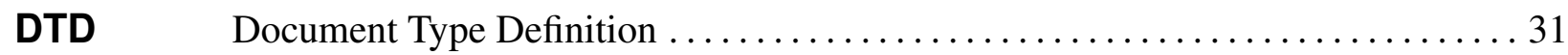

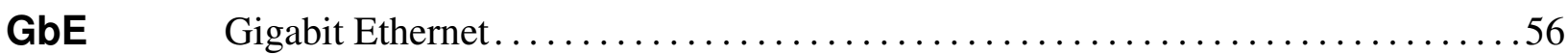

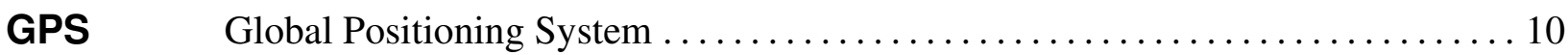

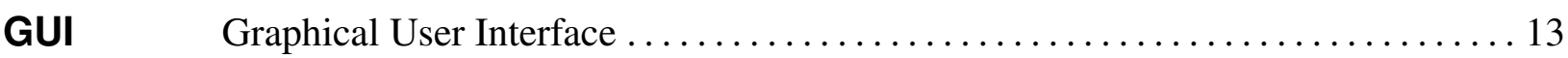

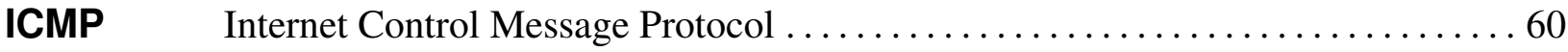

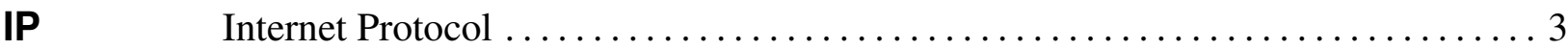

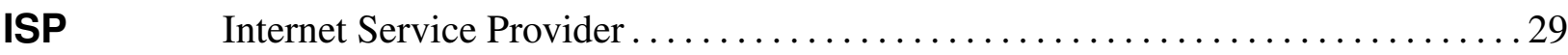

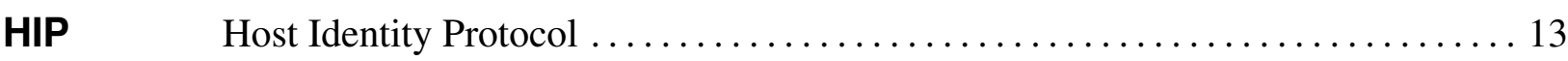

HOPES Handoff Prediction and Enhancement Scheme.......................23

HTML HyperText Markup Language ...........................60

HTTP Hypertext Transfer Protocol ................................ 51

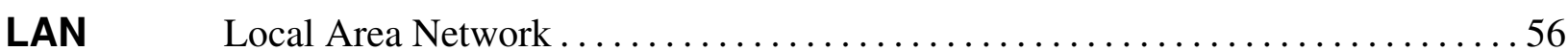

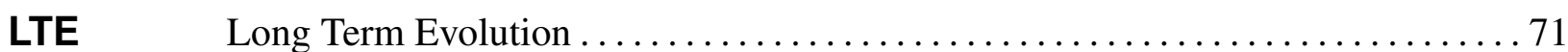

MAC Media Access Control ..................................... 10

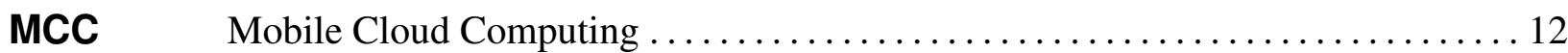

MIHA Media Independent Handover Architecture ........................... 19

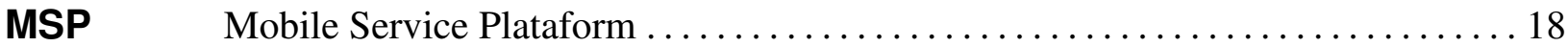

MUM $\quad$ Mobile agent-based Ubiquitous multimedia Middleware ................ 18

NGN Next Generation Network . . . . . . . . . . . . . . . . . . . . . . . . . 3

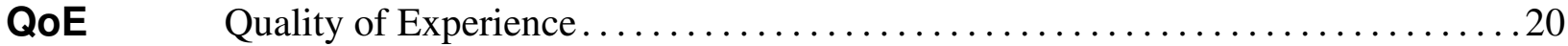




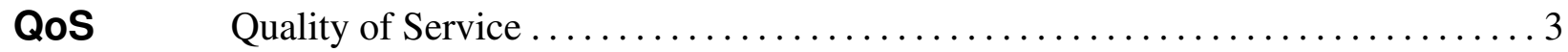

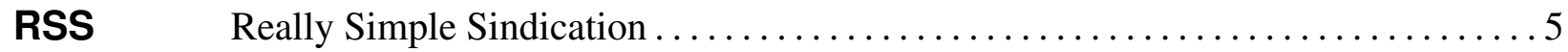

RSSI Received signal strength indication ........................... 59

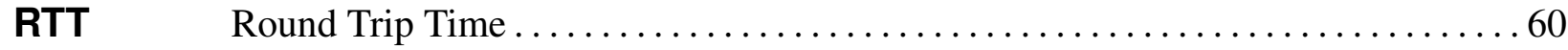

SGBD Sistema Gerenciador de Banco de Dados ..................... 55

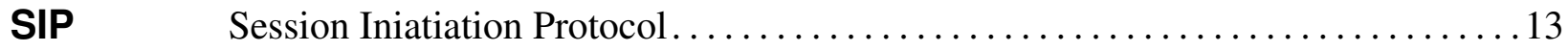

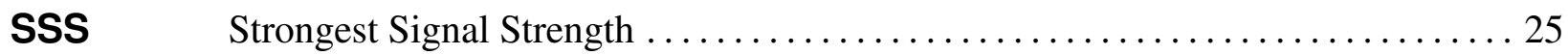

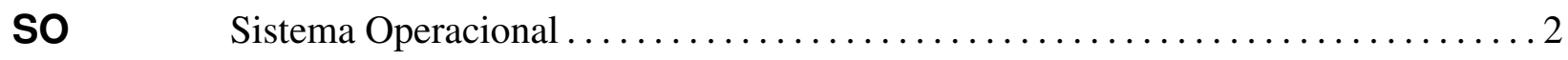

SOHand Service Oriented architecture for Handovers $\ldots \ldots \ldots \ldots \ldots \ldots \ldots \ldots \ldots$

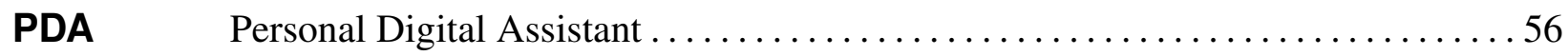

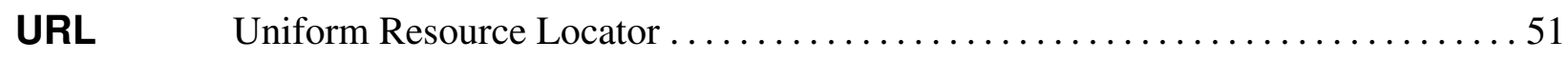

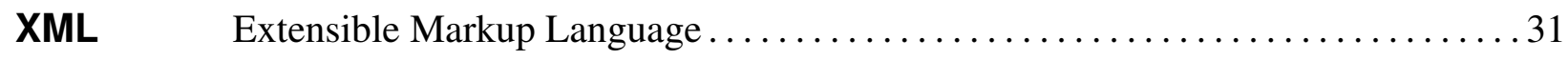

WLAN Wireless Local Area Network..................................20 
1.1 Principais eixos que suportam a evolução da conectividade sem fio. . . . . . . . . . 2

2.1 Cenário hipotético para ilustrar a motivação desta investigação. . . . . . . . . . . . 10

2.2 Ilustração da Computação Móvel na nuvem. . . . . . . . . . . . . . . . . . . . . 12

2.3 Arquitetura funcional de um ambiente ABC. Adaptada de (Gustafsson e Jonsson,

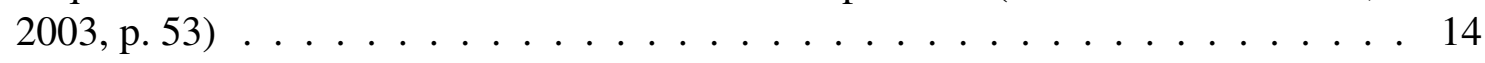

2.4 Algoritmo ideal para gerenciamento de conectividade sem fio. . . . . . . . . . 15

2.5 Principais componentes do gerenciamento de conectividade sem fio e ciente de

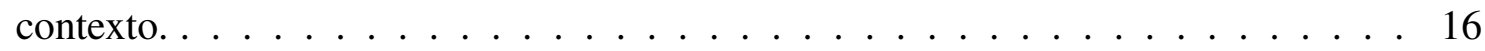

2.6 (a) Construindo o modelo. (b) Exemplo de cadeia de Markov. Adaptada de (Nicholson e Noble, 2008, p. 48). . . . . . . . . . . . . . . 17

2.7 Exemplo de handover ciente de contexto . . . . . . . . . . . . . . . . 18

2.8 Pilha de camadas TCP/IP e os mecanismos de gerenciamento de mobilidade. . . . 19

2.9 Módulos da arquitetura SOHand. . . . . . . . . . . . . . . . . . 22

2.10 Dois tipos de conectividade: (1) uma interface e múltiplas conexões, (2) múltiplas interfaces com uma conexão. . . . . . . . . . . . . . . . . . . . 24

2.11 Arquitetura de sensoriamento continuado. Adaptada de (Lane et al., 2010, p. 143). 25

2.12 Espectro de possibilidades de sensoriamento em termos de escala e nível envolvimento dos participantes na coleta de dados. . . . . . . . . . . . 26

2.13 Processo de geração, (1), e consumo, (2), de mídias sociais baseadas em localização. 28

3.1 Cenário de coleta de dados de contexto de conectividade sem fio. . . . . . . . . . 30

3.2 Exemplo de conjunto de dados de contexto de rede e suas respectivas fontes. . . . . 30

3.3 Exemplo de ponto de handover onde diferentes usuários trocaram de rede. . . . . . 32

3.4 (a) Exemplo hipotético de caminhos de conectividade. (b) Representação dos caminhos como grafos direcionados. . . . . . . . . . . . . . 33

3.5 Grafo de conectividade do exemplo hipotético. . . . . . . . . . . . . . 34

3.6 Instância dos grafos (1) $G_{\text {users }}$ e (2) $G_{\text {net }}$ para o exemplo hipotético. . . . . . . . 36

3.7 Dados coletados. . . . . . . . . . . . . . . . . 37

3.8 Áreas com alta densidade de trocas de rede. . . . . . . . . . . . . . 38 
3.9 Estimativa de consumo de energia e sobrecarga de armazenamento no dispositivo móvel. . . . . . . . . . . . . . . . . . . . . . 39

3.10 Frequência de varredura (1) e consumo de energia (2) em função da probabilidade de descobrir uma oportunidade de conectividade. . . . . . . . . . . . . . . . . 41

3.11 Grafo de conectividade criado no ambiente de experimentação (Lopes et al., 2010a). 42

4.1 Métodos: (1) Coletar dados de contexto de conectividade; (2) combina-los; (3) sumarizar os dados quantitativos de QoS; e, (4) compartilhar a combinação. . . . . . 46

4.2 Exemplo de dados de contexto de conectividade sem fio coletados por um usuário móvel. . . . . . . . . . . . . . . . . . . . . . 47

4.3 Principais processos no dispositivo móvel durante a coleta de dados de contexto. . . 48

4.4 Dados quantitativos de contexto de conectividade em um determinado ponto de handover.

4.5 Interface web mostrando uma lista de redes e os pontos de acesso mais utilizados de uma determinada rede. . . . . . . . . . . . . . . . . . . . . . . . . 4 49

4.6 (1) fragmento de um arquivo RSS. (2) representação textual do grafo de conectividade. . . . . . . . . . . . . . . . . . . 50

4.7 Interface web do gerenciador de contexto e uma visão abstrata da aplicação distribuída: (1) dados pessoais (2) feeds subscritos, (3) membros da comunidade, (4) agregador de RSS feeds, e (5) uma comunidade virtual B. . . . . . . . . . . . . . . 51

4.8 Popular mashup na web: (a) interface da rede social online; e (b) uma visão abstrata das principais entidades. . . . . . . . . . . . . . . . 52

4.9 Duas formas de interação: (1) compartilhando uma experiência; and (2) buscando por sugestões no circulo social do usuário móvel. . . . . . . . . . . . . . . . 53

5.1 Configuração dos servidores, APs e sistema de distribuição no ambiente de experimentação. . . . . . . . . . . . . . . . . . . . 56

5.2 Estimando a localização do dispositivo móvel. . . . . . . . . . . . . . . . . . 57

5.3 1) Distância em função da potência do sinal nos 28 pontos do prédio. 2) Comparação da distância estimada de 2 APs em diferentes andares. . . . . . . . . . . . 58

5.4 Resumo de como as métricas de QoS foram recuperadas. . . . . . . . . . . . . . 60

5.5 Evolução da qualidade do sinal em função do tempo. . . . . . . . . . . . . . . . 61

5.6 Histograma da vazão de dados(rx), durante quatro meses, para: (A) SSS, (B) Preditor de mobilidade, e (C) Social. . . . . . . . . . . . . . . . . . . . . . 62

5.7 Proporção das principais métricas sobre os valores máximos. . . . . . . . . . . . 63

5.8 Grafo de conectividade para o caminho entre Alpha e Charlie. . . . . . . . . . . . 64

5.9 Vazão e qualidade do sinal em função do tempo no caminho entre Alpha e Charlie e vice-versa. . . . . . . . . . . . . . . . . . . . 65

5.10 (1) Posição dos APs no ambiente. (2) Dados de contexto de conectividade coletados no ambiente. . . . . . . . . . . . . . . . . . . 65

5.11 Tempo para descobrir ilhas de conectividade em função do número de usuários móveis e seus padrões de mobilidade (Lopes et al., 2012b). . . . . . . . . . . . . . 66

6.1 Cenário de gerenciamento de conectividade sem fio em um futuro próximo. . . . . 72 
2.1 Trabalhos relacionados e o uso dos componentes de gerenciamento de conectividade. 25

3.1 Descrição dos parâmetros para cada grafo ou informação. . . . . . . . . . . . . . 36

3.2 Estimativa do número de varreduras, sobrecarga de armazenamento e consumo de

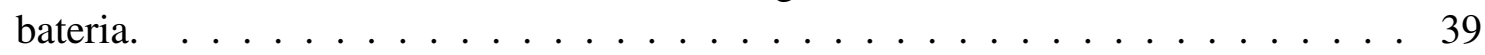

3.3 Crescimento do banco de dados em função do percentual de pontos de acesso descobertos durante uma caminhada (velocidade menor que $8 \mathrm{~km} / \mathrm{h}$ ). . . . . . . . 39

3.4 Sobrecarga de armazenamento e consumo de bateria empregando políticas de var-

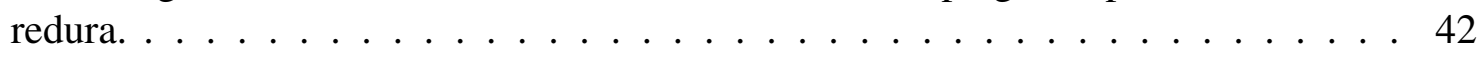

5.1 Erro dos três modelos aplicados para estimar a localização do dispositivo em função da potência do sinal. . . . . . . . . . . . . . . . . 58

5.2 Métricas de QoS observadas no caminho Alpha-Bravo. . . . . . . . . . . . . . 63 


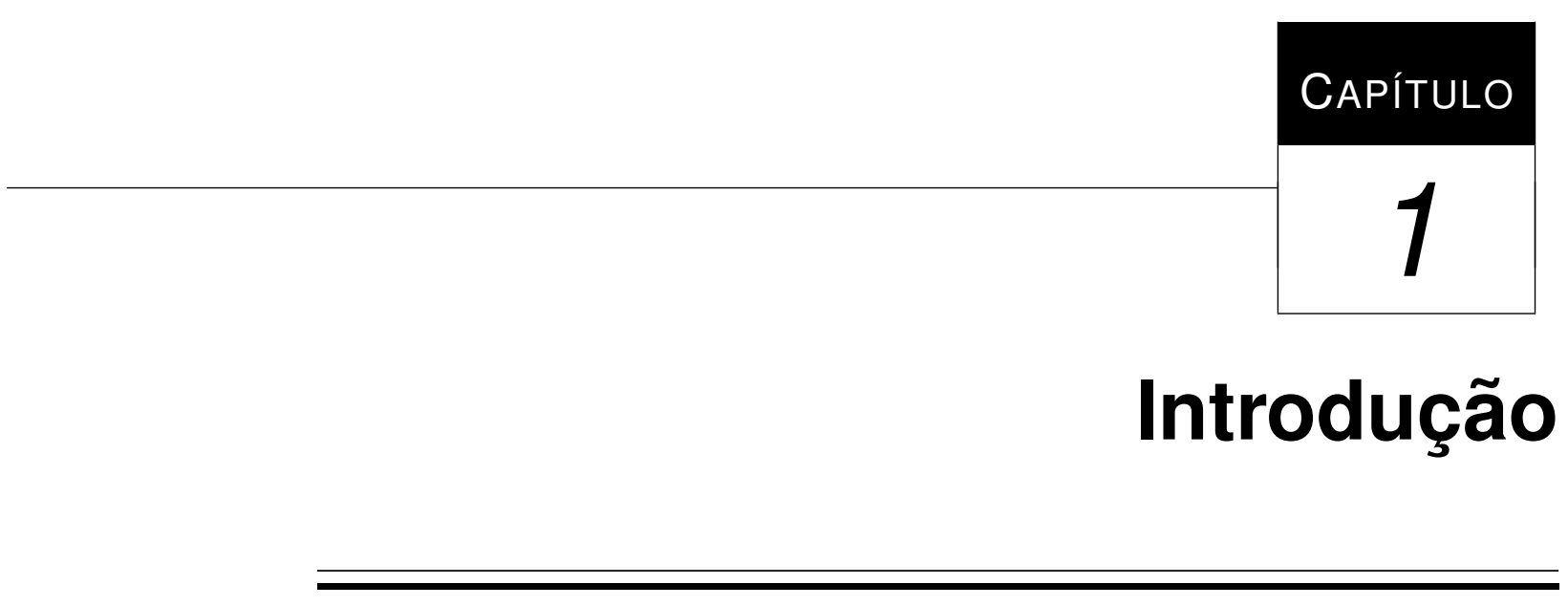

A capacidade de comunicação sem fio dos dispositivos móveis atuais e.g., telefones e tablets, permite que as pessoas se mantenham conectadas a Internet enquanto se movimentam de um lugar para outro em diversas escalas de espaço, como, por exemplo, de casa para o trabalho ou de uma cidade a outra. Observamos que com o passar dos anos a capacidade de comunicação e colaboração das pessoas melhora em função de três esforços essenciais: evolução e produção de hardware e tecnologias de comunicação sem fio; pesquisa e desenvolvimento de mecanismos de gerenciamento de conectividade sem fio; e projeto e implementação de aplicações sociais online.

Podemos visualizar tais esforços como eixos de um gráfico em três dimensões, como o apresentado na Figura 1.1. Nesse gráfico, a evolução da conectividade sem fio é uma curva regida por uma função contínua nos três eixos. Na presente investigação, propomos que as pessoas colaborem de forma oportuna para melhorar suas experiências de conectividade sem fio. Para alcançar tal objetivo, colocamos as pessoas, organizadas em círculos sociais online, suportadas pelo plano formado pelo gerenciamento de conectividade e pelas aplicações sociais para alavancar suas experiências de conectividade sem fio. As pessoas estão apoiadas nesse plano porque é possível gerenciar a conectividade sem fio de forma colaborativa, centrada nos usuários e com suporte de redes sociais online para disseminação das experiências de conectividade.

Retomando aos eixos na Figura 1.1, o hardware dos dispositivos móveis evolui com avançadas interfaces com o usuário, processadores mais velozes e mais econômicos, maior capacidade de armazenamento e disponibilidade de interfaces de rede sem fio que utilizam tecnologias de comunicação distintas em termos de vazão de dados suportada, velocidade de deslocamento do dispositivo e tamanho da área de cobertura do ponto de acesso (do inglês Access Point (AP)). 


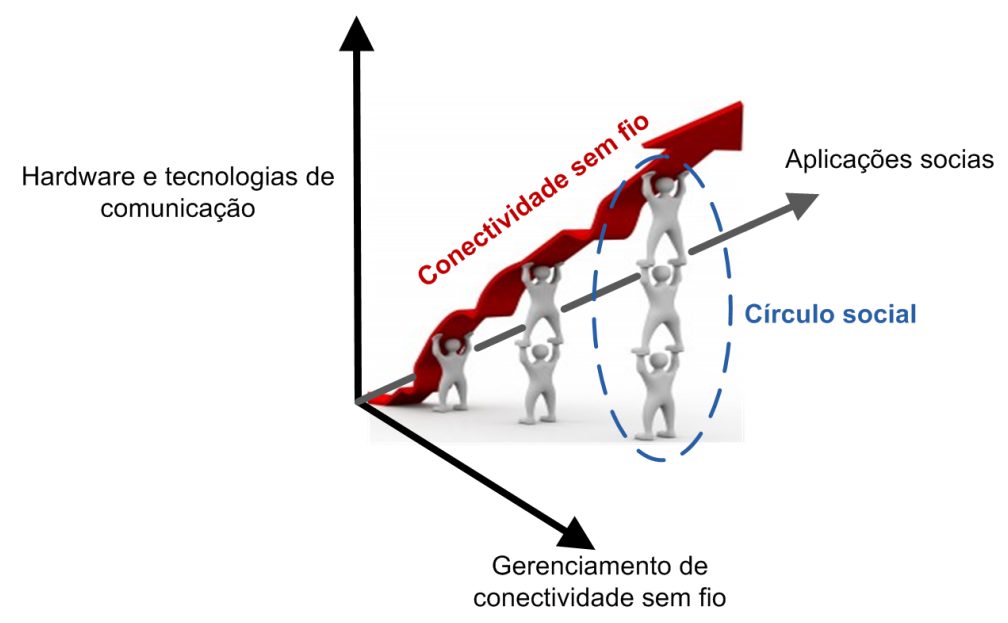

Figura 1.1: Principais eixos que suportam a evolução da conectividade sem fio.

Particularmente, os avanços na engenharia de conectividade sem fio melhoram as características fundamentais das tecnologias de comunicação sem fio e.g., largura de banda, área de cobertura e segurança.

Em paralelo, a comunidade científica desenvolve mecanismos para gerenciar a conectividade sem fio, outro eixo na Figura 1.1, explorando os recursos dos dispositivos móveis modernos e.g., múltiplas interfaces de rede sem fio, Sistema Operacional (SO) multi-tarefa, boa capacidade de processamento e de armazenamento. Nos dias atuais, existem propostas para transformar os dispositivos móveis em plataformas de sensoriamento. Essas iniciativas envolvem o desenvolvimento de arquiteturas para permitir o uso eficiente de dois ou mais sensores em termos de capacidade computacional e consumo de energia (Lane et al., 2010; Ganti et al., 2011).

As aplicações sociais online (Nazir et al., 2008), último eixo na Figura 1.1, utilizam conteúdo digital na web como elemento básico da comunicação ou colaboração. Tal conteúdo é chamado de mídia social (Kaplan e Haenlein, 2010), que agrega pessoas, tecnologias web e conteúdo digital para permitir que pessoas compartilharem suas experiências entre si (Multisilta e Milrad, 2009). Em outras palavras, as mídias sociais são um conjunto de experiências na vida real ou virtual mediada por tecnologias na forma de conteúdo digital (Smith et al., 2008).

A viabilidade desse relevante conteúdo digital depende de aplicações web como as redes sociais online (Garton et al., 1997; Kumar et al., 2010). Essas comunidades virtuais, (Ridings e Gefen, 2004), conectam pessoas com interesses em comum, com laços afetivos ou que já estão juntas compartilhando a mesma localização (Morr e Kawash, 2007). Atualmente, as pessoas equipadas com seus dispositivos móveis estão criando e consumindo mídias sociais em qualquer lugar. Algumas aplicações na web oferecem serviços que anexam a localização geográfica as mídias sociais, criando as chamadas mídias sociais baseadas em localização (Li e Chen, 2009b; Backstrom et al., 2010). Essas mídias são publicadas nos círculos sociais online e os membros podem postar comentários e re-compartilhar.

Entretanto, o desafio é manter os dispositivos móveis conectados enquanto o usuário está se movimentando por ambientes de rede com múltiplos provedores acesso que podem utilizar tec- 
nologias de comunicação distintas (Gustafsson e Jonsson, 2003), também chamadas de redes de próxima geração (do inglês Next Generation Network (NGN) (Berezdivin et al., 2002)). Dada a crescente complexidade dos ambientes NGN, o gerenciamento de conectividade ciente de contexto se torna caro em termos de computabilidade e de custo i.e., é computacionalmente complexo e tem alto preço monetário (Tlais e Weis, 2006).

A complexidade computacional ocorre porque o dispositivo móvel é responsável por executar tarefas essenciais gerenciamento como, por exemplo, recuperar, armazenar, sincronizar e processar dados de contexto de conectividade sem fio. Essas são funcionalidades básicas de diversas soluções para gerenciamento de conectividade sem fio publicadas na literatura e.g., (Chan et al., 1998; Yokota et al., 2002; Kim et al., 2007; Nicholson e Noble, 2008; Yami e Vakili, 2009; Wack, 2009; Nicholson et al., 2010; Prasad e Agrawal, 2010).

As investigações supracitadas fazem uso simultâneo do contexto de conectividade atual e de um conjunto destes dados, coletados no mesmo lugar no passado, para manter o dispositivo móvel conectado à Internet. O conjunto de informações é também chamado de perfil de mobilidade ou experiência de conectividade sem fio. Esse conjunto de dados históricos é utilizado como entrada por mecanismos de handover - troca de rede (Eastwood et al., 2008), por preditores de mobilidade do usuário (Song et al., 2006), por preditores de qualidade de serviço (do inglês Quality of Service $(Q o S))$ e por padrões e protocolos de gerenciamento de mobilidade (Chan et al., 2001).

No início desta investigação, uma fonte comum desse tipo de dados eram os bancos de dados públicos, também conhecidos como wardriving databases (Nicholson et al., 2006). Entretanto, estes bancos de dados têm tamanho considerável, se tornam desatualizados rapidamente e, geralmente, armazenam apenas informações básicas, como as disponíveis em beacons WiFi (IEEE 802.11) (LaMarca et al., 2005b).

Poucas investigações direcionam esforços para melhorar a relevância dos dados históricos de contexto de conectividade e para facilitar a atualização dos mesmos, que são fonte fundamental de informação para gerenciadores de conectividade atuais (Wack, 2009). Em geral, os dados de contexto devem ser locais, móveis, atuais, personalizados e sociais, para serem úteis para seus particulares propósitos. Com essa ideia em mente, iniciamos esta investigação organizando as principais tarefas do gerenciamento de conectividade sem fio e ciente de contexto em um conjunto de métodos. Demos prioridade para os dados e métodos utilizados para gerenciamento de conectividade IP (do inglês Internet Protocol (IP)) em ambientes NGN (Lopes et al., 2010a).

Os métodos para gerenciamento de conectividade sem fio, propostos na presente investigação, estão orquestrados em um laço retro alimentado. O processo pode ser assistido por uma comunidade virtual especializada ou por redes sociais populares (e.g., Twitter ${ }^{1}$ e Facebook ${ }^{2}$ ). A ideia é permitir a colaboração entre usuários móveis dentro de seus círculos sociais (Li e Chen, 2009a). Como resultado, o laço retro alimentado converge para melhores experiências de conectividade sem fio para todos os envolvidos.

\footnotetext{
$1_{\text {https: } / / \text { dev.twitter.com/ }}$

2 http: / / developers.facebook.com/
} 
Para viabilizar as interações entre os métodos, propusemos um modelo de dados baseado em grafos para representar as experiências de conectividade sem fio. Uma experiência de conectividade sem fio é um conjunto de dados de contexto, incluindo métricas de QoS, relacionadas a um ponto de acesso utilizado por um dispositivo móvel em um determinado lugar e horário. $\mathrm{O}$ conjunto de experiências de conectividade espaçadas pelo tempo e pela localização é representado por um grafo direcionado chamado caminho de conectividade $\left(G_{\text {path }}\right)$. Discutimos como coletar, combinar e compartilhar este tipo de dados, argumentando que as redes sociais online são lugares apropriados para alcançar pessoas de forma colaborativa.

A combinação dos caminhos de conectividade de dois ou mais usuários é chamado grafo de conectividade $\left(G_{c o n n}\right)$, que é o conteúdo compartilhado. Os dados de contexto associados ao grafo de conectividade podem ser utilizados para extrair informações úteis e.g., áreas com alta densidade de trocas de redes, a interação entre os usuários no compartilhamento de dados e a cobertura das redes sem fio. Isso é feito manipulando o grafo $G_{c o n n}$ e aplicando ferramentas de redes complexas (Barrat et al., 2004) e.g., a intensidade do vértice (do inglês vertex's strength) e o grau de centralidade do vértice. A viabilidade do modelo foi delimitada em termos de sobrecarga de armazenamento e de consumo de bateria.

A tarefa de coletar dados de contexto de conectividade sem fio é fundamental para o gerenciamento de conectividade ciente de contexto. Argumentamos que esse tipo de gerenciador pode ser projetado como uma aplicação de sensoriamento continuado, onde os sensores são as interfaces de rede sem fio. Considerando a escala da aplicação, esse mecanismo de gerenciamento pode ser classificado como aplicações de mobile crowdsensing (Ganti et al., 2011) ou de sensoriamento em comunidade (Lane et al., 2010). Nesse cenário, os usuários móveis podem compartilhar dados em círculos sociais online e extrair informações para mensurar e mapear as oportunidades de conectividade sem fio em uma determinada região.

Existem algumas arquiteturas propostas na literatura orquestrando os componentes para coletar, aprender, informar e compartilhar dados sensoriados. Entretanto, a comunidade científica concorda que existe pouca experiência prática no projeto e construção de sistemas de sensoriamento (Lane et al., 2010; Ganti et al., 2011). Os desafios técnicos estão relacionados ao compartilhamento de informação, privacidade dos envolvidos, análise de dados em larga escala e em como disponibilizar experiencias úteis para um grupo, comunidade ou população (Lane et al., 2010). As aplicações de sensoriamento disponíveis nos dias atuais foram projetadas para propósitos específicos (e.g., monitoramento de sinais vitais e congestionamentos). De maneira holística, não é claro quais componentes da arquitetura deveriam executar no dispositivo móvel e quais deveriam executar na nuvem (Ganti et al., 2011). A presente investigação contribui nesse sentido.

Um protótipo foi desenvolvido com objetivo de avaliar quantitativamente a nossa proposta (Lopes et al., 2011a). Validamos a proposta mostrando que mecanismos de tomada de decisão de handover podem ter resultados melhores com a solução proposta. Nosso protótipo foi utilizado por três pessoas em um ambiente de rede sem fio de aproximadamente $3.200 \mathrm{~m}^{2}$ por quatro meses. Mesmo com poucos membros, os resultados mostram que a nossa solução obteve melhores 
resultados de QoS se comparado ao uso do gerenciamento reativo dos SOs atuais, ou ao uso de um modelo de predição de mobilidade empregando dados não-compartilhados. Os resultados experimentais mostram que as experiências de conectividade sem fio melhoraram significativamente com a colaboração, mesmo em um ambiente com ótima cobertura de rede.

Algumas redes sociais online disponibilizam interfaces de programação para embutir aplicações de terceiros e plugins para permitir a interação entre sites comuns e a comunidade virtual. Durante a prototipação, exploramos essas possibilidades de duas formas: criando uma comunidade virtual especializada e fazendo mashups (Yu et al., 2008) com mídias sociais baseadas em localização. No primeiro caso, temos uma aplicação web que implementa o conjunto de métodos proposto. O circulo social é trazido para aplicação por meio de um plugin do Google+ ${ }^{3}$ (no início desta investigação era chamado de Google Friends Connect). Os dados de contexto são compartilhados em canais Really Simple Sindication (RSS) (Ma, 2009).

No segundo caso, os dados de contexto de conectividade sem fio são anexados a mídias sociais baseadas em localização. Esse tipo de mídia combina a localização do dispositivo móvel, em um mapa, com uma mensagem e link especificados pelo usuário. Isso permite que as pessoas busquem por experiências dos seus amigos no mesmo local recebendo também as experiências de conectividade sem fio deles. Com isso adicionamos relevância e visibilidade para as informações de contexto de conectividade sem fio compartilhadas. A relevância e visibilidade aumentam porque os dados de contexto de conectividade estão anexados a dados pertinentes que são publicados em redes sociais online.

\subsection{Hipótese}

A principal hipótese da presente investigação é:

Considerando a complexidade dos ambientes de rede sem fio de próxima geração, a capacidade de comunicação dos dispositivos móveis atuais e a popularidade e eficiência das redes sociais online, usuários móveis podem colaborar de maneira oportuna para melhorar suas experiências de conectividade sem fio de acordo com métricas de QoS.

\subsection{Desafios}

Verificar essa hipótese envolve o projeto de um mecanismo para o gerenciamento de conectividade sem fio enfrentando os seguintes desafios herdados da computação móvel e ciente de contexto:

- Conceber um modelo de dados adequado para permitir a colaboração entre usuários móveis e ser útil para o gerenciamento de conectividade sem fio. O modelo deve ser baseado em localização para representar a sequência de dados de contexto coletados enquanto

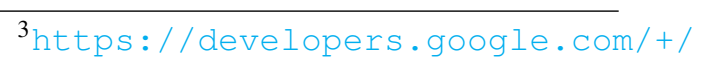


o usuário se movimenta de um lugar para outro e para representar a combinação de várias experiencias de conectividade sem fio de usuários distintos;

- Projetar um mecanismo de gerenciamento de conectividade sem fio, ciente de contexto e retroalimentado. O gerenciador deve utilizar dados de contexto de conectividade fio coletados no passado para criar modelos de previsão de mobilidade e de QoS. Os componentes do gerenciador devem estar organizados em um laço retroalimentado e devem convergir para melhores experiências de conectividade sem fio;

- Avaliar uma solução sistemática para melhorar a experiência de usuários móveis em ambientes de rede NGN. Desenvolver um protótipo e realizar um estudo comparativo com outros mecanismos reportados na literatura. Configurar um ambiente de experimentação e definir experimentos para verificar a eficiência da solução em termos de métricas de QoS (e.g., vazão de dados, latência e qualidade do sinal);

- Disponibilizar as informações de contexto de conectividade sem fio por meio de serviços na web. Desenvolver um sistema de entrega de dados na web que utilize as redes sociais online como suporte.

\subsection{Objetivo}

O principal objetivo da presente investigação é expandir a visão de Nicholson et. al (2008) que considera as pessoas seres de hábito. Eles exploraram os hábitos de deslocamento das pessoas para melhorar suas experiencias de conectividade sem fio. Nós acrescentamos que as pessoas são, também, seres sociais que interagem ou colaboram com diversas outras pessoas no dia-a-dia. Assim, temos o objetivo de projetar as ferramentas necessárias para permitir que as pessoas colaborem para melhorar suas experiências de conectividade sem fio enquanto estão se movimentando entre lugares distintos.

\subsection{Contribuições}

Em suma, a presente investigação começou tentando explorar os hábitos das pessoas para melhorar suas experiências de conectividade sem fio (Lopes et al., 2009). Direcionamos esforços para o desenvolvendo um protótipo para coletar dados de contexto de conectividade sem fio utilizando como base a investigação em (Nicholson e Noble, 2008). Definimos um modelo de dados para representar as informações de contexto de conectividade (Lopes et al., 2010a). Propomos a organização dos principais métodos do gerenciamento de conectividade sem fio em um laço retroalimentado (Lopes et al., 2010a,b).

As limitações de escalabilidade do modelo de dados motivaram o desenvolvimento de um sistema de entrega do tipo publish-subscribe com feeds RSS. Descrevemos como dados de contexto 
de conectividade podem ser utilizados para economizar bateria e espaço de armazenamento (Lopes et al., 2011b). Mostramos por meio de experimentos reais que a solução proposta pode melhorar significativamente métricas de QoS experimentadas em dispositivos móveis. Por fim, iniciamos a estudar, por meio de simulações, como a colaboração das pessoas varia em função dos padrões de mobilidade e número de pessoas (Lopes et al., 2012b).

\subsection{Estrutura da dissertação}

Este trabalho está organizado da seguinte forma: o próximo capítulo (Capítulo 2, Gerenciamento de conectividade sem fio) apresenta os conceitos fundamentais relacionados a computação móvel e ao gerenciamento de conectividade sem fio, apresenta o paradigma de sensoriamento continuado e examina o processo de criação e consumo das mídias sociais baseadas em localização. O Capítulo 3 (Contexto de conectividade sem fio) introduz o modelo de dados adotado para manipular contexto de conectividade sem fio e discute sua viabilidade em termos de sobrecarga de armazenamento e consumo de energia. O Capítulo 4 (Proposta) descreve os detalhes do conjunto de métodos gerenciamento de conectividade sem fio com suporte de redes sociais online. O Capítulo 5 (Avaliação quantitativa) descreve os experimentos realizados para avaliar quantitativamente a solução proposta na presente investigação. Por fim, o Capítulo 6 (Conclusão e trabalhos futuros) apresenta as considerações finais deste trabalho, juntamente, com as contribuições alcançadas e os trabalhos futuros. 



\section{Conceitos fundamentais}

esse capítulo, são apresentados os conceitos fundamentais relacionados ao gerenciamento de conectividade sem fio. Começamos descrevendo o cenário que motivou a presente investigação. Trata-se de um ambiente de rede de próxima geração, ou NGN, cujos desafios vêm da heterogeneidade do sistema de acesso e da mobilidade dos usuários. Na última década, investigações propuseram componentes essenciais para o gerenciamento de conectividade sem fio nesses ambientes de próxima geração. Descrevemos aqui os principais componentes, que são: o preditor de mobilidade, o mecanismo de handover e o gerenciador de mobilidade.

Também examinamos os principais trabalhos que propõem gerenciar a conectividade sem fio com sensibilidade ao contexto, incluindo o projeto onde a presente investigação nasceu. Nos últimos anos, emergiram na literatura pesquisas que propõem o uso de dispositivos móveis como plataforma de sensoriamento. Discutimos como os objetivos da presente investigação são congruentes aos desse novo paradigma computacional. Por fim, examinamos as mídias sociais baseadas em localização que são utilizadas para adicionar relevância e visibilidade aos dados de contexto de conectividade sem fio.

\subsection{Cenário}

Nesta seção reproduzimos a descrição do cenário de conectividade sem fio definido para embasar a presente investigação em meados de 2008. Imaginemos um cenário hipotético onde uma pessoa, chamada Alice, sai do trabalho e se dirige para casa, conforme ilustração na Figura 2.1. Durante o caminho, Alice faz uso do seu telefone para ler notícias, ver vídeos e para conversar com amigos. No instante $i_{0}$, ela inicia sua jornada para casa. 
Sua movimentação é detectada pela análise sistemática das coordenadas geográficas recuperadas por meio de um Global Positioning System (GPS) no dispositivo móvel ou por qualquer outro sistema de localização. No instante $i_{1}$, Alice chega próximo a borda da rede atual i.e., qualidade do sinal menor ou igual a um limite obtido empiricamente.

Em seguida, o gerenciador de conectividade sem fio no telefone de Alice realiza uma consulta ao módulo servidor, do sistema de gerenciamento, passando como parâmetro as coordenadas geográficas no início da movimentação e as coordenadas atuais, mais as informações do contexto de conectividade sem fio e.g., as redes sem fio alcançáveis, o percentual de bateria disponível e as aplicações em uso.

Se existirem registros passados nesse mesmo ponto da rede, será retornado uma lista, ordenada pelo número de escolhas de rede realizada, com os endereços Media Access Control (MAC) dos pontos de acesso disponíveis na direção em que o usuário tende a se movimentar; chamamos esse processo de retroalimentação ou feedback. No caso ilustrado, só existe a opção "Rede A", portanto é feita a associação e autenticação no novo ponto de acesso dessa rede sem fio.

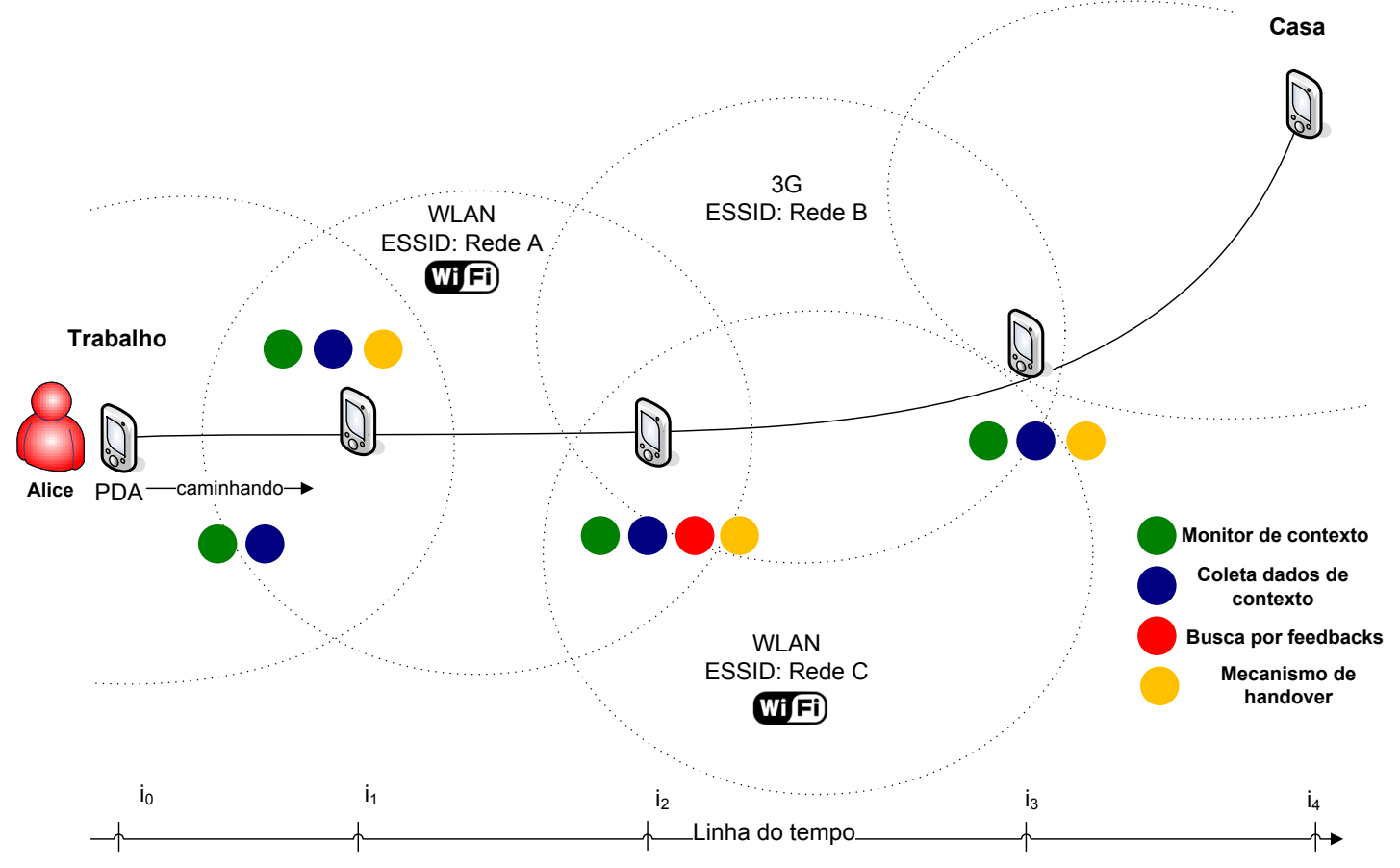

Figura 2.1: Cenário hipotético para ilustrar a motivação desta investigação.

No instante $i_{2}$, Alice novamente se aproxima da borda da rede atual e nesse caso existem duas opções de acesso: "Rede B"e "Rede C". Em lugares onde existem mais de uma opção de rede sem fio os feedbacks podem ser úteis. Imaginemos que o dispositivo de Alice se associe ao ponto de acesso da "Rede C"e no instante $i_{3}$ se associe ao AP da "Rede B". Essas informações serão armazenadas pelo módulo que coleta contexto e são chamadas de dados históricos de contexto de conectividade sem fio ou, também, de experiências de conectividade sem fio. 
Em uma eventual revisita ao mesmo percurso, o mecanismo de handover, no dispositivo móvel de Alice, poderá analisar a experiência passada e inferir que a "Rede B"é a melhor opção no instante $i_{2}$, tal decisão eliminará uma associação desnecessária no caminho.

Considerando que trocar de rede é caro em termos de energia, a ação de evitar um handover corrobora para materialização do conceito Always Best Connected ( $A B C$ ) por meio do uso racional dos escassos recursos do dispositivo móvel, neste caso a bateria. Com objetivo de reduzir a complexidade do desenvolvimento da solução esboçada foram definidos os principais módulos do sistema, a saber: monitor de contexto, coletor de contexto de conectividade, recuperador de feedbacks, mecanismo de handover, sincronização de informações de contexto e interface com usuário.

O monitor de contexto é o responsável por verificar as mudanças no contexto de conectividade como, por exemplo, a movimentação do usuário i.e., mudanças de coordenadas geográficas) e informações de QoS das redes disponíveis. Adicionalmente, esse monitor deve implementar mecanismos para predição de mobilidade e garantia de QoS com abordagens semelhantes as utilizadas em (Su et al., 2000; Soh e Kim, 2003), nesta ordem.

O módulo que faz a recuperação e armazenamento de informações de contexto é responsável por coletar os dados provenientes das diversas fontes de contexto e armazena-los localmente em um banco de dados. O buscador de feedbacks tem que permitir a recuperação de experiências passadas em determinados lugares, caso elas existam.

O mecanismo de handover deve implementar um algoritmo para escolha do próximo AP fazendo uso das informações do contexto de conectividade atual e eventuais feedbacks. Além disso, é o módulo responsável por manipular as interfaces de rede nos processos de associação e desassociação de um ponto de acesso.

Em momentos oportunos, boas condições de rede, as informações de contexto armazenadas no dispositivo móvel devem ser sincronizadas com um banco de dados central de onde serão recuperados os feedbacks. Em complemento, se faz necessária uma interface com o usuário móvel para visualização e compartilhamento das informações de contexto conectividade sem fio disponíveis.

Essa interface com o usuário deve permitir a definição de preferências de acesso sem fio e.g., operadora de telefonia celular preferida, dados de autenticação dos provedores de acesso e padrões de conectividade como: sempre online ou conectar-se sob demanda. Adicionalmente, parâmetros de privacidade e segurança também podem ser configurados pela interface com o usuário. Isso envolve a frequência e local de compartilhamento de dados de contexto e a recuperação dos mesmos.

Na presente investigação, argumentamos que as redes sociais online são lugares interessantes para compartilhar experiências de conectividade sem fio. Dessa forma, a interface com o usuário também deverá permitir a definição das redes sociais online, bem como dos dados de autenticação para publicar e acessar dados nos círculos sociais. 


\subsection{Computação móvel}

Em meados da década de 1990, foi previsto que em um futuro próximo aquela data, milhões de usuários estariam carregando computadores portáteis equipados com tecnologias de acesso sem fio e, dessa forma, implementariam o novo paradigma computacional denominado Computação Móvel ou Nômade (Imielinski e Badrinath, 1994).

Esse paradigma permitiria que as pessoas equipadas com os computadores móveis acessassem informações e recursos de rede enquanto se deslocam. Em suma, a Computação Móvel tem o objetivo de atender a necessidade de computação e comunicação de usuários móveis, enquanto eles se movem de um lugar para outro de forma transparente, integrada e conveniente (Kleinrock, 1995).

As previsões de Imielinski et al. (1994) são realidade nos dias atuais, devido a portabilidade e as capacidades de computação e comunicação dos dispositivos móveis e.g., telefones e tablets, e a disponibilidade de tecnologias de comunicação sem fio e provedores de acesso. Tais elementos compõem um ambiente que possibilita o acesso permanente a uma rede fixa ou móvel em qualquer lugar e a qualquer hora i.e., possibilita o acesso a informação e serviços enquanto em movimento.

A computação móvel está mudando a forma como trabalhamos, nos comunicamos, nos divertimos, estudamos e fazemos outras atividades quando estamos em movimento ou não desejamos ficar "presos"a uma infra-estrutura fixa de comunicação de dados (Mateus e Loureiro, 1998). Tal mudança é produto da soma das características almejadas pela Computação Móvel, que são: a independência de localização, de movimento, de plataforma e a disponibilidade de acesso a serviços de rede sem fio (Kleinrock, 1995).

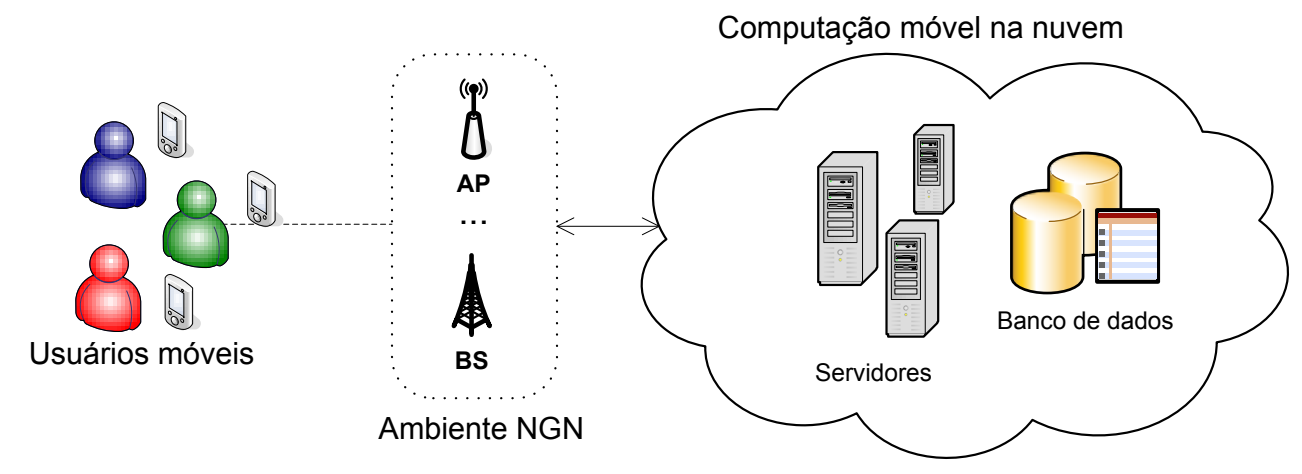

Figura 2.2: Ilustração da Computação Móvel na nuvem.

Nos últimos anos, a Computação Móvel foi para a nuvem (do inglês Mobile Cloud Computing (MCC) (Guan et al., 2011)). Alavancada pela capacidade de comunicação dos dispositivos móveis nos ambientes de rede sem fio atuais, aplicações móveis transferem parte ou toda carga de processamento e de armazenamento para a nuvem, conforme ilustração na Figura 2.2. Essa abordagem remove as limitações dos dispositivos móveis em termos de recursos de processamento e de armazenamento, e oferece um novo nível de segurança centralizada para aplicações críticas e.g., aplicações de pagamento com telefones e aplicações bancárias (Klein et al., 2010). 


\subsection{Redes sem fio de próxima geração}

O cenário discutido na Seção 2.1 descreve uma pessoa, a Alice, utilizando conectividade IP enquanto se movimenta em um ambiente de rede sem fio de próxima geração ou NGN (Berezdivin et al., 2002; Varshney e Jain, 2001). Esses ambientes de rede futurísticos buscam a interoperabilidade entre diversas tecnologias de comunicação sem fio, para permitir que seus usuários permaneçam sempre conectados à melhor rede ou a combinação das redes disponíveis, $\mathrm{ABC}$. $\mathrm{O}$ conceito $\mathrm{ABC}$ tem o objetivo de manter o dispositivo móvel conectado à rede que ofereça as melhores condições em termos de custo monetário, consumo de energia e QoS (Gustafsson e Jonsson, 2003).

Dessa forma, as redes $\mathrm{ABC}$ devem permitir que os usuários móveis se conectem a serviços na web por meio da tecnologia de comunicação mais apropriada em termos de alguns parâmetros pré-definidos e.g., requisitos de QoS da aplicação, preferências pessoais ou características do dispositivo móvel em questão (Fodor et al., 2004). Tais parâmetros podem ser definidos pelo usuário, pelas aplicações ou serem recuperados do contexto de conectividade sem fio. O último caso será examinado em detalhes no Capítulo 3.

Outra contribuição de Fordor et al., (2004), é a identificação de dois requisitos fundamentais para a efetiva implementação do conceito $\mathrm{ABC}$, que são: o desenvolvimento de algoritmos para a seleção automática do acesso sem fio, e o projeto e implementação de uma arquitetura que suporte o conceito. Os algoritmos devem garantir que os usuários móveis façam uso da melhor conectividade sem fio disponível no ambiente, em função de parâmetros definidos por preferências do usuário, pelos requisitos das aplicações em uso e pelo contexto de conectividade atual e passado.

A arquitetura deve permitir a descoberta de pontos de acesso, administrar a mobilidade do dispositivo e implementar uma entidade de seleção de acesso que receba os parâmetros e execute um algoritmo para a escolha da melhor rede sem fio. Para ilustrar, existem algoritmos para seleção de acesso, na literatura, que garantem o atendimento dos requisitos de QoS das aplicações executando no dispositivo móvel e fazendo uso de serviços na web (Furuskar, 2002; Fodor et al., 2004; Furuskar e Zander, 2005). Em complemento, Gustafsson et al. (2003) propuseram uma arquitetura para as redes ABC, conforme apresenta o diagrama na Figura 2.3. Nessa figura, são apresentadas as entidades que compõem a arquitetura do lado do dispositivo móvel e do lado da rede ABC.

Do lado do dispositivo móvel, tem-se um gerenciador de link responsável pela descoberta de pontos de acesso. Uma vez identificados, o administrador de acesso faz a seleção e administração da conexão. Para permitir a mobilidade faz-se necessária a implementação do lado cliente de algum mecanismo de mobilidade e.g., Mobile IP, Host Identity Protocol (HIP) ou Session Iniatiation Protocol (SIP). Também é prevista uma interface gráfica com o usuário, do inglês Graphical User Interface (GUI), para configuração do gerenciador de acesso e um diálogo para definição dos parâmetros de conexão ou para seleção manual da conexão sem fio, caso o usuário deseje ou seja necessário. 


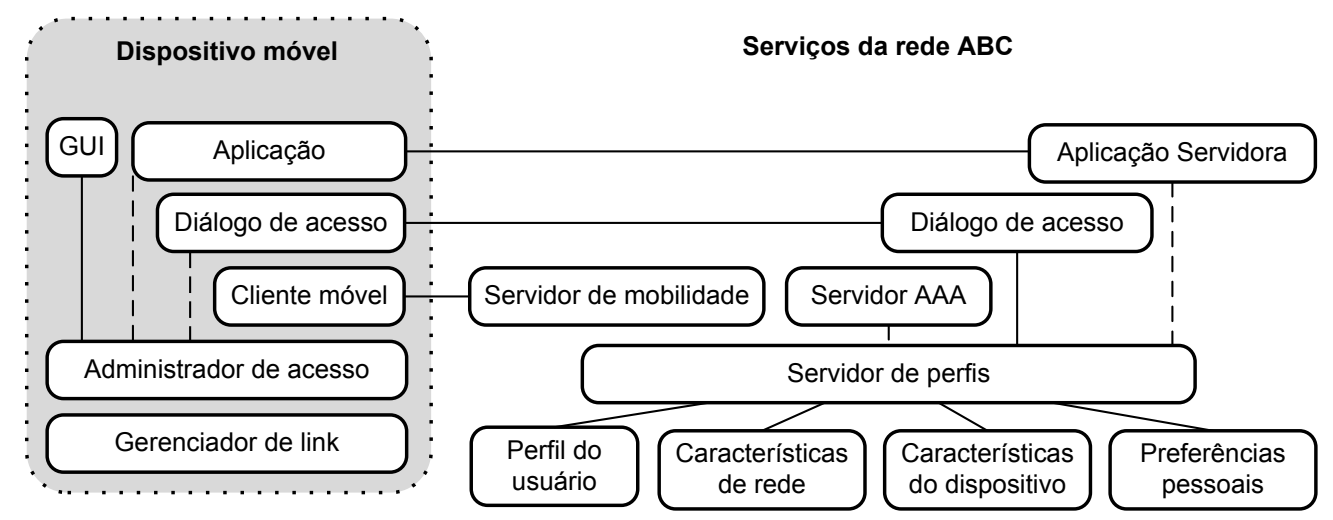

Figura 2.3: Arquitetura funcional de um ambiente ABC. Adaptada de (Gustafsson e Jonsson, 2003, p. 53)

Do lado da rede $\mathrm{ABC}$, na Figura 2.3, tem-se um servidor de perfis que é responsável pela gerência dos perfis de usuários, das preferências pessoais, das características dos dispositivos móveis e das redes sem fio. Um servidor de autenticação (do inglês Authorization, Authentication and Accounting $(A A A))$ é o responsável pela autorização de acesso, pela autenticação do usuário/dispositivo e pelo gerenciamento de privilégios e recursos da conta. O servidor de mobilidade implementa o lado servidor de algum mecanismo que ofereça mobilidade. E, finalmente, o diálogo de acesso permite que o usuário defina os parâmetros das conexões.

Com essa arquitetura espera-se que o usuário móvel faça um único login no sistema e obtenha a melhor conectividade enquanto se movimenta de um lugar para outro, de forma eficiente, transparente e conveniente i.e., sem a necessidade de intervenção do usuário durante os eventuais handovers. Para ilustrar, será possível iniciar o download de um arquivo em uma determinada rede sem fio e mantê-lo durante as eventuais trocas de redes que serão necessárias enquanto o usuário está se movimentando de um lugar para outro. Uma implementação pragmática desta arquitetura é um problema em aberto no estado da arte e a presente investigação contribui nesse esforço.

Quanto aos protocolos de comunicação em redes de computadores, é consenso da comunidade científica que o protocolo IP continuará sendo amplamente utilizado para homogeneizar os ambientes NGN na camada de rede. Dessa forma, estas redes continuarão sendo baseadas nos princípios, serviços e protocolos da Internet, formando as chamadas all-IP Networks (Akyildiz et al., 2004). Diversos trabalhos na literatura abordam problemas relacionados a disponibilidade de conectividade IP em ambientes NGN. Entre eles, alguns tratam o problema da redução da latência de handover propondo algoritmos (Hasswa et al., 2007), arquiteturas (Ahmed et al., 2006) e políticas de acesso (Vidales et al., 2004).

\subsection{Algoritmo ideal para gerenciamento de conectividade}

Investigações relacionadas ao gerenciamento da conectividade sem fio, combinam predição de mobilidade e mecanismos para garantir QoS no acesso a serviços ubíquos em ambientes inteli- 
gentes (Sun e Sauvola, 2005). Adicionalmente, mecanismos de handover e de gerenciamento de mobilidade são considerados críticos em algumas investigações na literatura e.g., (Sun e Sauvola, 2005; Nicholson et al., 2006; Song et al., 2006; Nicholson e Noble, 2008; Baladron et al., 2012).

O diagrama na Figura 2.4 apresenta o algoritmo ideal para o gerenciamento de conectividade sem fio, delimitado e proposto em (Nicholson et al., 2010). O gerenciamento de conectividade sem fio ideal seria possível se: antes do AP atual se tornar inacessível (1), o dispositivo móvel deveria saber qual usar em seguida (2). E ainda, já tivesse se associado e recebido um endereço IP (3), da rede do novo AP, para então realizar a troca de ponto de acesso.

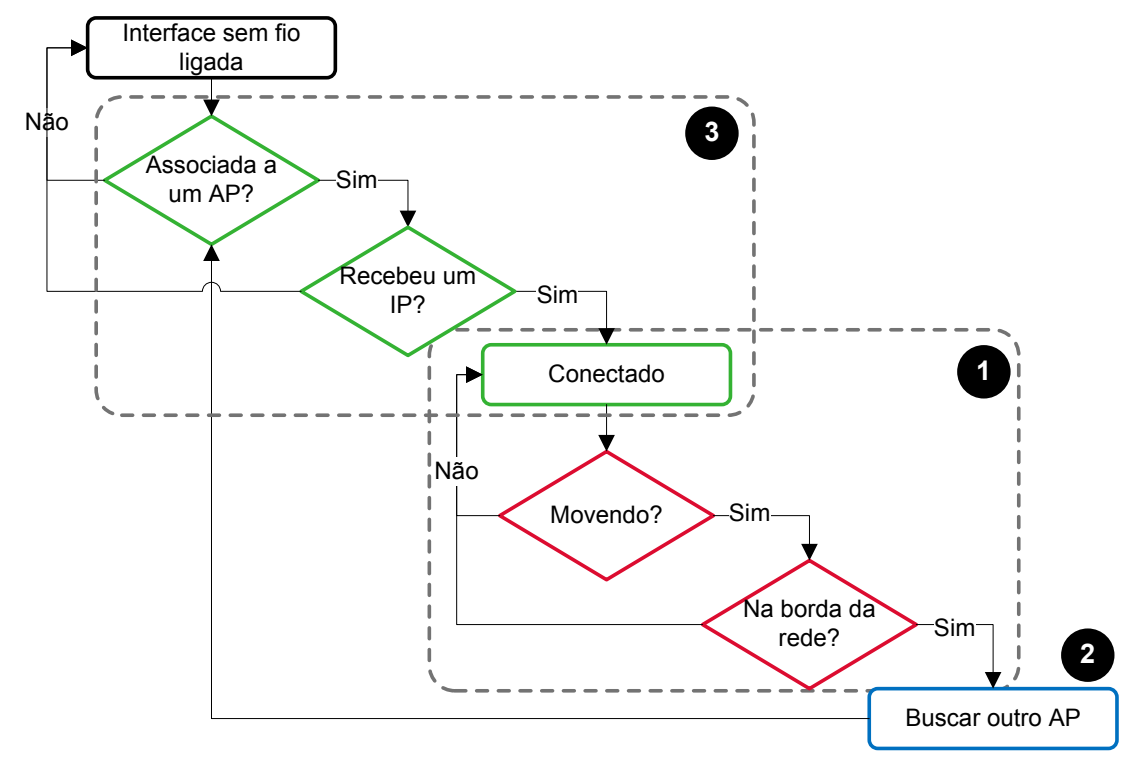

Figura 2.4: Algoritmo ideal para gerenciamento de conectividade sem fio.

Na presente investigação, contribuímos para o esforço de implementar o algoritmo supracitado colocando os dados históricos de contexto de conectividade como fonte fundamental de informação para outros três componentes, como apresenta o diagrama na Figura 2.4. Nessa figura, temos os três componentes responsáveis por implementar os três passos do algoritmo ideal: (1) preditor de mobilidade; (2) mecanismo de handover; e (3) gerenciador de mobilidade. O preditor de mobilidade é responsável por prever a localização geográfica do dispositivo móvel, com base em dados de contexto de conectividade sem fio coletados anteriormente.

Quando o usuário chega a uma região onde o ponto de acesso atual se torna indisponível ou não atente os requisitos de QoS da aplicação, é necessário ativar um mecanismo de handover. Adicionalmente, vários mecanismos de handover, reportados na literatura, são sensíveis ao contexto e.g., (Prehofer et al., 2003; Bellavista et al., 2007; Hasswa et al., 2007). Por fim, para manter vivas as conexões da camada de transporte é necessário fazer uso de um mecanismo de gerenciamento de mobilidade e.g., Mobile IP ou TCP migrate.

Teoricamente, a combinação desses componentes atendem os requisitos do gerenciamento de conectividade ideal, mencionado anteriormente e esboçado na Figura 2.4. Cada um desses com- 
ponentes serão examinados nas próximas subseções e os dados históricos de contexto de conectividade sem fio serão discutidos no Capítulo 3.

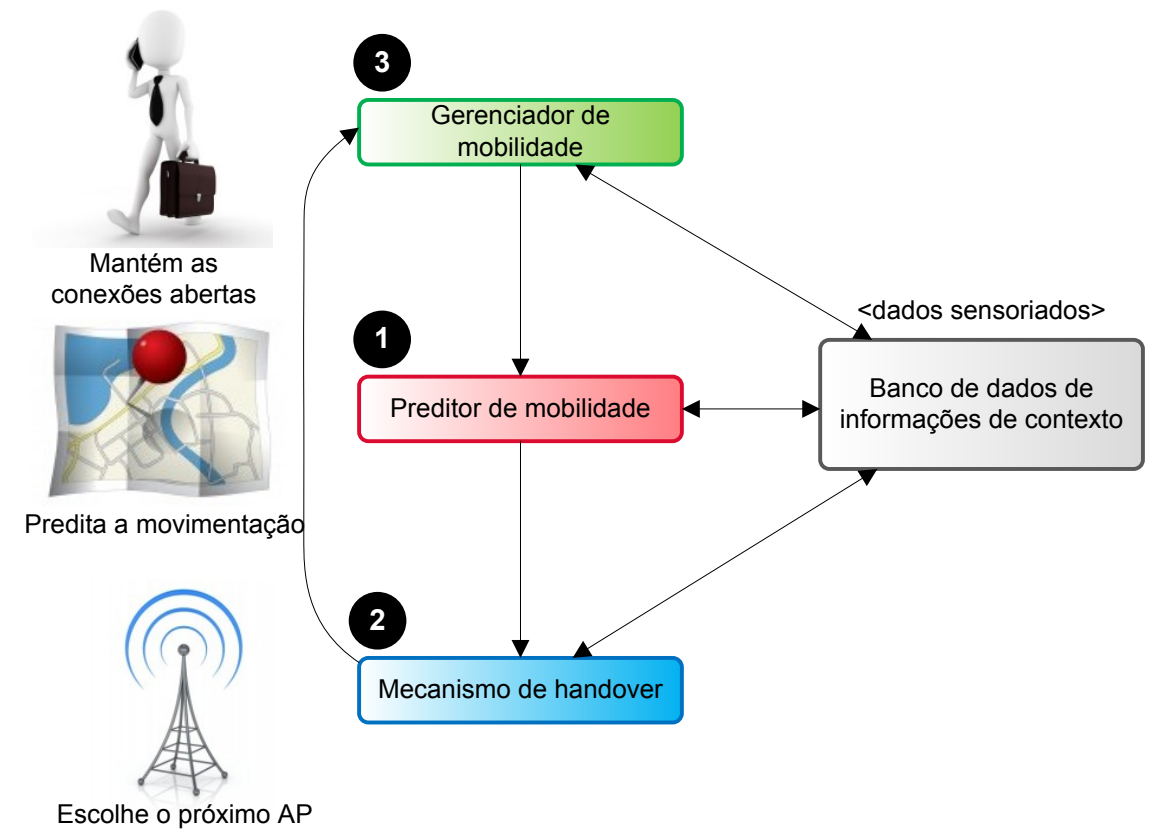

Figura 2.5: Principais componentes do gerenciamento de conectividade sem fio e ciente de contexto.

\subsubsection{Preditor de mobilidade}

A predição de mobilidade estima a localização geográfica do dispositivo móvel em um futuro próximo, dado a localização atual e um conjunto de dados de histórico de mobilidade ou de contexto de conectividade (Song et al., 2006). É um mecanismo fundamental para sistemas que têm o objetivo de provisionar ou garantir recursos de conectividade para dispositivos móveis, (Sleem e Kumar, 2005; Rahmati e Zhong, 2007; Nicholson e Noble, 2008; Tragos et al., 2009). Para ilustrar, o conhecimento prévio da localização do dispositivo pode ser utilizado para pré-alocar recursos de rede com objetivo de garantir vazão mínima quando o dispositivo está trocando de ponto de acesso.

Algumas soluções na literatura utilizam uma cadeia de Markov para modelar o sistema de predição (Song et al., 2006; Nicholson e Noble, 2008; Prasad e Agrawal, 2010). Esse tipo de preditor recebe com entrada uma sequencia de símbolos e.g., $\left(a_{1}, a_{2}, \ldots, a_{n}\right)$, como dados históricos, e estima o próximo símbolo dado o contexto atual, que é uma sequência de $k$ (ordem) símbolos recentes no histórico $\left(a_{n-k+1}, \ldots, a_{n}\right)$ (Song et al., 2006).

Nesta investigação, empregamos um modelo de Markov de segunda ordem, $k=2$, cujos estados são compostos pela localização passada e pela localização atual, conforme ilustração na Figura 2.6a. Como resultado, o preditor retorna uma lista de localizações e suas respectivas probabilidades de serem escolhidas. Tal modelo pode ser representado como o grafo apresentado no diagrama 
na Figura 2.6b, onde os pontos são as localizações e o peso das arestas são as probabilidades de movimento entre eles.

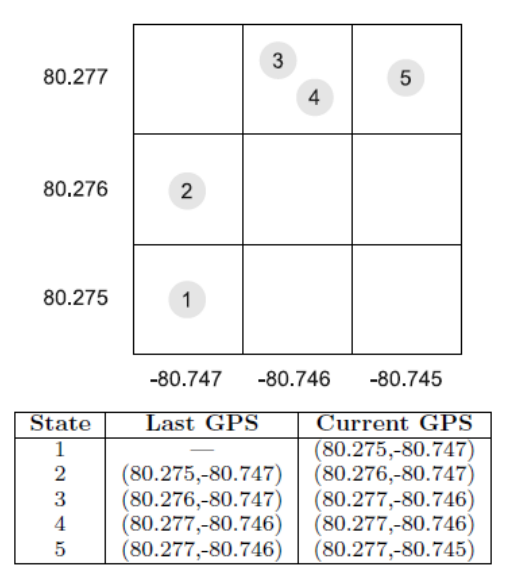

(a)

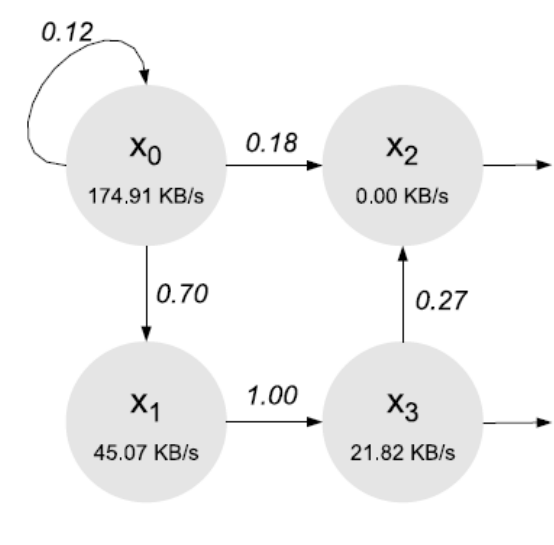

(b)

Figura 2.6: (a) Construindo o modelo. (b) Exemplo de cadeia de Markov. Adaptada de (Nicholson e Noble, 2008, p. 48).

A precisão do preditor de mobilidade é limitada a quantidade e qualidade dos dados históricos disponíveis, incluindo a precisão do sistema de localização utilizado para recuperar a localização do dispositivo móvel e.g., o GPS pode ter erro entre 1 e 30 metros dependendo do equipamento examinado. Em complemento, a precisão também está relacionada a quantos passos a frente é necessário antecipar ou prever (Araujo et al., 2012).

\subsubsection{Mecanismos de handover}

Os mecanismos de handover controlam a troca de APs, com objetivo de manter o dispositivo conectado enquanto se movimenta de um lugar para outro (Sun e Sauvola, 2005). Os handovers podem ocorrer entre duas redes IP distintas que utilizam a mesma tecnologia de comunicação sem fio, também chamado de handover horizontal. Em complemento, o handover vertical, entre redes com tecnologias de comunicação distintas, pode ser classificado como downward e upward (Pyun, 2008). No primeiro caso, a vazão disponível na conexão é reduzida e no último caso a vazão é incrementada.

Existem vários pontos críticos relacionados ao handover vertical que são temas de pesquisa (Kassar et al., 2008; Haibo et al., 2010; Yan et al., 2010) e.g., o chaveamento transparente e eficiente entre tecnologias de comunicação sem fio distintas (Balasubramaniam e Indulska, 2004). A mudança de rede ainda exige uma ação do usuário i.e., o usuário tem que escolher a nova rede ou interface de rede e eventualmente definir alguns parâmetros de segurança e autenticação.

Mais recentemente, surgiram abordagens envolvendo handover ciente de contexto, onde merece destaque o trabalho descrito em (Wei et al., 2006), que utiliza a tecnologia denominada Active Network para gerenciar as informações do dispositivo móvel e da rede sem fio, realizando hando- 
ver levando em conta o nível do congestionamento, a vazão disponível, a qualidade do sinal e a velocidade do usuário.

Bellavista et al. (2007) propõem um middleware, chamado Mobile agent-based Ubiquitous multimedia Middleware (MUM), que gerencia a conectividade sem fio fazendo uso de informações das interfaces de rede, de QoS e de localização. Em adição, Halteren et al. (2006) propuseram o middleware Mobile Service Plataform (MSP) (Pawar et al., 2008) que baseia-se em uma estimativa de QoS no ambiente de rede sem fio em questão para garantir o QoS fim-a-fim entre o dispositivo móvel e o provedor de conteúdo.
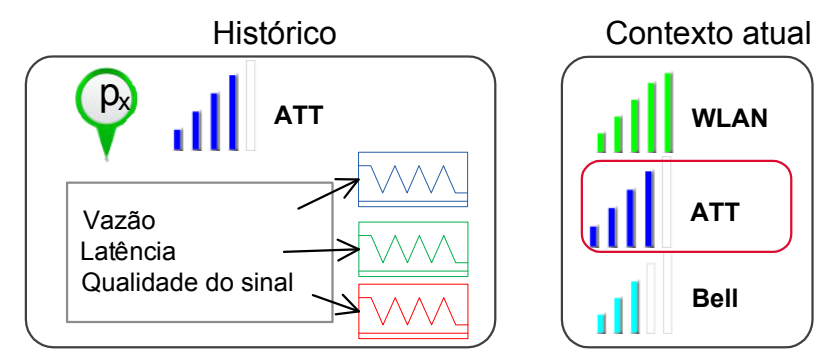

Figura 2.7: Exemplo de handover ciente de contexto.

Em suma, as investigações supracitadas levam em consideração o histórico de dados de contexto de conectividade em um determinado local e o contexto atual para escolher o próximo AP, conforme ilustração na Figura 2.7. A presente investigação tem o objetivo de melhorar as decisões de troca de rede indiretamente organizando os componentes de gerenciamento de conectividade sem fio em um laço retroalimentado, onde a colaboração de usuários móveis converge para melhores experiências de conectividade para todos envolvidos. Com foco em experimento reais, implementamos um mecanismo de handover similar ao VIRGIL, proposto em (Nicholson et al., 2006).

Esse algoritmo executa as seguintes tarefas: faz uma varredura no(s) ambiente(s) de rede sem fio buscando por pontos de acesso disponíveis; testa a conectividade IP se associando a cada um e tentando recuperar um endereço IP utilizando o Dynamic Host Configuration Protocol (DHCP); em caso de sucesso no teste, os dados do AP são armazenados e.g., nome da rede, endereço $M A C$, qualidade do sinal e portas abertas. Na nossa implementação, não realizamos um conjunto de testes no AP, mas fazemos log das experiências de QoS reais do dispositivo móvel. Mais detalhes são discutidos no Capítulo 5 (Avaliação quantitativa).

\subsubsection{Gerenciador de mobilidade}

Em movimento, o usuário não pode confiar em apenas uma rede sem fio, mas deve explorar a variedade de opções de conectividade disponível no caminho (Nicholson e Noble, 2008). Adicionalmente, é necessário manter as conexões de transporte abertas quando o dispositivo se desassocia de uma rede e se associa a outra. O gerenciador de mobilidade permite que diferentes redes inte- 
roperem para garantir mobilidade dos dispositivos móveis (Chan et al., 2001; Kimura et al., 2010, 2012). Para ilustrar, na camada IP tem-se o Mobile IP conforme ilustrado na Figura 2.8.

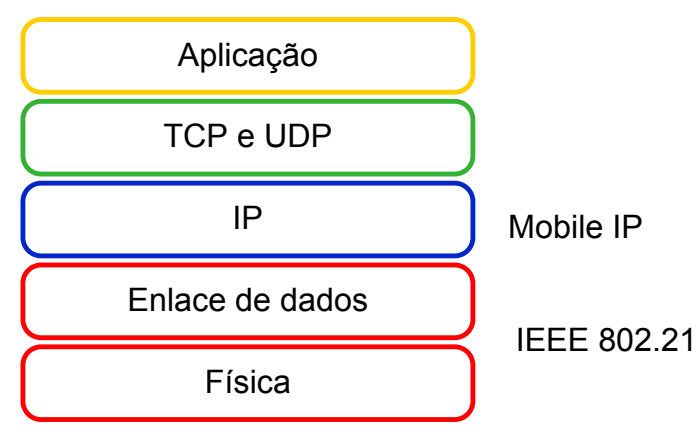

Figura 2.8: Pilha de camadas TCP/IP e os mecanismos de gerenciamento de mobilidade.

A ação de mudar de ponto de acesso, ou handover ou handoff, é o gatilho de um conjunto de mecanismos para manter o dispositivo móvel conectado à Internet. Primeiro, a conexão na camada física e de enlace de dados devem ser ajustadas para desassociar da rede atual e se associar a próxima rede. Em sequência, as conexões IP devem ser manipuladas para não interromper as conexões de transporte. Para fazer isso, existe um padrão em desenvolvimento chamado IEEE 802.21 (IEEE802.21, 2009) nas camadas 1 e 2, e mecanismos como Mobile IP na camada 3, ambos estão na Figura 2.8 e são brevemente descritos na sequência.

O padrão IEEE 802.21 propõe uma arquitetura para realizar handovers independente de meio de acesso, do inglês Media Independent Handover Architecture (MIHA), que oferece serviços de baixo nível para permitir handovers entre redes com diferentes tecnologias de comunicação sem fio (IEEE802.21, 2009). Em complemento, o padrão prevê a capacidade de troca de informações entre as camadas de rede, com objetivo de otimizar as trocas de rede.

Por exemplo, existe um esforço para permitir a interoperabilidade entre o padrão IEEE $802.16 \mathrm{~m}$ (vazão de até $100 \mathrm{mbps}$ a uma velocidade de até $250 \mathrm{~km} / \mathrm{h}$ ) e o padrão IEEE 802.11 VHT (vazão de 1 gbps com baixa velocidade) que vai satisfazer os requisitos de vazão e de mobilidade em baixa e alta velocidade (Eastwood et al., 2008). Esse tipo de investigação justifica as pesquisas relacionadas ao gerenciamento de conectividade ciente de contexto, porque torna possível sua implementação em um futuro próximo.

Uma camada acima, mobile IP permite que os usuários troquem de rede sem fio mantendo as conexões de transporte intactas, por meio de um mecanismo que triangula os fluxos de dados (Yokota et al., 2002). Isso é possível porque o protocolo é capaz de rotear pacotes IP independente da localização do dispositivo móvel. Para tanto, cada dispositivo móvel é identificado pelo endereço IP na rede de origem e representado por um agente local, independente da localização atual do dispositivo na Internet.

Quando o dispositivo está longe da sua rede de origem e.g., a rede de uma empresa ou universidade, um túnel é configurado entre seu endereço atual e o o endereço do agente na origem. Todas as conexões IP são estabelecidas com o agente na origem e os pacotes são encaminhados pelo túnel que é restabelecido depois de uma troca de rede. 
Na presente investigação, não propomos soluções para os problemas relacionados ao gerenciamento de mobilidade. Os mecanismos supracitados são utilizados como infra-estrutura para o projeto e implementação de uma solução na camada de aplicação, conforme indicado na Figura 2.8. Dessa forma, quando um handover ocorre assumimos que uma implementação da MIHA irá gerenciar a conectividade na camada de enlace e que soluções como o Mobile IP e o TCP migrate serão capazes de manter todas as conexões abertas depois da troca de domínio IP. Com isto, nossa solução centrada no usuário é uma abordagem complementar para coletar e compartilhar contexto de conectividade sem fio.

\subsection{Gerenciamento de conectividade ciente de contexto}

\subsubsection{Arquitetura SOHand}

A presente investigação nasceu em 2007 dentro do projeto Service Oriented architecture for Handovers (SOHand) que era parte do projeto KyaTera ${ }^{1}$. O KyaTera tem o objetivo de conectar as competências e recursos laboratoriais necessários para desenvolver ciência, tecnologias e aplicações da Internet do futuro, com suporte de uma rede óptica de alta velocidade (10 Gbps) entre universidades e institutos de pesquisa do estado de São Paulo.

Dentro desse contexto, o principal desafio da arquitetura SOHand é minimizar a percepção de mudança de qualidade da conexão sem fio quando um handover acontece. Para tanto, a arquitetura propõe o uso da ciência de contexto de conectividade para auxiliar o processo de handover (Moreira et al., 2007) e assume que os ambientes de rede sem fio de próxima geração terão as seguintes características:

- Diferentemente dos sistemas utilizados atualmente em redes celular e Wireless Local Area Network (WLAN)s, onde a administração e a escolha dos pontos de acesso para associação a uma rede é completamente realizado pelo provedor de acesso, o usuário terá mais controle da sua interação com a rede (Patanapongpibul e Mapp, 2003);

- Algumas informações sobre o ecossistema de rede e.g., o usuário, a aplicação e o contexto de rede, serão coletadas dinamicamente e eventualmente compartilhadas entre os usuários, os provedores de acesso e provedores de conteúdo;

- O relacionamento entre o usuário e os provedores será baseado em Quality of Experience (QoE) e não apenas em QoS. Tais métricas poderão ser definidas e auditadas pelos usuários móveis;

- Os handovers cientes de contexto utilizarão políticas de acesso para oferecer suporte adequado à mobilidade em plataformas ubíquas, facilitando a manipulação das complexidades e do comportamento dinâmico impostos pelo ambiente de rede sem fio (Vidales et al., 2004);

${ }^{1}$ http://kyatera.ifi.unicamp.br 
- Eventualmente, as redes sem fio domésticas poderão ser partes da infra-estrutura dos provedores de acesso, o que irá demandar maior flexibilidade no gerenciamento de estratégias e colaboração entre as entidades envolvidas;

- A informação semântica das ontologias, permitem que o sistema esteja mais perto da implementação do paradigma da Computação Autonômica (Stojanovic et al., 2004).

A idéia central da arquitetura SOHand é disponibilizar uma plataforma abstrata (interfaces) para apoiar a prestação de serviços avançados de rede. A base do sistema é uma versátil estrutura de informação, uma ontologia, que podem ser compartilhadas entre provedores e usuários. Uma ontologia (Vanni et al., 2006) será a tecnologia de unificação para promover comum entendimento dos termos e relacionamentos que podem ser mantidos entre provedores de acesso ou de conteúdo.

O cliente possui módulos capazes de capturar informações do usuário, da rede e dos dispositivos móveis. O provedor de acesso pode ser classificado em categorias de serviço como, tradicional e.g., rede celular ou redes WiFi, ou comunitário e.g., redes em malha e células Femto (Chandrasekhar et al., 2008; Golaup et al., 2009).

Em ambos os casos, o usuário é beneficiado com a associação e correlação das informações contextuais para enriquecer a sua experiência nos ambientes de rede sem fio. O gerenciamento da conectividade é feito por meio de uma abordagem centrada no usuário, em detrimento a usual abordagem centrada no provedor de acesso. Dessa forma, a escolha do ponto de acesso passa a ser feita pelo usuário e embasada por informações contextuais.

$\mathrm{Na}$ arquitetura SOHand os serviços são facilidades e.g., troca de mensagens, vídeos e voz, que um provedor de conteúdos oferece para os usuários móveis por meio de um serviços de acesso. Uma entidade pode oferecer acesso e conteúdo ao mesmo tempo. O usuário, durante o consumo de um serviço, passa transparentemente pelas redes dos provedores de acesso e a conectividade é gerenciada por um broker.

Esse broker, ilustrado na Figura 2.9, atua como intermediário entre o cliente e o provedor, se necessário. Informações do usuário, do dispositivo ou de qualquer serviço relacionado, podem ser utilizadas durante uma sessão para estruturar a segurança, privacidade, QoS, tarifação e outras políticas.

A arquitetura SOHand é composta pelo lado cliente, lado provedor e um broker, conforme diagrama na Figura 2.9. Nesta figura, têm-se no lado cliente diversas fontes de contexto. Cada uma fornece informações que podem ser coletadas pelo dispositivo móvel. O gerenciador de contexto tem a função de processar as informações de contexto, armazená-las em um banco de dados local, monitorar as condições da rede atual, do dispositivo e das preferências do usuário.

O módulo de negociação utiliza os serviços disponibilizados pelos provedores de acesso, no ambiente de rede sem fio em questão, para negociar acesso com base em políticas pré-definidas e informações de contexto de conectividade. O gerenciador de handover decide qual é o melhor ponto de acesso para a troca, utilizando as preferências informadas pelo usuário. 


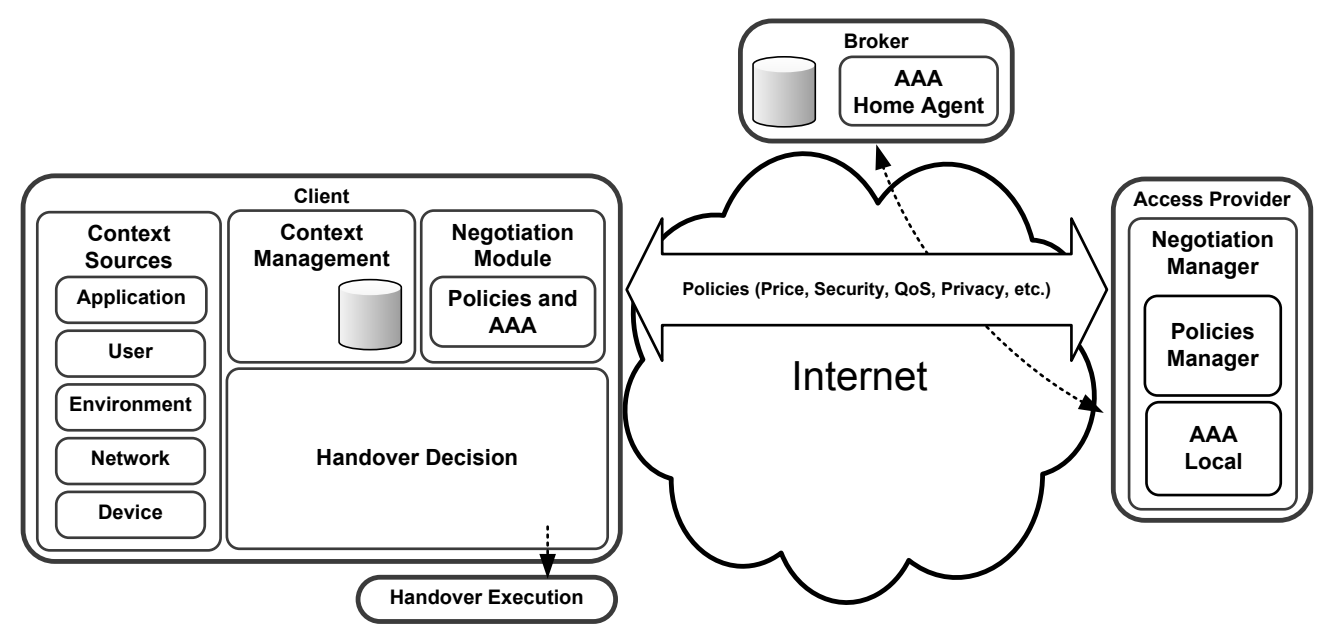

Figura 2.9: Módulos da arquitetura SOHand.

O provedor de acesso possui um gerenciador de negociação formado por dois módulos: gerenciador de políticas, responsável por informar as políticas de acesso de acordo com a localização do usuário, e o AAA local, que após a negociação é responsável por autenticar, autorizar e tarifar o cliente.

Por fim, o broker é o componente da arquitetura responsável por disponibilizar as funcionalidades do AAA home, para auxiliar no processo de autenticação e possui um banco de dados centralizado com as informações de contexto de conectividade dos seus clientes.

\subsubsection{Trabalhos relacionados}

As pessoas têm hábitos que as fazem tomar decisões similares todos os dias, inclusive a respeito do caminho a ser tomado para ir de um lugar para outro (Nicholson e Noble, 2008). Complementando essa visão, a pessoas são seres sociais que vivem em sociedade interagindo e colaborando com outras pessoas com bastante frequência. Na presente investigação, propomos que os dados de contexto de conectividade sem fio sejam compartilhadas em círculos sociais online para promover a colaboração entre os usuários móveis.

$\mathrm{Na}$ literatura, existem várias soluções cientes de contexto para gerenciar conectividade sem fio e.g., (Yokota et al., 2002; Sun e Sauvola, 2005; Rahmati e Zhong, 2007; Nicholson e Noble, 2008; Tragos et al., 2009; Tsao e Sivakumar, 2009; Wack, 2009). Essas investigações combinam a predição de mobilidade com mecanismos de handover, de maneiras particulares, para manter o dispositivo móvel conectado enquanto se movimenta de um lugar para outro. Algumas investigações empregam padrões de mobilidade para alocar recursos de rede apropriadamente (Nicholson e Noble, 2008; Yami e Vakili, 2009; Prasad e Agrawal, 2010). O principal objetivo é melhorar as condições de QoS para aplicações em dispositivos móveis.

Entretanto, leva tempo para construir um modelo de mobilidade eficiente, porque é necessário um conjunto de dados de contexto como entrada. A solução proposta nesta investigação pode 
complementar estas abordagens oferecendo dados de contexto para criar o modelo inicial. Em função do tempo, o modelo pode ser adequado aos padrões de mobilidade do usuário móvel.

Tês trabalhos serviram de fundação e motivação para a presente investigação, são eles: BreadCrums (Nicholson e Noble, 2008), Handoff Prediction and Enhancement Scheme (HOPES) (Sleem e Kumar, 2005) e QoSIS.net (Wack, 2009). Todos eles utilizam dados históricos de contexto de conectividade para melhorar o processo de tomada de decisão na escolha das redes de acesso sem fio. Nós argumentamos que a solução proposta na presente investigação é complementar as investigações supracitadas e esta subseção se desdobra com essa discussão.

O mecanismo denominado BreadCrumbs, (Nicholson e Noble, 2008), explora a derivativa de conectividade de um usuário móvel para realizar handovers cientes de contexto. O sistema mantem um histórico de dados de contexto de conectividade sem fio e utiliza um modelo personalizado para previsão de mobilidade no dispositivo do usuário. A ideia central é rastrear o dispositivo do usuário combinando o preditor de mobilidade e o histórico de dados de contexto de conectividade para prever futuras condições de rede.

Os autores realizaram experimentos reais com aplicações de navegação e multimídia, para mostrar que estas previsões podem ser utilizadas para tomar decisões em resposta a futuras condições de rede. As previsões são feitas para um futuro bastante próximo, entre 10 segundos e 5 minutos, enquanto o usuário está se movimentando. O objetivo é melhorar as experiências de conectividade sem fio ou reduzir o consumo de bateria ou ambos (Nicholson e Noble, 2008).

Sleem at al. (2005) argumentam que o provedor de acesso pode predizer a mobilidade do usuário. Com isso, o ambiente de rede sem fio pode realizar ações preemptivas antes que o movimento aconteça e.g., serviços de rede em uma nova localização podem ser liberados para uso sem registro convencional. Para conseguir isso, os autores propuseram a arquitetura HOPES que tem o objetivo de explorar técnicas de predição em gerenciadores de mobilidade para melhorar a qualidade da comunicação fim-a-fim entre o dispositivo móvel e um provedor de conteúdo.

O sistema utiliza predição ciente da topografia da rede sem fio e combina o histórico de dados de contexto do usuário, o contexto atual e a topografia das células da rede. A combinação dessas informações é utilizada para prever a mobilidade entre células de rede para antecipar a necessidade de um handover. A arquitetura proposta envia com frequência as informações necessárias para o provedor de acesso, para que o mesmo possa ativamente responder a movimentação do dispositivo móvel, em detrimento a lidar com os efeitos da movimentação depois que ela aconteceu (Sleem e Kumar, 2005).

O sistema QoSIS.net oferece em qualquer lugar, a qualquer hora e de qualquer forma serviços predições de QoS baseadas em localização por meio de uma forma colaborativa de compartilhar informação (Wack, 2009). Um mapa da história de conectividade sem fio e de previsões é mantido no dispositivo do usuário. Esse mapa é automaticamente atualizado, em intervalos de tempo regulares ou no momento em que a predição é requisitada. 
O sistema de predição emprega algoritmos de mineração de dados para identificar padrões no banco de dados histórico de métricas de QoS mensuradas pelos dispositivos móveis e provedores de acesso. Uma requisição para o serviço de predição, envolve o instantâneo processamento destes dados históricos pelo mecanismo de predição (Wac et al., 2009). Não existe evidências técnicas de como os dispositivos móveis se atualizam automaticamente e a complexidade de tempo para processar as requisições de predição de QoS.

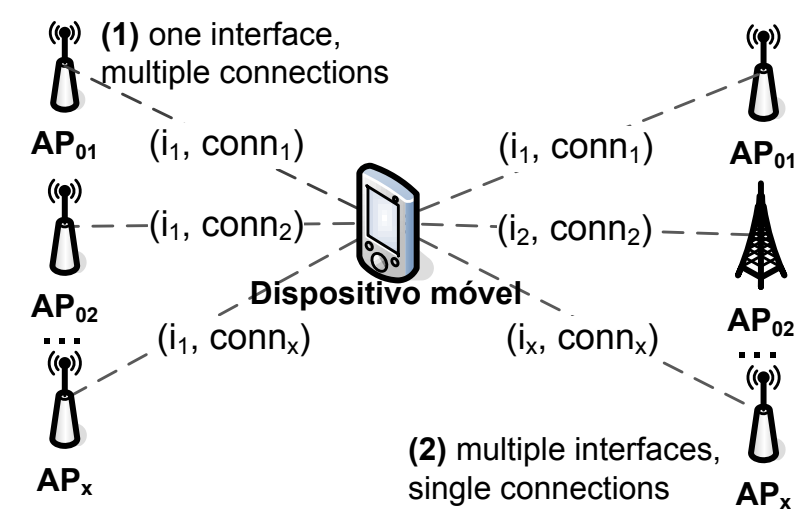

Figura 2.10: Dois tipos de conectividade: (1) uma interface e múltiplas conexões, (2) múltiplas interfaces com uma conexão.

Investigações recentes estão explorando múltiplas interfaces de rede para aumentar a vazão de dados, fazendo uso da diversidade de provedores de acesso. Duas ou mais interfaces de rede sem fio suportam paralelismo em fluxos de dados, melhoram os tempos de handover, e permitem comunicação direta com dispositivos próximos (Chandra e Bahl, 2004; Nicholson et al., 2010). A Figura 2.10 ilustra dois casos típicos: (1) uma interface de rede e múltiplas conexões; e (2) múltiplas interfaces com uma conexão.

Para ilustrar, Juggler é a implementação, na camada 2, de um serviço de virtualização de interfaces de rede sem fio do padrão IEEE 802.11, que executem a camada MAC em software. O principal objetivo é melhorar a vazão de dados, especificamente, quando a largura de banda sem fio é superior a conexão do AP com o sistema de distribuição. Por meio da multiplexação de fluxo de dados por várias redes, empregando interfaces de redes sem fio virtuais (Nicholson et al., 2010). Acreditamos que dados históricos de contexto de rede podem auxiliar a tomada de decisão para escolher o segundo ou $x^{\text {th }}$ ponto de acesso.

Em suma, os trabalhos mencionadas anteriormente, sumarizados na Tabela 2.1, estão investigando a otimização de handovers utilizando predição de mobilidade, e confiando em banco de dados de QoS públicos ou privados. Entretanto, poucos esforços foram direcionados pra oferecer dados com melhor qualidade em termos de facilidade de acesso, manipulação e atualização.

$\mathrm{Na}$ presente investigação, discutimos como estes preditores podem ter melhor desempenho usando nossa solução baseada em colaboração em círculos sociais online. Em complemento, elas poderiam usar nossa solução para entregar informações de conectividade para outros usuários móveis. 


\begin{tabular}{|l|l|l|l|}
\hline Trabalho & Preditor de mobilidade & Mecanismo de handover & Gerenciador de mobilidade \\
\hline \hline Breadcrumbs & Mapa de mobilidade & Strongest Signal Strength $($ SSS $)$ & Independente \\
\hline HOPES & Centralizado & Programável & Independente \\
\hline QoSIS.net & Centralizado & Centralizado & Independente \\
\hline
\end{tabular}

Tabela 2.1: Trabalhos relacionados e o uso dos componentes de gerenciamento de conectividade.

\subsection{Sensoriamento continuado}

A coleta de dados de contexto de conectividade é uma tarefa essencial para o gerenciamento de conectividade sem fio. Argumentamos que esse tipo de gerenciamento pode ser projetado como uma aplicação de sensoriamento continuado. Essas aplicações executam tarefas de coleta de dados periodicamente e.g., monitoramento de sinais vitais de uma pessoa.

Algumas arquiteturas recentes orquestram componentes para sensoriar, aprender, informar e compartilhar dados coletados (Lane et al., 2010; Ganti et al., 2011), como apresenta o diagrama na Figura 2.11. O componente de sensoriamento coleta dados de sensores e.g., localização geográfica e redes disponíveis, e o componente de aprendizado extrai informações do conjunto de dados e.g., lugares com boa cobertura de rede.

Em seguida, é necessário fazer algo de útil com estas informações e.g., ligar a interface de rede sem fio quando o dispositivo móvel chegar em uma área com boa cobertura de rede. Por fim, esta experiência deve ser compartilhada e.g., em círculos sociais para outras pessoas terem ciência dos benefícios descobertos e utilizados.

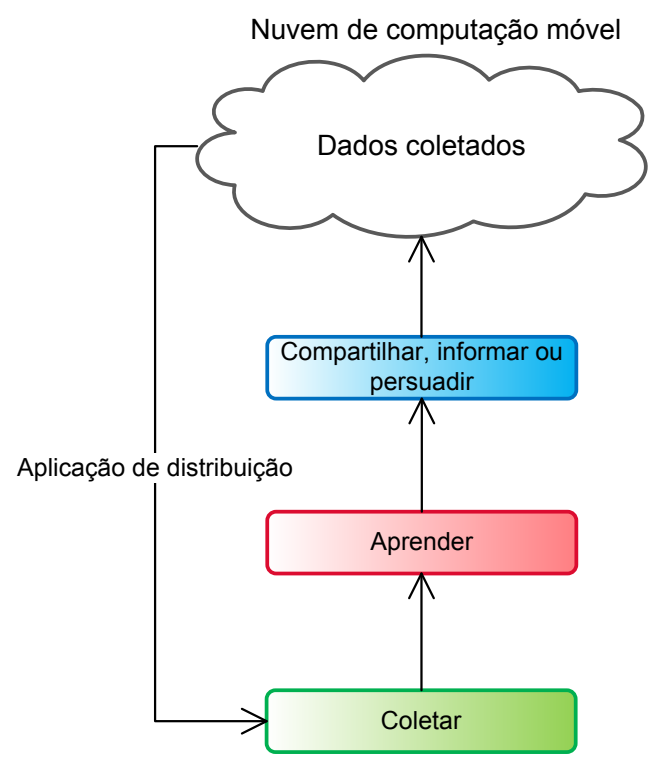

Figura 2.11: Arquitetura de sensoriamento continuado. Adaptada de (Lane et al., 2010, p. 143).

Considerando o propósito do sistema de sensoriamento, ele pode alcançar múltiplos níveis de escala (Lane et al., 2010; Ganti et al., 2011), eixo $x$ na Figura 2.12, definidos como:

- Pessoal: a aplicação coleta, analisa e apresenta dados de uma pessoa e.g., monitoramento de sinais vitais e acompanhamento de rotinas de exercícios físicos; 
- Grupo: conecta pessoas que utilizam aplicações com objetivo em comum, e que querem compartilhar informações sensoriadas livremente ou com proteção de privacidade;

- Comunidade: as aplicações representam coleção de dados de larga escala, cuja análise e compartilhamento pode ser útil para uma comunidade. Requer a cooperação de pessoas desconhecidas e que não irão confiar umas nas outras.

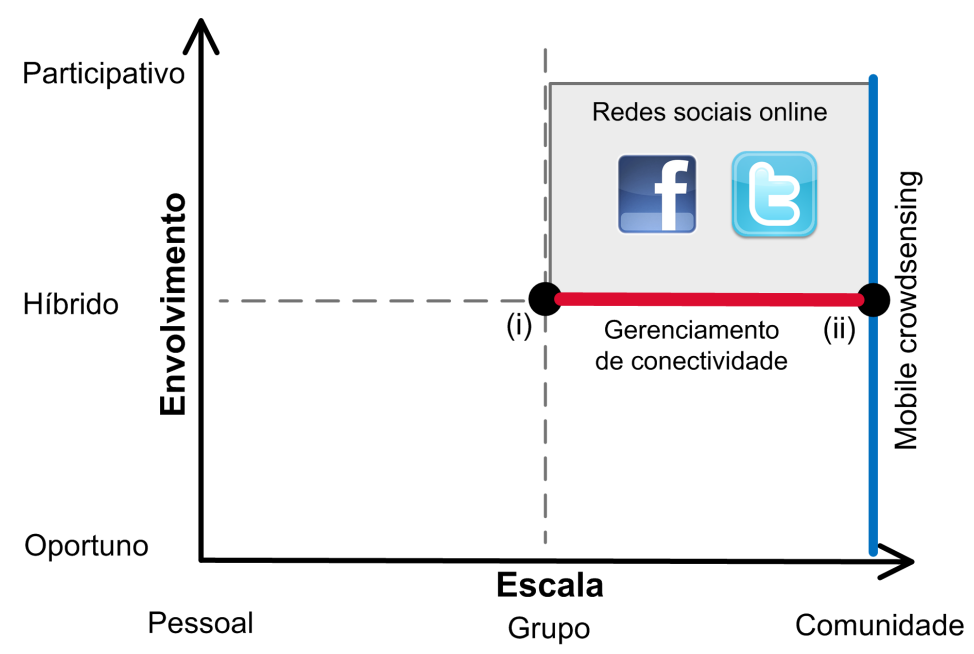

Figura 2.12: Espectro de possibilidades de sensoriamento em termos de escala e nível envolvimento dos participantes na coleta de dados.

Em relação ao envolvimento das pessoas, existem três pontos bem definidos, eixo $y$ na Figura 2.12, chamados de sensoriamento: participativo, oportuno e híbrido (Lane et al., 2010; Ganti et al., 2011). No sensoriamento participativo o usuário manualmente determina como, quando, o que e onde coletar os dados e.g., tirar uma foto ou escrever um comentário.

No sensoriamento oportunístico a tarefa de coletar dados é automatizada sem a necessidade do envolvimento do usuário (Lane et al., 2010) e.g., rastreamento da localização geográfica. Por fim, a abordagem híbrida combina dados coletados ativamente e oportunisticamente e.g., uma foto geo-referenciada.

O plano na Figura 2.12, também apresenta onde as redes sociais online estão localizadas em termos de escala e envolvimento. Na presente investigação, estamos interessados em aplicações com envolvimento híbrido e com escala entre grupo e comunidade, conforme o segmento de (i) a (ii) na Figura 2.13. Esse segmento inclui as redes sociais populares como Facebook e Twitter, que ocupam o quadrante formado pelo envolvimento híbrido e participativo, na base - eixo $x$, e escala entre grupo e comunidade, lado esquerdo - eixo y na Figura 2.12.

Nossa visão também tem um ponto em comum com as aplicações chamadas mobile crowdsensing, que são sistemas de sensoreamento comunitário que exploram o envolvimento participativo ou oportunístico das pessoas (Ganti et al., 2011), ponto (ii) na Figura 2.12. 


\subsection{Mídia social baseada em localização}

As redes sociais online disponibilizam informações ricas criadas ou relacionadas a uma comunidade e com referência geográfica e temporal, porque as pessoas são uma ótima fonte deste tipo de informação (Motani et al., 2005). A diversidade de conteúdo vêm de aplicações de terceiros que são embutidas nos sistemas online.

Para ilustrar, serviços baseados em localização estão sendo utilizados para compartilhar experiências em um determinado lugar dentro das redes sociais online, também chamada de mídia social baseada em localização (Li e Chen, 2009a). Geralmente, tal mídia combina (do inglês mashup (Yu et al., 2008)) a localização do usuário em um mapa, com uma mensagem/link, e posta a combinação nos círculos sociais do usuário.

Na presente investigação, discutimos como anexar o contexto de conectividade sem fio as mídias sociais baseadas em localização. De modo geral, os dados de contexto devem ser locais, móveis, atuais, personalizados e sociais para serem úteis. Para disponibilizar dados com estas propriedades, desenvolvemos um conjunto de métodos para manipular contexto de conectividade sem fio com suporte das redes sociais online no compartilhamento dos dados.

Uma mídia social é o conteúdo digital resultante da iteração ou colaboração entre pessoas por meio de aplicações web e.g., blogs e redes sociais online. Essa nova mídia mudou o conceito de autoria e leitura porque o processo de consumo e disseminação de informação está associado ao processo de geração e compartilhamento de informação (Zeng et al., 2010).

Em movimento, as pessoas podem criar e consumir mídias sociais baseadas em localização utilizando dispositivos móveis modernos. A conectividade sem fio é um recurso fundamental para estes dispositivos que vão de um lugar para outro utilizando sistemas de acesso heterogêneos. Isso justifica o esforço para alavancar interações sociais para assistir o gerenciamento de conectividade sem fio.

As redes sociais online podem ser utilizadas para descarregar os bancos de dados no dispositivo móvel adicionando escala e recursos computacionais para processar dados de contexto coletados (Lane et al., 2010). Nossa hipótese é que as experiências de conectividade sem fio de usuários móveis podem ser manipuladas em anexo a mídias sociais baseadas em localização. O objetivo é adicionar relevância e disponibilizar dados de contexto de conectividade locais, móveis, atuais e sociais.

O processo de geração e consumo de mídias sociais baseadas em localização é sumarizado na Figura 2.13. Os usuários móveis assumem o papel de criador, (1), quando estão gerando conteúdo digital e compartilhando em seus círculos sociais. Por exemplo, o usuário tira uma foto, escreve uma mensagem, se conecta a uma rede sem fio e posta o conteúdo em uma rede social online.

Eles são consumidores, (2), quando estão procurando por conteúdo ou interagindo com ele. Por exemplo, o usuário está em um lugar específico, se conecta a uma rede sem fio, busca por fotos de amigos no mesmo lugar, e posta um comentário na foto para adicionar sua experiência. 


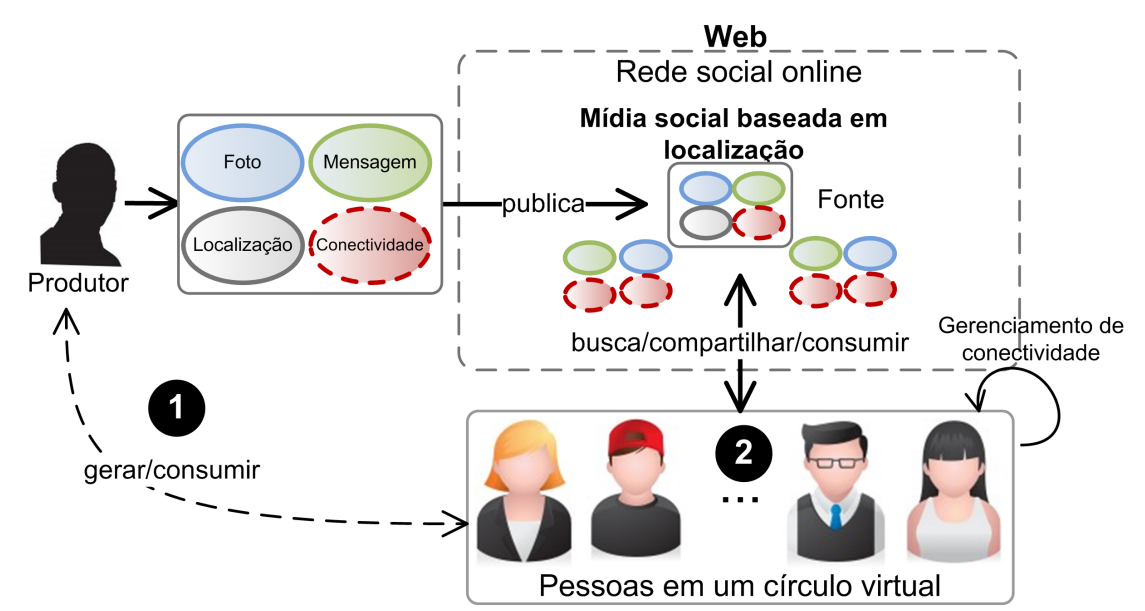

Figura 2.13: Processo de geração, (1), e consumo, (2), de mídias sociais baseadas em localização.

\subsection{Considerações finais}

A próxima geração de redes de acesso sem fio provavelmente serão complexos sistemas heterogêneos, compostos por várias tecnologias de acesso sem fio e habitados por dispositivos móveis equipados com duas ou mais interfaces de rede sem fio que implementarão mais de uma tecnologia de comunicação e executarão diversas aplicações baseadas na web. Esse cenário justifica a investigação de soluções cientes de contexto para gerenciar conectividade sem fio.

Observamos que várias soluções na literatura fazem uso de dados históricos de contexto de conectividade sem fio para criar modelos de previsão. Dessa forma, coletar dados de contexto é uma tarefa essencial e argumentamos que os sistemas cientes de contexto podem ser projetados como um sistema de sensoriamento continuado.

Mídias sociais baseadas em localização combinam informações de diversas fontes e acreditamos que é possível anexar as experiências de conectividade a elas. O próximo capítulo define o que é contexto de conectividade sem fio e descreve um modelo de dados para representa-lo e as ferramentas utilizadas para manipula-los. 


\section{CAPÍTULO}

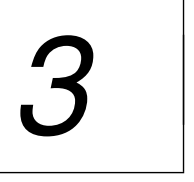

\section{Contexto de conectividade sem fio}

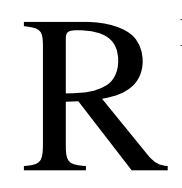

lembrando o capítulo anterior, trabalhos na literatura gerenciam a conectividade sem fio empregando simultaneamente o contexto de conectividade atual e um conjunto destes dados coletados no passado. Neste capítulo, apresentamos detalhes dos dados que compõem o conjunto denominado contexto de conectividade sem fio. Propomos um modelo de dados para representar tal conjunto de dados com ciência da localização geográfica e ciência temporal.

A viabilidade do modelo é delimitada em termos de sobrecarga de armazenamento e de consumo de energia. Para finalizar, discutimos como o modelo de dados pode ser utilizado para economizar energia e espaço de armazenamento durante a coleta, que é feita enquanto o usuário está se movimentando de um lugar para outro conectado à Internet e fazendo uso de serviços na web.

\subsection{Dados de contexto de conectividade}

As interfaces de rede sem fio podem ser manipuladas com sensores capazes de coletar informações sobre o ambiente de rede em que está associada e, também, capturar informações de outras redes disponíveis por meio de radiodifusão, como apresenta a ilustração na Figura 3.1. Nessa figura, o dispositivo está em um ambiente com três WLANs gerenciadas por provedores de acesso (do inglês Internet Service Provider (ISP)s), distintos.

Os dados de contexto de rede disponíveis por radiodifusão são recuperados por meio de varreduras nos canais utilizados pela tecnologia de comunicação sem fio em particular. Esses dados de contexto têm como fonte os APs disponíveis no ambiente e são fundamentais para recuperar as experiências de conectividade sem fio dos usuários móveis. 


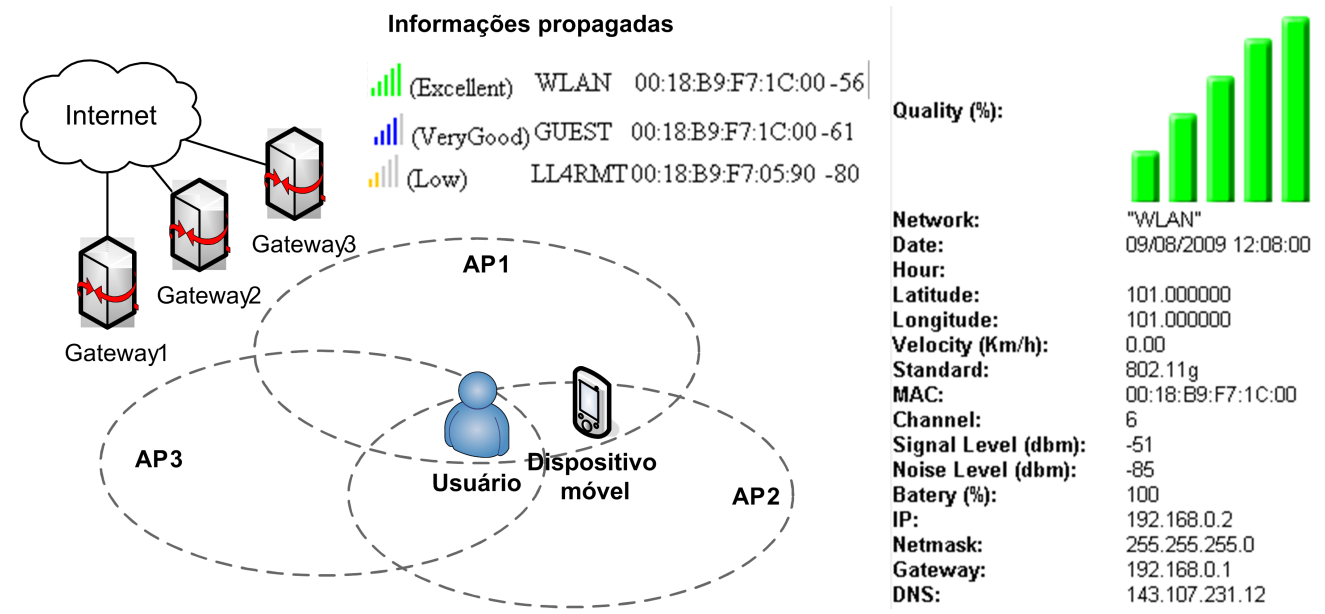

Figura 3.1: Cenário de coleta de dados de contexto de conectividade sem fio.

Uma experiência de conectividade sem fio é um conjunto de dados de contexto de conectividade. Incluindo parâmetros de QoS relacionados a um ponto de acesso utilizado, por uma pessoa com um dispositivo móvel, em um determinado local e um horário específico. Esses dados são recuperados de diferentes fontes e.g., perfil do usuário, pontos de acesso e localização.

A mobilidade do dispositivo móvel pode ser definida como um conceito lógico em detrimento a um físico (Sun e Sauvola, 2005). Onde a mobilidade significa a mudança da localização lógica de um ponto de acesso em detrimento a mudança de localização geográfica do dispositivo. Com essa visão em mente, definimos e estruturamos um conjunto de dados de contexto de conectividade sem fio, como ilustrado no diagrama na Figura 3.2.
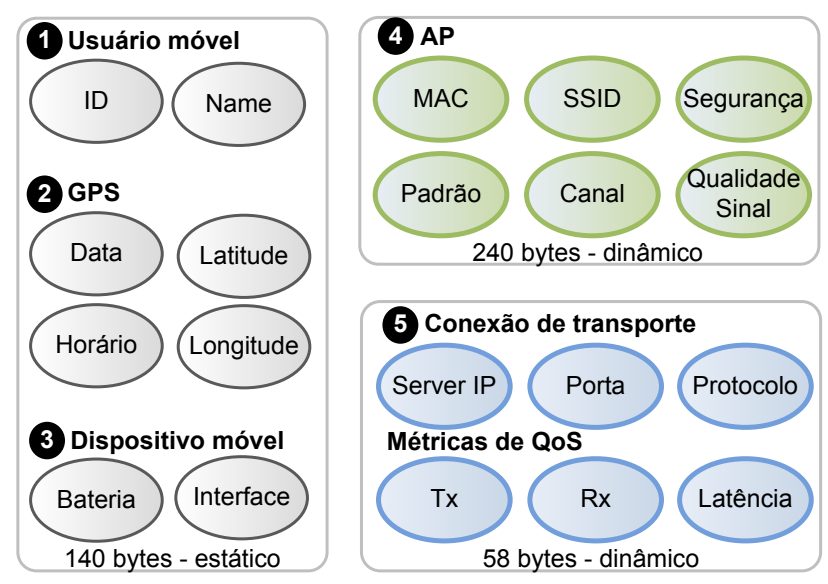

Figura 3.2: Exemplo de conjunto de dados de contexto de rede e suas respectivas fontes.

Para Bettini et. al (2010) um modelo de dados de contexto adequado reduz a complexidade das aplicações cientes de contexto e facilita a sua manutenção e evolução. Seguindo esta recomendação, definimos as fontes de dados de contexto: (1) usuário móvel, (2) dispositivo móvel, (3) GPS, (4) ponto de acesso, e (5) conexões de transporte, como ilustrado na Figura 3.2. Os dados recuperados destas fontes foram especificados levando em consideração nosso ambiente de desenvolvimento e experimentação, com objetivo de atender os requisitos de um protótipo executável. 
Para tanto, analisamos conjuntos de dados disponíveis no repositório Community Resource for Archiving Wireless Data At Dartmouth $(C R A W D A D)^{1}$. Esse repositório permite que pesquisadores publiquem conjuntos de dados utilizados em em artigos científicos. Em geral, os traces de experimentos em redes sem fio são armazenados em diversos formatos não padronizados. São arquivos criados para um propósito ou aplicação específica no formato Extensible Markup Language (XML) acompanhados do Document Type Definition (DTD) ou schema para facilitar o parser.

Não temos a intenção de definir um conjunto de dados gerais ou padronizáveis. Manipulando este conjunto de dados apropriadamente podemos inferir algumas informações úteis para o gerenciamento de conectividade sem fio. Por exemplo: quem é o usuário; onde e quando ele ou ela estava conectado; associado a um ponto de acesso particular; e com determinadas conexões de transporte abertas.

Em cada varredura em busca de oportunidades de conectividade sem fio, os dados de contexto podem variar em função do número de pontos de acesso disponíveis e da quantidade de conexões de transporte abertas. A ilustração na Figura 3.2, também, indica um subconjunto dados estático e dois dinâmicos em termos de sobrecarga de armazenamento. Em uma determinada varredura, os dados relacionados a data, hora e usuário móvel irá aparecer apenas uma vez no conjunto, chamamos de subconjunto estático.

Por outro lado, os subconjuntos dinâmicos são compostos pelos dados relacionados aos pontos de acesso e conexões de transporte. As estimativas de tamanho dos subconjuntos de dados apresentados na Figura 3.2 foram estimados utilizando os tipos de dados da linguagem de programação Java $^{2}$. Dessa forma, as instâncias desses subconjuntos variam em função do número de pontos de acesso disponíveis e das conexões de transporte abertas, detalhes são discutidos na Seção 3.3.

\subsection{Modelo de dados}

\subsubsection{Caminho de conectividade}

Ilustrando um cenário hipotético, uma pessoa pode fazer uso de conectividade sem fio enquanto se move entre os pontos turístico $p_{1}$ e $p_{4}$, conforme ilustração na Figura 3.4a. Durante o deslocamento, pode ser necessário realizar trocas de rede, em pontos particulares, para manter o dispositivo móvel conectado durante o caminho, chamamos estes lugares de pontos de handover, conforme ilustração na Figura 3.3.

Nesses pontos, o conjunto de dados de contexto de conectividade sem fio, (Rahmati e Zhong, 2007; Tsao e Sivakumar, 2009), é coletado e a troca de rede é feita levando em consideração o contexto de rede atual e passado, com objetivo de atender os requisitos de QoS das aplicações sendo utilizadas pelo usuário. No final da percurso, a rota que conecta os pontos de handover é

\footnotetext{
1http: / / crawdad.cs.dartmouth.edu/

$2_{\text {http: } / / \text { java.com }}$
} 
chamada de caminho de conectividade. Em outras palavras, cada experiência de conectividade sem fio espaçada por tempo e localização é chamada de caminho de conectividade.

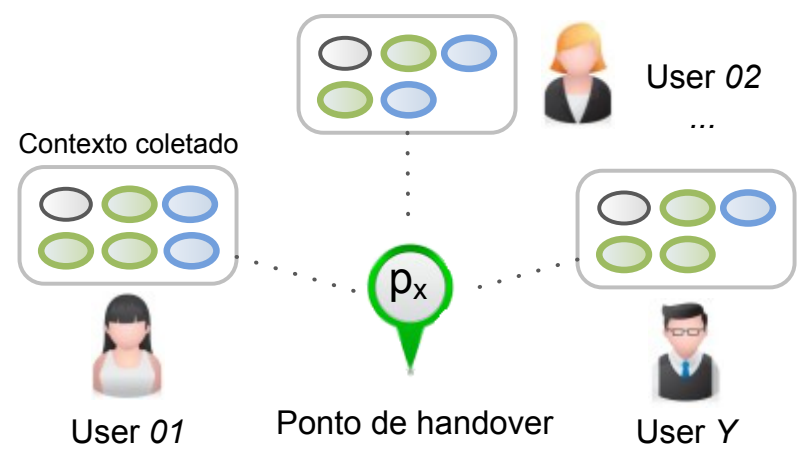

Figura 3.3: Exemplo de ponto de handover onde diferentes usuários trocaram de rede.

O caminho de conectividade de um usuário móvel pode ser modelado como um grafo direcionado ou, formalmente, $G_{p a t h}=\left(V_{p a t h}, E_{\text {path }}\right)$ Equação 3.3. Onde $V_{\text {path }}$ é um conjunto de pontos de handover e $E_{\text {path }}$ é um conjunto de arestas. Cada aresta indica a rede sem fio que foi utilizada entre os pontos de handover e o conjunto de redes disponíveis com legendas formatadas como: $<$ redeAtual $>,<\{$ redesDisponveis $\}>$.

$$
G_{\text {path }}=\left(V_{\text {path }}, E_{\text {path }}\right)
$$

Onde:

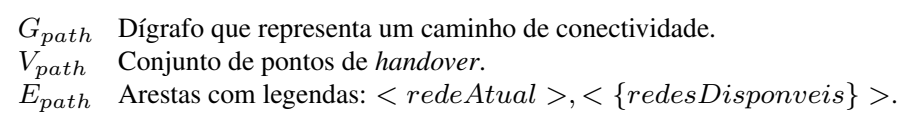

A ilustração (b), na Figura 3.4, mostra os caminhos de conectividade de três usuários no ponto turístico. Por exemplo, do vértice $p_{1}$ ao $p_{2}$ o usuário, User $_{01}$ estava associado a rede "WLAN"e estavam disponíveis as redes "ATT"e "Bell". O caminho de conectividade sumariza todos os dados de contexto coletados durante a movimentação de um usuário.

Dados os caminhos de conectividade de todos usuários móveis no circulo social de alguém, um algoritmo é aplicado para combina-los em um novo grafo chamado grafo de conectividade ou $G_{\text {conn }}$, como ilustrado na Equação 3.2. A próxima subseção examina os detalhes da construção do grafo de conectividade.

$$
G_{\text {conn }}(V, E)=\operatorname{Combina}\left(G_{\text {path }}[\text { user.length }()]\right) \text {. }
$$

\subsubsection{Grafo de conectividade}

A ilustração na Figura 3.4b mostra três caminhos de conectividade sobrepostos em uma hipotética rota entre $p_{1}$ e $p_{4}$. Os três usuários tiveram um conjunto de pontos de handover diferentes 


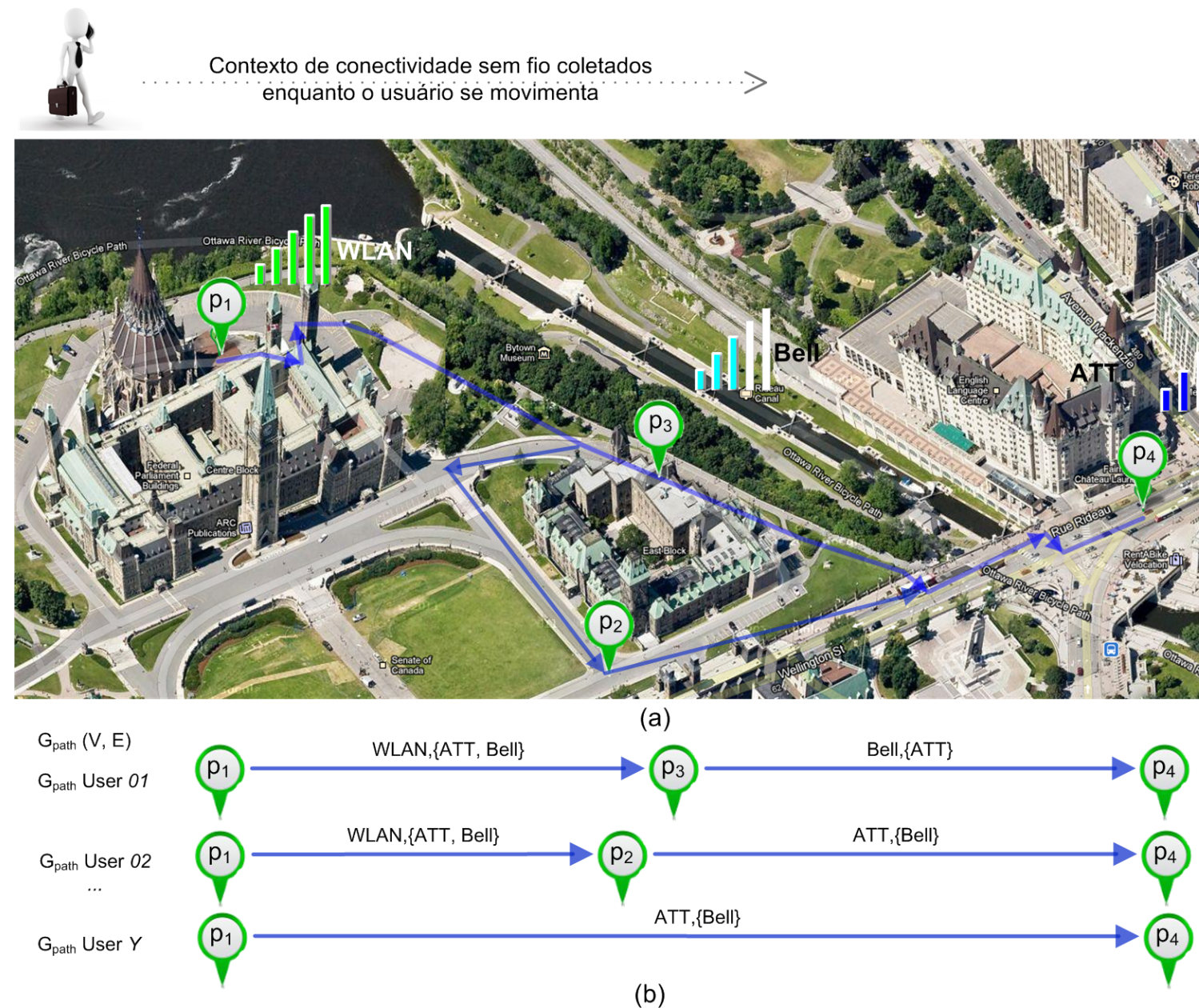

Figura 3.4: (a) Exemplo hipotético de caminhos de conectividade. (b) Representação dos caminhos como grafos direcionados.

no caminho, entretanto alguns são comuns. A probabilidade destas coincidências depende do número de usuários móveis, características das redes sem fio e tamanho das áreas de sobreposição entre duas ou mais redes sem fio. A combinação destes caminhos representa todo o conhecimento descoberto pelos usuários neste ambiente de rede sem fio.

O desafio agora é representar estes dados de forma interessante para serem compartilhados em círculos sociais online. Escolhemos construir um dígrafo, $G_{c o n n}=\left(V_{\text {conn }}, E_{c o n n}\right)$ Equação 3.2, que combina os caminhos de conectividade em uma representação simplificada. O conjunto de vértices, $V$, continuam sendo pontos de handovers provenientes da união de todos os $V_{\text {path }} s$ dos $G_{\text {path }} s$. Entretanto, o conjunto de arestas, $E$, contém os usuários móveis que utilizaram o mesmo ponto de acesso entre os dois pontos de handover.

Como resultado, temos um dígrafo que compila todos os dados de contexto de conectividade coletados, com o seguinte formato de legenda nas arestas: "atualAP, \{todosUsuarios $\}$ ". Os vértices são conectados por arestas que representam a rede sem fio utilizada entre os pontos de handover e o conjunto de usuários que escolheram a mesma rede nesta parte do caminho. Uma 
representação textual de $G_{c o n n}$ i.e., um arquivo XML, é a mídia compartilhada nos círculos sociais online, maiores detalhes são examinado no Capítulo 4.

$$
G_{\text {conn }}=\left(V_{\text {conn }}, E_{\text {conn }}\right)
$$

Onde:
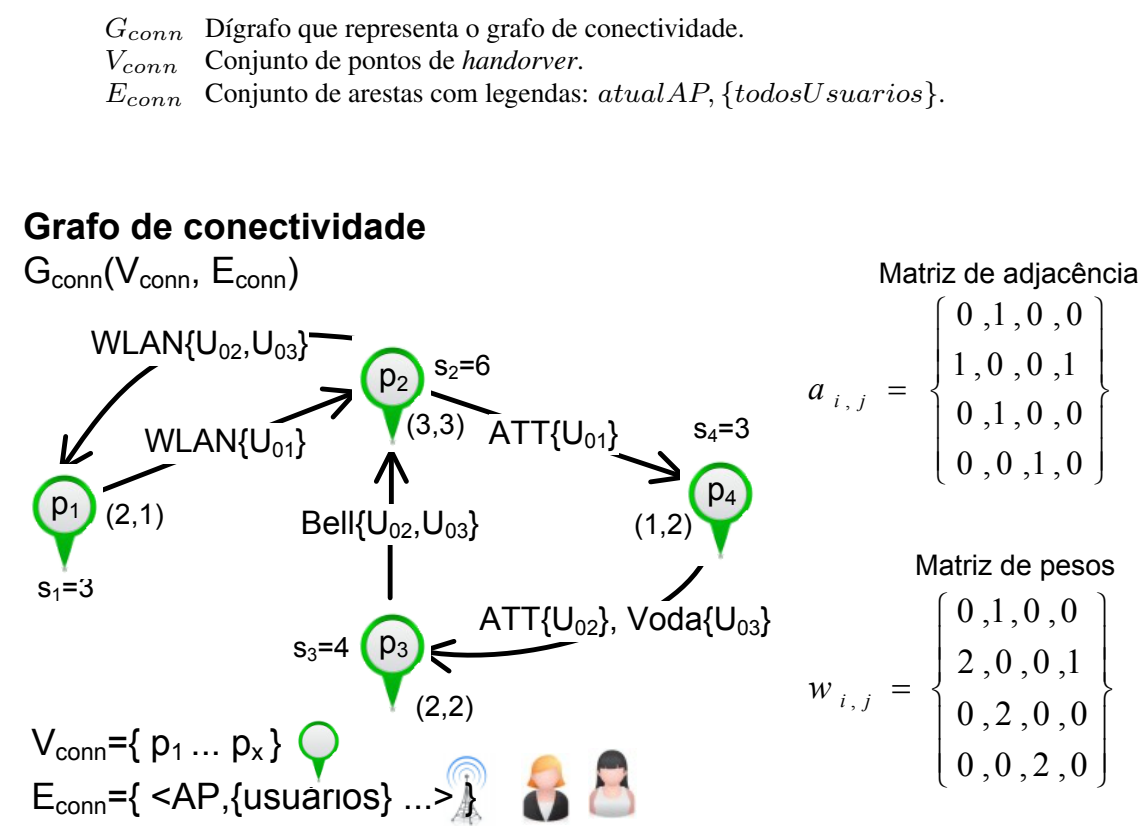

Figura 3.5: Grafo de conectividade do exemplo hipotético.

Para construir o grafo de conectividade, $G_{c o n n}$, utilizamos o Algoritmo 1 que recebe como entrada os caminhos de conectividade. O algoritmo percorre o conjunto de pontos de handovers, $V_{\text {path }}$, de todos usuários (linhas 2 e 3). Na sequência, é necessário identificar os pontos de handovers de todos caminhos de conectividade e procurar pelos pontos similares em uma área com tamanho pré-definido (linha 4).

Uma forma de resolver o problema é escolher uma área com diâmetro igual ao erro do sistema de localização empregado e.g., GPSs nos dispositivos móveis tem erro de aproximadamente 15 metros. Nesse caso, utilizamos um sistema de localização com erro de aproximadamente 9 metros, detalhes no Capítulo 5.

Aplicamos um algoritmo para fazer busca em área com complexidade $O(n \log n)$ (Quddus et al., 2007). Na primeira execução, o algoritmo percorre todos usuários e seus respectivos pontos de handover, como descrito no Algoritmo 1. Em seguida, o grafo é construído passo a passo adicionando vértices e arestas ao chamado grafo de conectividade, linhas de 5 a 10 . Antes de inserir um novo vértice é necessário verificar se já não existe um nó que representa aquele ponto de handover.

Uma vez construído o grafo de conectividade, a complexidade para adicionar e remover um ponto de handover é $O(\log n)$ vezes a complexidade de busca. É importante destacar que a redução 


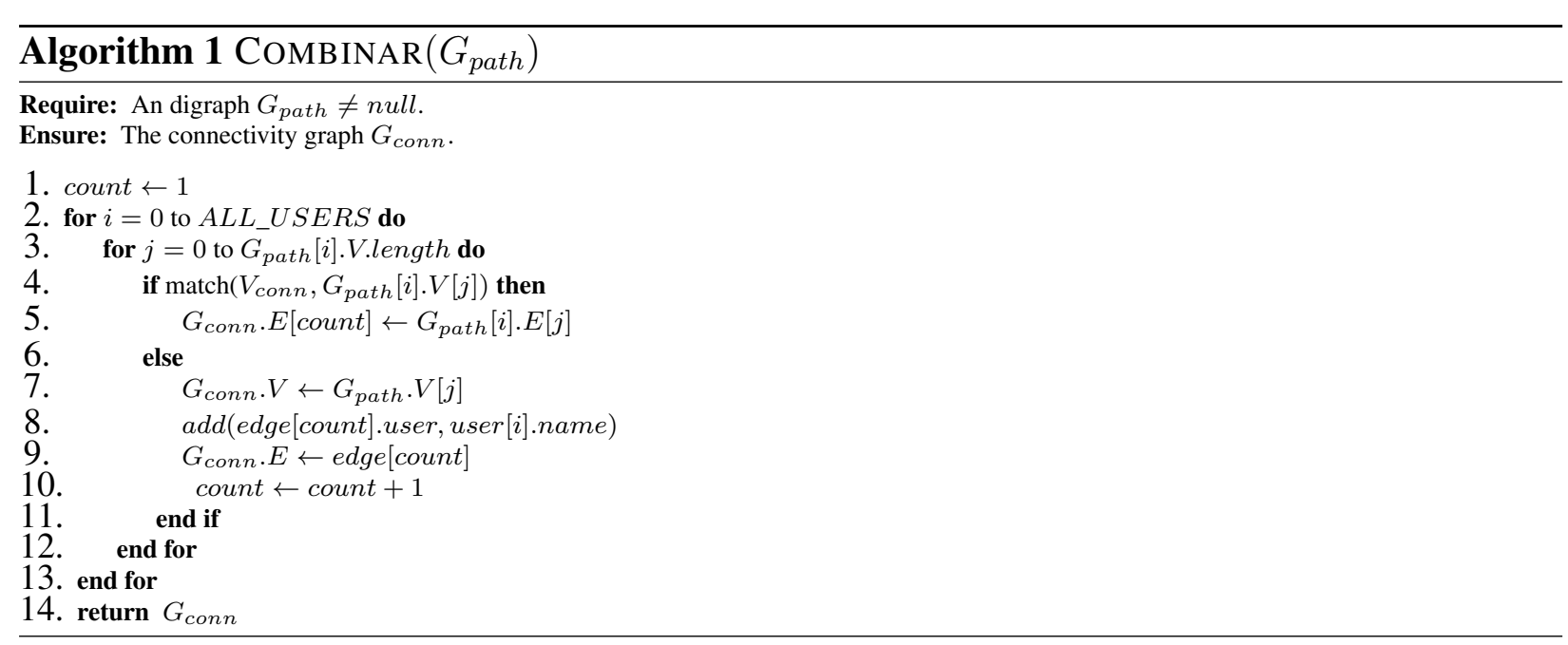

do grafo simplifica a atualização dos dados de contexto, porque o algoritmo não será executado toda vez que uma atualização for necessária.

Entretanto, a escalabilidade é um problema para esta abordagem, porque a complexidade de tamanho e de tempo para construir o grafo de conectividade restringe a cobertura de grande áreas com alta densidade de usuários e.g., o campus de uma universidade ou uma cidade inteira. Isto justifica a escolha das redes sociais online para adicionar escala a solução. No Capítulo 4 discutimos como adicionamos escala a solução empregando uma forma inteligente de entregar os dados.

\subsubsection{Manipulando o grafo de conectividade}

Manipulando os dados de contexto de conectividade associados a um $G_{\text {conn }}$ podemos derivar informações sobre as condições das redes sem fio e sobre o comportamento dos usuários móveis. Por exemplo, computando o grau dos vértices, $k_{i}$, os pontos com maior número de handovers são destacados no grafo. O grau de um vértice $i$ é definido como o total de arestas para ele (saída) ou proveniente dele (entrada) ou $k_{i}=\sum_{j} a_{i j}$, onde $a_{i, j}$ é a matriz de adjacência de $G_{\text {conn }}$.

Na Figura 3.5 é apresentado o grau do de cada vértice acompanhado do grau de entrada e de saída com legendas: "grau(entrada, sada)". Dessa forma, tem-se o número de vezes os usuários se associaram (grau de entrada) ou se desassociaram (grau de saída) a um AP, em um determinado ponto de handover em $V_{\text {conn }}$.

Para obter um valor absoluto calculamos a intensidade do vértice (do inglês vertex strength), $s_{i}$, para obter um valor absoluto, conforme Equação 3.4 (Barrat et al., 2004). Onde $w_{i, j}$ é uma matriz de pesos que conta o número de handovers em cada vértice considerando a direção, também ilustrada na Figura 3.5. Quanto maior a intensidade, $s_{i}$, mais justa é a relação de colaboração entre os dois elementos (Yu e Fan, 2010).

$$
s_{i}=\sum_{i=1}^{N} a_{i j} w_{i j} .
$$


Onde:

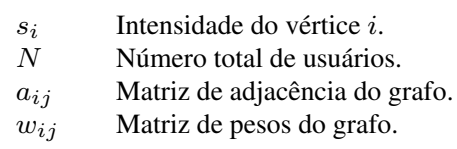

A partir de $G_{\text {conn }}$ outros dois grafos podem ser derivados: $G_{\text {users }}$ e $G_{n e t}$, apresentados na Figura 3.6 (1) e (2), respectivamente. $G_{\text {users }}$ mostra todos os usuários, como vértices, e o número de vezes que interagiram compartilhando um ponto de handover, número nas legendas das arestas. Dado um usuário móvel o conceito dos outros usuários é o número de interações ou intensidade do vértice $s_{i}$, também calculado com a Equação 3.4.
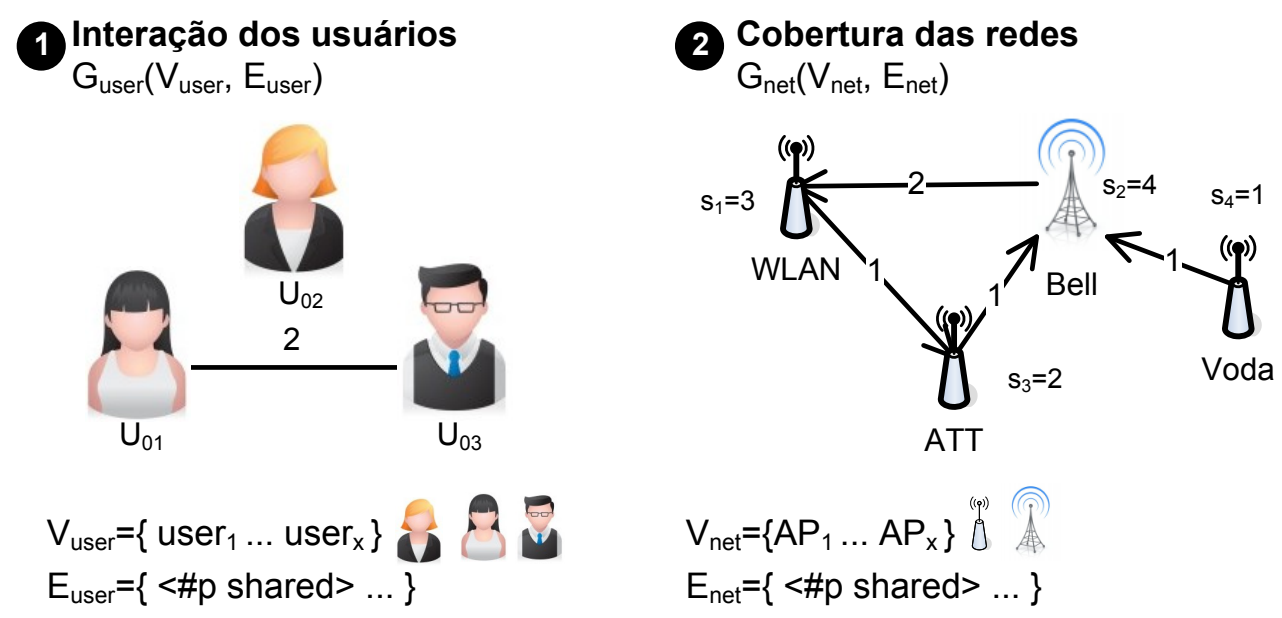

Figura 3.6: Instância dos grafos (1) $G_{\text {users }}$ e (2) $G_{n e t}$ para o exemplo hipotético.

Por outro lado, $G_{n e t}$ é um dígrafo que tem os APs como vértices e as arestas representam o número de handovers entre dois APs. Cada grafo tem sua matriz de adjacência, $a_{i, j}$, matriz de pesos, $w_{i, j}$, e a intensidade dos vértices, $s_{i}$, para recuperar as informações pertinentes em cada caso. A Tabela 3.1 lista estes parâmetros e seus significados em cada grafo.

\begin{tabular}{|c|c|c|c|}
\hline Grafo-Informação & $a_{i j}$ - adjacência & $w_{i j}-$ pesos & $s_{i}$ - intensidade \\
\hline$G_{\text {conn }}-$ Áreas de handover & $\begin{array}{l}\text { conexão entre pontos de han- } \\
\text { dover }\end{array}$ & $\begin{array}{l}\text { número de handovers entre os } \\
\text { pontos }\end{array}$ & $\begin{array}{l}\text { total de handovers feitos no } \\
\text { ponto }\end{array}$ \\
\hline$G_{\text {users }}$ - Interação & $\begin{array}{l}\text { usuários que compartilharam } \\
\text { um ponto de handover }\end{array}$ & $\begin{array}{l}\text { número de vezes que os usuá- } \\
\text { rios compartilharam um ponto } \\
\text { de handover }\end{array}$ & $\begin{array}{l}\text { total de compartilhamentos no } \\
\text { circulo social }\end{array}$ \\
\hline$G_{n e t}-$ Cobertura & APs usados em sequência & $\begin{array}{l}\text { número de handovers entre } \\
\text { APs }\end{array}$ & $\begin{array}{l}\text { total de handovers entre os } \\
\text { APs }\end{array}$ \\
\hline
\end{tabular}

Tabela 3.1: Descrição dos parâmetros para cada grafo ou informação.

Adicionalmente, $G_{\text {users }}$ é desconexo quando um ou mais usuários são novos no círculo social ou não possuem interação com um usuário especifico e.g., o usuário "A"na Figura 3.6 (1). Nesse caso, o grau de centralidade, $c_{i}$, é utilizado para computar as interações do usuário no compartilhamento de dados. O grau de centralidade é calculado pela Equação 3.5 (Fei et al., 2011), onde $k_{i}$ é o grau do vértice e $N$ é o total de pessoas no círculo social. 


$$
c_{i}=\frac{k_{i}}{N-1}
$$

Onde:

$$
\begin{array}{ll}
c_{i} & \text { Grau de centralidade do vértice } i . \\
k_{i} & \text { Grau do vértice } i . \\
N & \text { Número total de usuários. }
\end{array}
$$

Em suma, a partir do grafo de conectividade, $G_{c o n n}$, é possível descobrir as seguintes informações:

- Áreas de handover: áreas onde as pessoas realizam handovers com frequência, também chamadas áreas de alta densidade de handovers;

- Interação entre os usuários móveis: dado um usuário, o conceito dos usuários em seu círculo social é computada contando o número de pontos de handover em comum, quanto maior o número maior a interação no compartilhamento;

- Cobertura das redes: computa a popularidade de um AP contando o número de usuários que se associaram em função do tempo. Também, revela como os usuários estão combinando APs para se manterem conectados quando estão em movimento.

\subsubsection{Exemplo de aplicação}

Para ilustrar, imaginemos que pessoas estão utilizando um determinado ambiente de rede sem fio e coletando dados de contexto de conectividade enquanto trabalham no lugar. Na Figura 3.7 tem-se caminhos nesse ambiente de rede sem fio e os principais pontos onde foram coletados dados de contexto de conectividade. O diâmetro dos círculos indicam a quantidade de dados de contexto coletados pelos dispositivos móveis das pessoas.

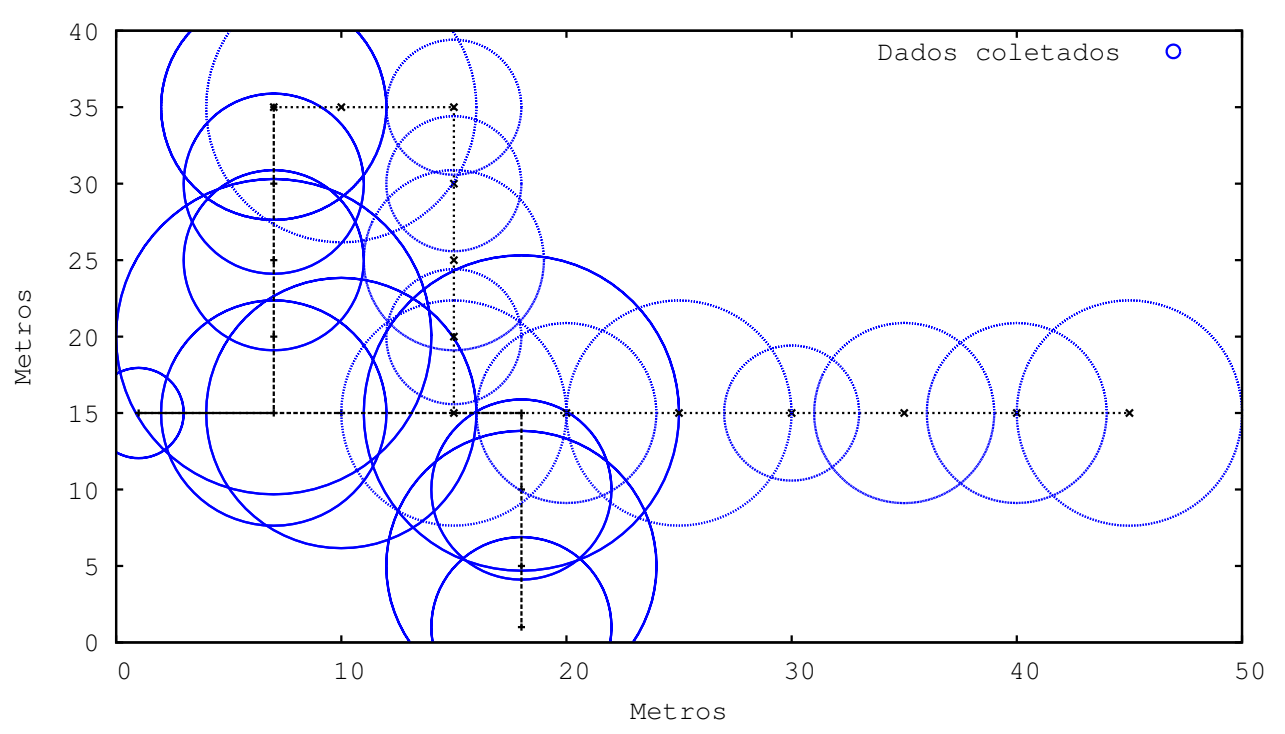

Figura 3.7: Dados coletados. 
Analisando esses dados podemos identificar os pontos de handover e construir um grafo de conectividade. Ainda podemos calcular a intensidades dos vértices e recuperar as áreas onde handovers foram feitos com frequência e.g., $s_{i}>50$ conforme novo gráfico na Figura 3.8.

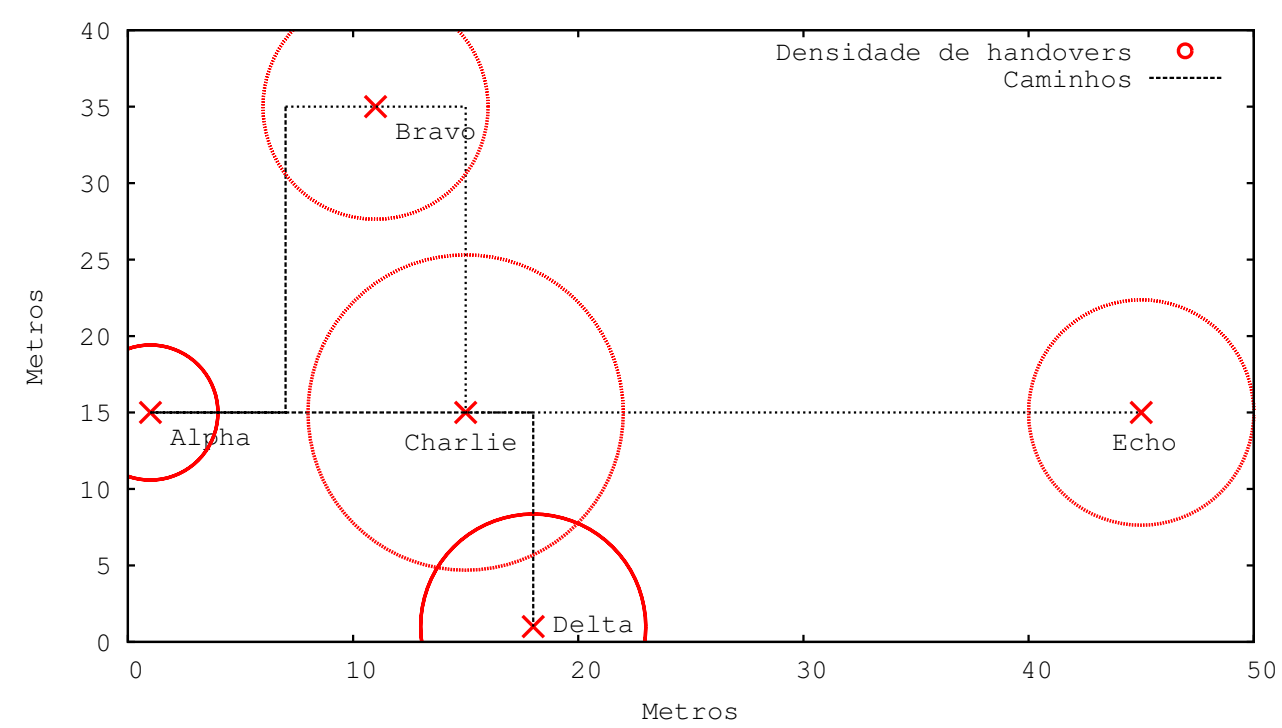

Figura 3.8: Áreas com alta densidade de trocas de rede.

Com isso, os dados históricos de contexto de conectividade são sumarizados para que possam ser utilizados de forma eficiente e útil. Na próxima seção, 3.3, examinamos como o grafo de conectividade pode ser utilizado para economizar espaço de armazenamento e reduzir o consumo de bateria na coleta de dados de contexto de conectividade sem fio.

\subsection{Viabilidade}

O estudo da viabilidade do modelo de dados foi motivado pela constatação de que coletar dados de contexto consome energia, processamento e armazenamento do dispositivo móvel, conforme ilustração na Figura 3.9. Nessa figura, tem-se a estimativa de consumo de bateria e sobrecarga de armazenamento para descobrir oportunidades de conectividade sem fio. São cinco frequências de varreduras onde a primeira descobre mais de $80 \%$ das oportunidades de conectividade, simbolizada por $>80$, e a última $20 \%$ das oportunidades. Essa figura mostra que descobrir mais de $80 \%$ das oportunidades de conectividade é significativamente mais caro em termos de sobrecarga de armazenamento e consumo de bateria.

Na Tabela 3.2 são listados os resultados estimados em função do tempo para os cinco percentuais de descoberta de oportunidades. Os parâmetro são: A) número de varreduras; B) sobrecarga de armazenamento e C) percentual de bateria. A estimativa de cada parâmetro é feita a cada dez segundo e termina com sessenta segundos. Esses resultados motivaram o estudo da viabilidade do modelo em termos de sobrecarga de armazenamento e consumo de energia que é descrito nas próximas subseções. 


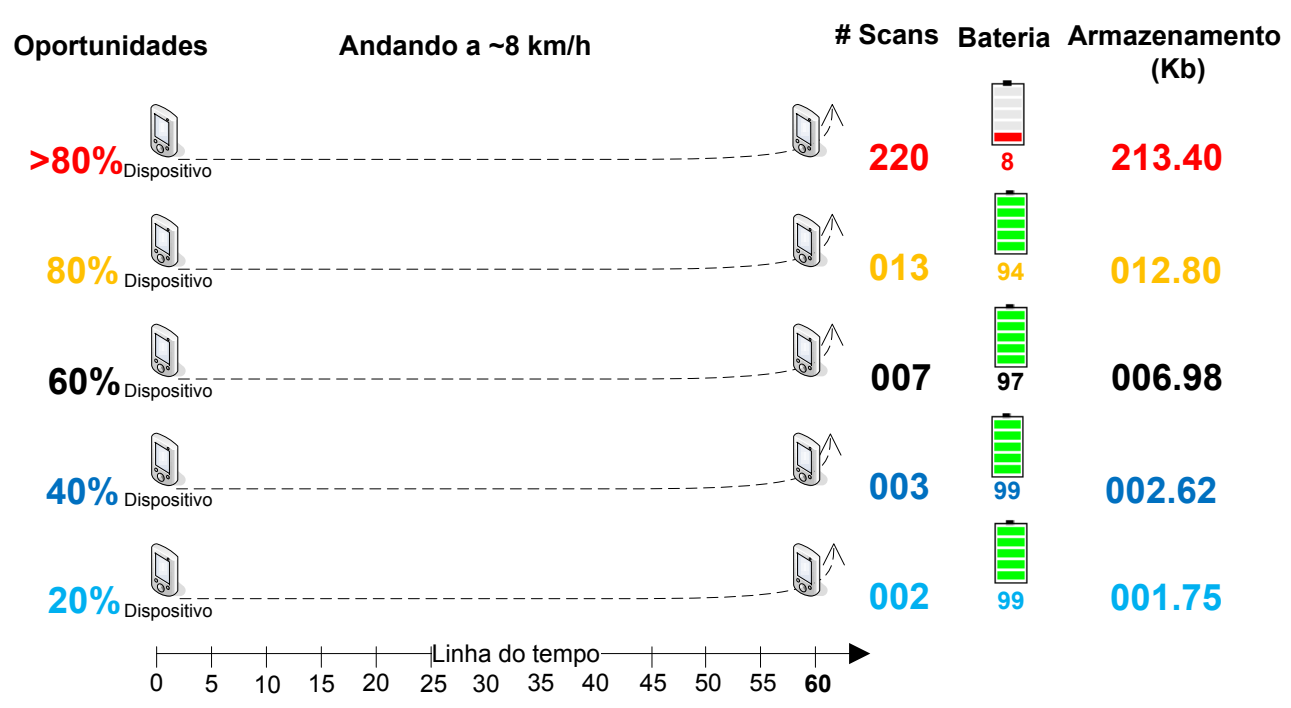

Figura 3.9: Estimativa de consumo de energia e sobrecarga de armazenamento no dispositivo móvel.

\begin{tabular}{|c|c|c|c|c|c|c|c|c|c|c|c|c|c|c|c|}
\hline \multirow{2}{*}{ Tempo (s) } & \multicolumn{3}{|c|}{$>80 \%$} & \multicolumn{3}{|c|}{$80 \%$} & \multicolumn{3}{|c|}{$60 \%$} & \multicolumn{3}{|c|}{$40 \%$} & \multicolumn{3}{|c|}{$20 \%$} \\
\hline & $\mathbf{A}$ & B & C & $\mathbf{A}$ & B & $\mathbf{C}$ & $\mathbf{A}$ & B & $\mathbf{C}$ & $\mathbf{A}$ & B & C & $\mathbf{A}$ & B & C \\
\hline 0 & 0 & $\overline{0,0}$ & 100 & 0 & 0,0 & 100 & 0 & 0,0 & 100 & 0 & 0,0 & 100 & 0 & 0,0 & 100 \\
\hline 10 & 40 & 38,8 & 83 & 2 & 2,3 & 99 & 1 & 1,1 & 99 & 1 & 0,5 & 99 & 0 & 0,0 & 99 \\
\hline 20 & 80 & 77,6 & 66 & 5 & 4,6 & 98 & 2 & 2,3 & 99 & 1 & 0,5 & 99 & 1 & 0,5 & 99 \\
\hline 30 & 120 & 116,4 & 50 & 7 & 6,9 & 97 & 4 & 3,4 & 98 & 2 & 1,7 & 99 & 1 & 0,5 & 99 \\
\hline 40 & 160 & 155,2 & 33 & 10 & 9,3 & 96 & 5 & 4,6 & 98 & 2 & 1,7 & 99 & 2 & 1,7 & 99 \\
\hline 50 & 200 & 194,0 & 16 & 12 & 11,6 & 95 & 6 & 5,8 & 97 & 3 & 2,9 & 98 & 2 & 1,7 & 99 \\
\hline 60 & 240 & 232,8 & 0 & 14 & 13,9 & 94 & 7 & 6,9 & 97 & 4 & 3,4 & 98 & 2 & 2,3 & 99 \\
\hline
\end{tabular}

Tabela 3.2: Estimativa do número de varreduras, sobrecarga de armazenamento e consumo de bateria.

\subsubsection{Sobrecarga de armazenamento}

Recuperar dados de contexto de conectividade sem fio arbitrariamente pode ser caro em termos de sobrecarga de armazenamento. Isso ocorre porque as varreduras são realizadas com frequência para descobrir os pontos de acesso disponíveis no ambiente. Cada tecnologia de comunicação sem fio realiza a varredura de uma forma particular.

A frequência de varredura está fortemente relacionada a possibilidade de achar oportunidades de conectividade, como listado na Tabela 3.3. Nessa tabela, são listados os intervalos de varredura, em segundos, para cada percentual de oportunidades de conectividade descobertas.

\begin{tabular}{|l|c|c|}
\hline Oportunidades (\%) & Intervalo (s) (Falaki, 2008) & Tamanho (Kbytes) \\
\hline \hline 20 & 1500 & 32.40 \\
40 & 1000 & 48.60 \\
60 & 500 & 97.20 \\
80 & 250 & 194.40 \\
$>80$ & $<15$ & $3,240.40$ \\
\hline
\end{tabular}

Tabela 3.3: Crescimento do banco de dados em função do percentual de pontos de acesso descobertos durante uma caminhada (velocidade menor que $8 \mathrm{~km} / \mathrm{h}$ ). 
Em complemento, apresenta uma estimativa de sobrecarga de armazenamento de um dispositivo móvel recuperando dados de contexto de conectividade durante 24 horas, variando os intervalos de varredura. Por exemplo, um dispositivo realizando varreduras em um intervalo de $250 \mathrm{~s}$ i.e., descobrindo $80 \%$ das oportunidades de conectividade disponíveis, irá acumular 194 Kbytes de dados de contexto no final do dia.

Em cada varredura coletamos o conjunto de dados de contexto examinado anteriormente na Figura 3.2. Existe um subconjunto estático e dois dinâmicos, em termos de tamanho de armazenamento. O espaço de armazenamento pode ser estimado pela Equação 3.6. Esta equação computa o tamanho do banco de dados em função do tempo, do número de usuários e da frequência de varredura.

$$
\text { Database }=\sum_{i=1}^{u} \frac{t_{i}}{o} *\left(c+\sum_{i=1}^{n} x_{i} * s_{i}\right) .
$$

Onde:

$$
\begin{aligned}
& \text { número de usuários } \\
& \text { tempo total de varredura } \\
& \text { intervalo de varredura } \\
& \text { tamanho do subconjunto estático } \\
& \text { número de subconjuntos dinâmicos } \\
& \text { número de instâncias de um subconjunto } \\
& \text { tamanho do subconjunto }
\end{aligned}
$$

Por exemplo, os valores de tamanho estimados na Tabela 3.3 foram calculados para um usuário, $u=1$, realizando varreduras durante 24 horas, $t_{1}=86.400 \mathrm{~s}$, em uma área com aproximadamente 2,4 pontos de acesso por varredura (Nicholson et al., 2006), $x_{1}=2,4$.

Analisando os valores de tamanho, apresentados na Tabela 3.3, observa-se um crescimento linear até $80 \%$, e um crescimento acentuado para mais de $80 \%$, citado como $>80 \%$. Isso significa que descobrir mais de $80 \%$ das oportunidades de conectividade sem fio i.e., fazer varreduras com intervalo menor que $15 \mathrm{~s}$, é significativamente caro em termos de sobrecarga de armazenamento.

Adicionalmente, a Figura. 3.10 (1) é possível observar que o crescimento do tamanho do banco de dados não é proporcional ao decremento da frequência de varredura.

\subsubsection{Consumo de energia}

A bateria é outro recurso limitado do dispositivo móvel muito utilizado na coleta dados de contexto de conectividade sem fio. Para estimar o consumo de energia, assumimos que realizar uma varredura, com uma interface de rede sem fio IEEE 802.11, demora $5 \mathrm{~ms}$ em modo de recepção consumindo $300 \mathrm{~mW}$ (Desset et al., 2009).

Utilizando as frequências de varreduras, anteriormente listadas na Tabela 3.3, é possível estimar o consumo de energia (joules) em função do percentual de oportunidades de conectividade sem fio descobertas, como plotado no gráfico na Figura. 3.10 (2). O comportamento é similar ao observado 
na sobrecarga de armazenamento i.e., existe um crescimento acentuado no consumo de energia para intervalos de varredura menores que 15 segundos.

(1) Frequencia vs. oportunidade

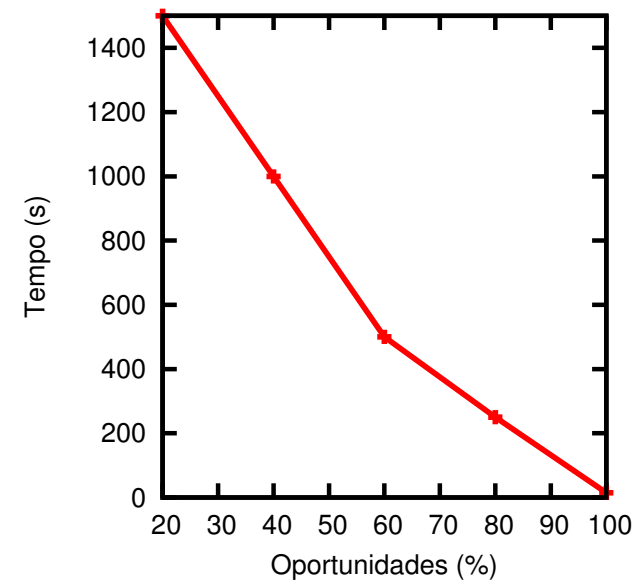

(2) Energia vs. oportunidade

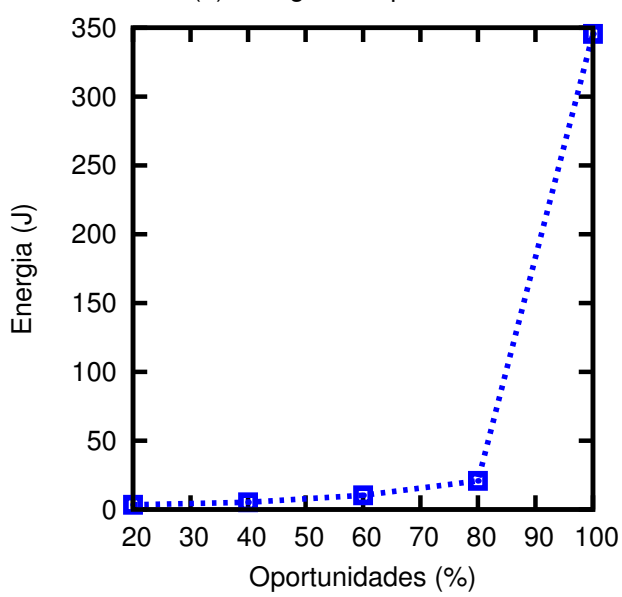

Figura 3.10: Frequência de varredura (1) e consumo de energia (2) em função da probabilidade de descobrir uma oportunidade de conectividade.

Comparando os dois gráficos na Figura 3.10, (1) and (2), é possível identificar uma forte relação entre a frequência de varredura e o consumo de energia. Existe uma relação inversa, entretanto, não linear. Essa informação pode ser combinada com o conhecimento de áreas de alta densidade de handovers, que podem ser identificadas manipulando o grafo de conectividade, como descrito anteriormente na seção 3.2.

Com isso, é possível definir políticas de varredura inteligentes i.e., realizar varreduras com mais frequência em áreas com alta probabilidade de troca de ponto de acesso (Lopes et al., 2010a). Na próxima subseção, 3.3.3, discutimos como as políticas para economizar recursos foram definidas.

\subsubsection{Economizando recursos}

O grafo de conectividade, $G_{c o n n}$, pode ser utilizado para identificar áreas com alta densidade de handovers. Para tanto, é preciso percorrer o grafo contando o número de arestas e usuários chegando e saindo dos vértices, também chamados de pontos de handover. Quanto maior a contagem, mais alta é a densidade de handovers.

A principal idéia é economizar espaço de armazenamento e bateria definindo políticas para realizar varreduras. Para ilustrar, na Figura 3.11 tem-se um grafo de conectividade com quatro vértices, $p_{1}$ to $p_{4}$, recuperado no ambiente de experimentação que será descrito no Capítulo 5.

Suponhamos, que existem três usuários móveis caminhando entre esses quatro pontos de handover, em sequência, e fazendo uso de conectividade sem fio. O caminho soma aproximadamente 210 metros dentro do prédio de uma universidade. Cada dispositivo móvel está fazendo uso de políticas distintas para realizar varreduras, chamadas: 


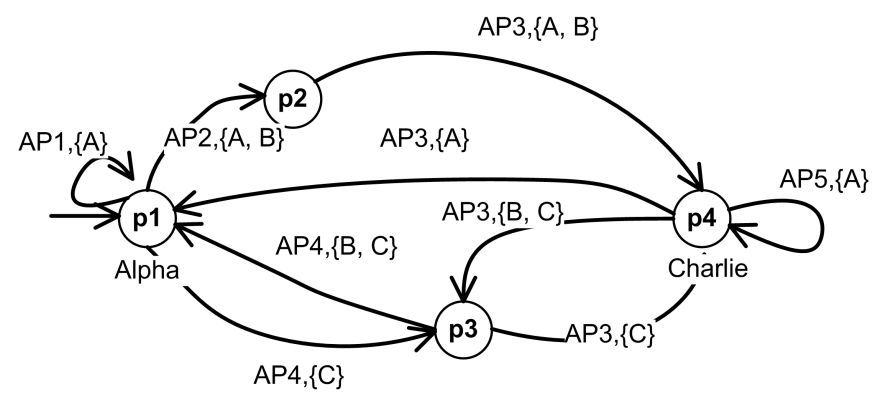

Figura 3.11: Grafo de conectividade criado no ambiente de experimentação (Lopes et al., 2010a).

- Constante $>\mathbf{8 0} \%$ : laço constante para descobrir mais de $80 \%$ das oportunidades de conectividade no ambiente i.e., intervalo de varredura menor que 15 segundos;

- Preemptiva $>\mathbf{8 0 \%}$ : realiza varreduras com intervalo de 15 segundos quando o dispositivo móvel está em um ponto de handover no grafo de conectividade. A ideia é buscar por oportunidades de conectividade quando o dispositivo está dentro de uma área com alta probabilidade de troca de ponto de acesso;

- Preemptiva 80\%: realiza varreduras com intervalos de 250 segundos quando o dispositivo está perto de um ponto de handover no grafo de conectividade.

O volume de dados acumulado em função do tempo e o consumo de energia, até o final do caminho, são apresentados na Tabela 3.4. Utilizando a política constante $>80 \%$ como base de comparação, as duas outras políticas preemptivas economizaram aproximadamente $30 \%$ e $75 \%$ de ambos recursos, para $>80 \%$ e $80 \%$, nesta ordem.

\begin{tabular}{|l|c|c|}
\hline Política (\%) & Armazenamento (Kbytes) & Energia (J) \\
\hline \hline Constante $>80 \%$ & 7.31 & 0.78 \\
Preemptiva $>80 \%$ & 5.06 & 0.54 \\
Preemptiva $80 \%$ & 1.12 & 0.12 \\
\hline
\end{tabular}

Tabela 3.4: Sobrecarga de armazenamento e consumo de bateria empregando políticas de varredura.

É importante destacar que estas três políticas obtiveram qualidade de serviço equivalentes. Políticas para descobrir até $60 \%$ das oportunidades de conectividade sem fio tiveram desempenho de QoS inferior as listadas na Tabela 3.4. Por esta razão elas não foram listadas na tabela. Esse fato, também, indica uma relação inversa entre economizar recursos e fazer uso das melhores condições de QoS em ambientes de redes sem fio. A relação entre descobrir oportunidades de conectividade e o uso de recursos do dispositivo é um ponto importante que pode ser aprofundado em investigações futuras. 


\subsection{Considerações finais}

Definimos o conjunto de dados de contexto de conectividade analisado os principais mecanismos de gerenciamento de conectividade sem fio na literatura. O principal critério para escolha dos trabalhos relacionados foi a descrição de aspectos práticos que pudessem guiar o desenvolvimento de um protótipo funcional.

Em complemento, o modelo de dados proposto não explora a diversidade de dados de contexto disponíveis nos dispositivos móveis atuais. Esse modelo foi projetado para atender os requisitos do protótipo desenvolvido durante o desdobramento da presente investigação. O modelo é simples e delimitamos sua viabilidade em termos de sobrecarga de armazenamento e consumo de energia durante a coleta de dados de contexto de conectividade sem fio. 



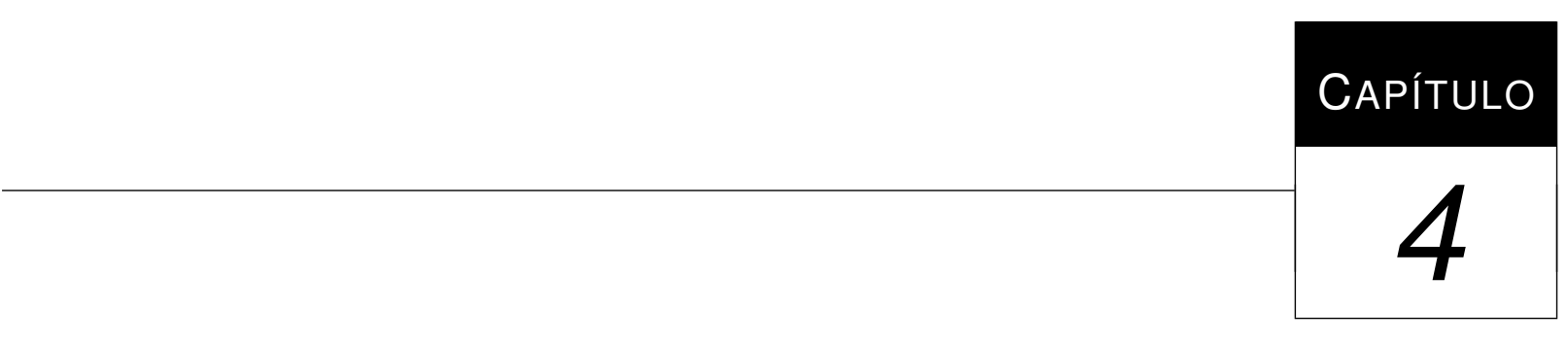

\section{Proposta}

$\mathrm{N}$ o capítulo anterior apresentamos um modelo de dados para representar o contexto de conectividade sem fio e discutimos sua viabilidade. Neste capítulo, descrevemos detalhes do conjunto de métodos proposto nesta investigação, que utiliza os dados de contexto de conectividade sem fio como elementos fundamentais. Com esses métodos, os principais componentes do gerenciamento de conectividade sem fio ciente de contexto são organizados em um laço retroalimentado, cujo objetivo é melhorar as experiências de conectividade sem fio de forma colaborativa.

Recentemente, emergiram na literatura investigações que propõem utilizar os dispositivos móveis como plataforma de sensoriamento. Argumentamos que este novo paradigma tem objetivos congruentes aos da presente investigação. Discutimos detalhes de como o projeto e implementação do conjunto de métodos evoluiu desde o início desta investigação em 2007. Por fim, descrevemos os principais desafios na implementação da solução proposta.

\subsection{Laço retroalimentado}

Propomos gerenciar a conectividade sem fio em ambientes de rede de próxima geração, cenário descrito anteriormente no Capítulo 2, com um conjunto de métodos que organiza os principais componentes em um laço retroalimentado. Três entidades essenciais compõem a solução: as pessoas com seus dispositivos móveis, os círculos sociais em redes sociais online e o gerenciador de contexto, com é ilustrado na Figura 4.1.

A solução é centrada no usuário i.e., os métodos executam no dispositivo móvel do usuário, com suporte de servidores na web e redes sociais online, sem fazer uso de informações adminis- 


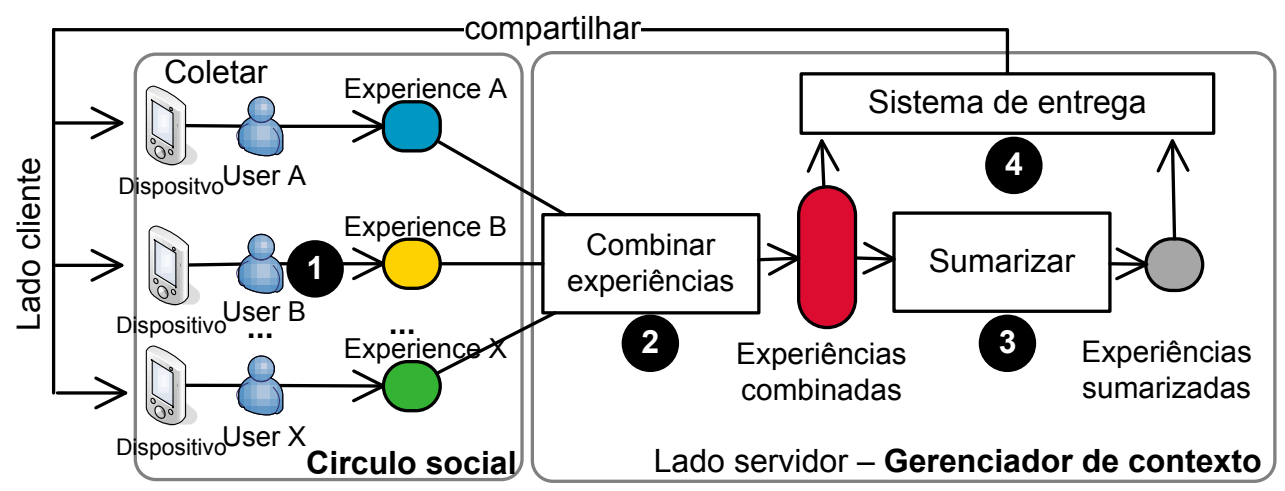

Figura 4.1: Métodos: (1) Coletar dados de contexto de conectividade; (2) combina-los; (3) sumarizar os dados quantitativos de QoS; e, (4) compartilhar a combinação.

trativas do provedor de acesso. Dessa forma, os hábitos de conectividade sem fio das pessoas é essencial para descoberta de oportunidades de conectividade. Em complemento, a frequência de uso de redes sociais online é importante para o compartilhamento das experiências de conectividade sem fio, especificamente no caso em que os dados de contexto são anexados a mídias sociais baseadas em localização.

No dispositivo móvel, lado cliente - Figura 4.1, estão implementados os mecanismos responsáveis por gerenciar a conectividade sem fio e.g., só o $\mathrm{SO}$ ou os mecanismos cientes de contexto examinados no Capítulo 2. As pessoas carregam seus dispositivos experimentando diferentes condições de QoS em ambientes de rede compartilhados e.g., em um prédio, bairro ou campus.

Por fim, os usuários móveis podem colaborar, com outros em seus círculos sociais, para descoberta de oportunidades de conectividade sem fio. O gerenciador de contexto, lado servidor, assiste o processo de colaboração por meio de serviços. Por exemplo, os usuários podem compartilhar suas experiencias de conectividade ou buscar pela combinação das experiências de todos os membros (Lopes et al., 2010a).

O diagrama na Figura 4.1, também, destaca os quatro métodos fundamentais e o fluxo de dados entre eles. Para iniciar, é necessário coletar e armazenar as experiências de conectividade dos usuários em um determinado lugar, esse é o método coletar conforme Figura 4.1 (1). Tal componente pode ser implementado usando interfaces de programação do sistema operacional e protocolos de rede.

O segundo método, Figura 4.1 (2), é responsável por combinar as experiências de conectividade sem fio em um formato interessante e útil. Para tanto, empregamos o modelo de dados baseado em grafos que combina todas as experiências em um grafo de conectividade (Lopes et al., 2010a), esse modelo é apresentado e discutido no Capítulo 3.

Em um determinado local e.g., dentro das instalações de uma empresa, vários usuários móveis podem ter tido experiências de conectividade sem fio. Nesse caso, uma busca por experiências passadas irá retornar várias instâncias de dados de contexto de conectividade. Para reduzir o volume 
dos dados, empregamos um método para sumarizar os dados quantitativos utilizando ferramentas estatísticas, como ilustra a Figura 4.1 (3).

Por fim, estas informações são disponibilizadas pra todos membros pelo sistema de entrega, Figura 4.1 (4). Um canal é criado, em um alimentador RSS, para distribuir as informações de contexto combinadas e sumarizadas dentro dos círculos sociais online. Os principais detalhes desses quatro métodos são examinados nas próximas subseções.

\subsubsection{Coletar e combinar}

No capítulo 3, apresentamos um conjunto de dados de contexto de conectividade sem fio que foram especificados para um protótipo. A ilustração na Figura 4.2 mostra uma interface web do protótipo com um conjunto de dados de contexto de conectividade sem fio coletados em um determinado local.

\begin{tabular}{|c|c|c|c|c|c|c|c|c|}
\hline ID & Date & Time & User & Tx Down & Tx Up & Latency & Battery & APS \\
\hline 58498 & $29 / 0$ & $15: 16: 15$ & & & 5.3333304 & & & 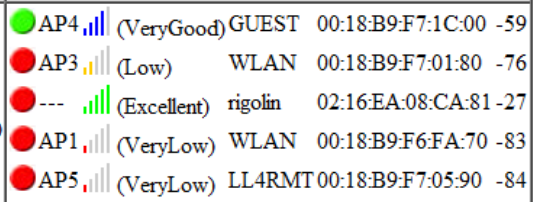 \\
\hline 58497 & $9 / 03 / 2010$ & 15:15:34 & & & 4 & 4 & $\bigoplus_{\text {(Low) }}$ & 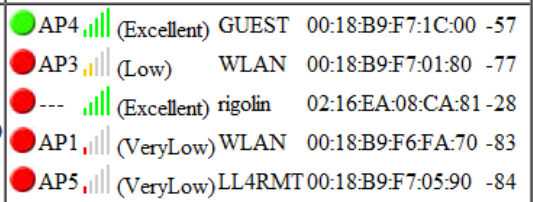 \\
\hline
\end{tabular}

Figura 4.2: Exemplo de dados de contexto de conectividade sem fio coletados por um usuário móvel.

Para coletar esses dados, consideramos que os dispositivos móveis atuais estão equipados com duas ou mais interfaces de comunicação sem fio e possuem um GPS ou podem utilizar outro sistema de localização disponibilizado pelo provedor de acesso, conforme ilustração na Figura 4.3. Nessa figura, tem-se uma visão abstrata do processo de gerenciamento de conectividade sem fio proposto na presente investigação.

No dispositivo móvel, a coleta de dados de contexto é realizada em segundo plano (background) e com frequência variável e.g., é muito frequente quando o usuário está se movimentando de um lugar para outro ou pode ser feita segundo políticas de varredura. Sob o ponto de vista do sensoriamento continuado, a coleta de dados de contexto de conectividade é feita de forma oportuna i.e., sem a participação ativa do usuário móvel. Os dados de contexto coletados com espaçamento temporal e geográfico são representados pelo grafo denominado caminho de conectividade, que também foi examinado em detalhes no Capítulo 3.

A dinâmica da coleta envolve a recuperação dos dados de contexto de conectividade utilizando as interfaces de programação (do inglês Application Programming Interface (API)) do sistema operacional. Esses dados são organizados no dígrafo denominado caminho de conectividade, ou 


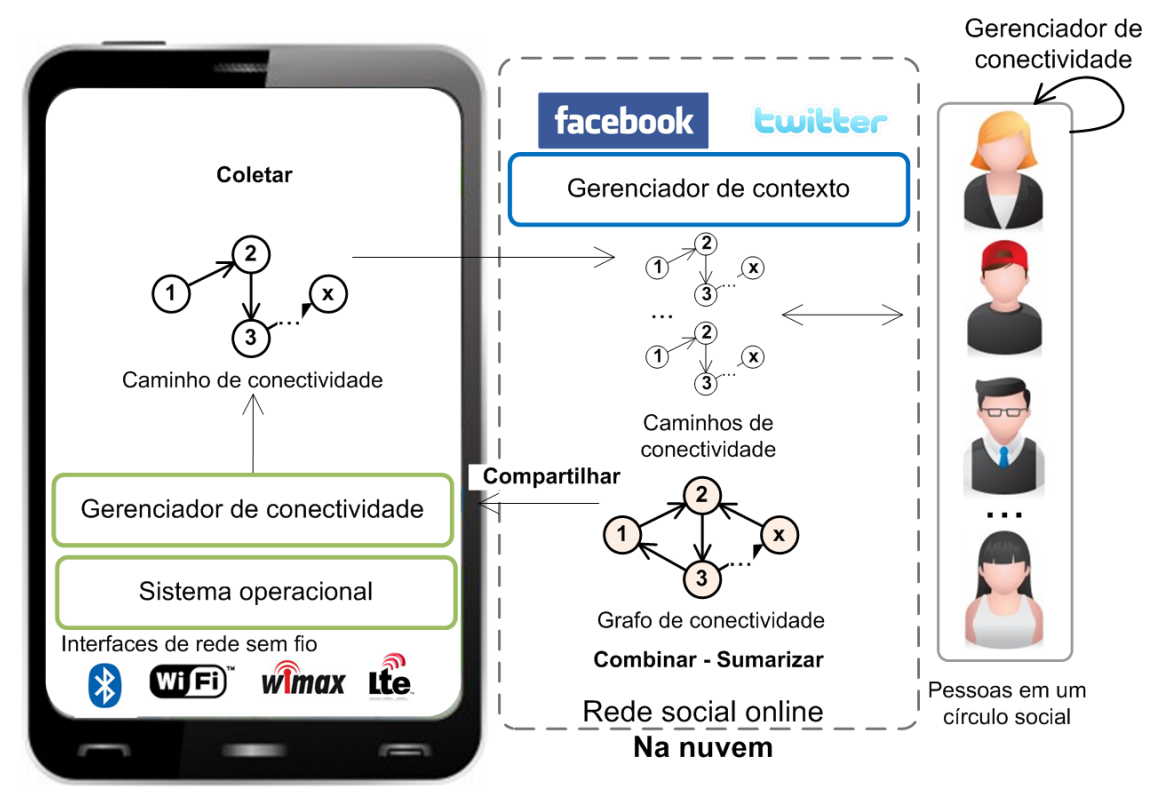

Figura 4.3: Principais processos no dispositivo móvel durante a coleta de dados de contexto.

$G_{\text {path }}$, no gerenciador de contexto. Em momentos oportunos ou em anexo a mídias sociais baseadas em localização, o caminho de conectividade é enviado para uma rede social online e.g., quando o usuário se conecta a uma rede para postar conteúdo geo-referenciado.

Nas redes online podem existir outros usuários móveis compartilhando suas experiências de conectividade sem fio. Então, essas experiências precisam ser combinadas no grafo de conectividade que é compartilhado entre todos os envolvidos fechando o laço retroalimentado. O gerenciador de contexto é o responsável em gerar e atualizar o grafo de conectividade no canal RSS, detalhes do sistema de entrega na subseção 4.1.3.

\subsubsection{Sumarizar}

Em cada ponto de handover o dispositivo móvel coleta um conjunto de dados quantitativos e.g., vazão, latência e qualidade do sinal, conforme ilustração na Figura 4.4. O banco de dados de contexto de conectividade sem fio cresce em função do número de usuários e da frequência que eles utilizam ambientes de rede sem fio. De qualquer forma, estes bancos de dados têm tamanho considerável e não são manipuláveis por dispositivos móveis.

Dessa forma, propusemos condensar os dados quantitativos utilizando ferramentas estatísticas e.g., média, desvio padrão, histogramas e quartis. Os quartis dividem os dados históricos em quatro partes cada uma contendo $25 \%$ dos dados e são simples de computar e os algoritmos de tomada de decisão podem ter mais detalhes sobre um AP em particular, em um determinado lugar.

O protótipo desenvolvido faz uso de mashups, do lado servidor, para mostrar os dados da rede de contexto de conectividade sem fio combinados de forma resumida. Ele usa gráficos e mapas do Google ${ }^{1}$ para condensar os dados históricos armazenados.

\footnotetext{
1https://developers.google.com/chart/ e https://developers.google.com/maps/
} 


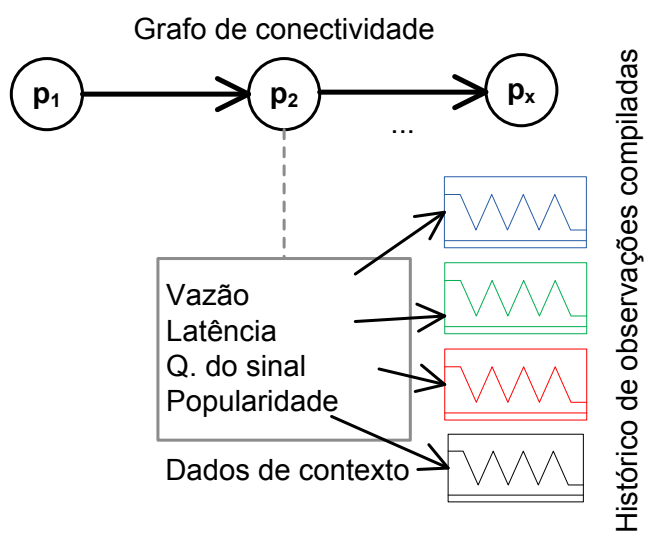

Figura 4.4: Dados quantitativos de contexto de conectividade em um determinado ponto de handover.

$\mathrm{Na}$ Figura 4.5, tem-se uma interface web com uma lista de redes sem fio descobertas, e o sistema permite que o usuário clique na rede para ver detalhes como os pontos de acesso mais utilizadas. Foi o esforço de tentar apresentar os dados de contexto de conectividade de forma condensada e útil que motivou a criação do modelo de dados e fundamentou a ideia de compartilhar dados sumarizados.

\begin{tabular}{|c|c|c|c|c|c|}
\hline \multicolumn{5}{|l|}{ Networks } & \multirow{2}{*}{$\begin{array}{l}\text { Occurrence of access points in the database } \\
00: 18: 89: F 7: 04: 50(17 \%)\end{array}$} \\
\hline Network Name & Encryption & Quality & Mode & Signal (dbm) & \\
\hline WLAD & 2 & . & Managed & -76 & \\
\hline Testje & $O$ & , Illl $(40 \%)$ & Managed & -77 & 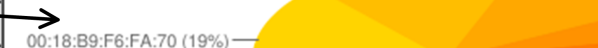 \\
\hline LL4RMT & O & inll $(29 \%)$ & Managed & -81 & \\
\hline GUEST & 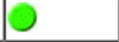 & $(27 \%)$ & Managed & -81 & \\
\hline
\end{tabular}

Figura 4.5: Interface web mostrando uma lista de redes e os pontos de acesso mais utilizados de uma determinada rede.

\subsubsection{Compartilhar}

Depois que os dados são coletados, combinados e sumarizados, tem-se o grafo de conectividade que precisa ser compartilhado entre os usuários móveis para fechar o laço retroalimentado. Considerando que os ambientes as redes sem fio de próxima geração estarão em constante mudança, propomos que os gerenciadores de conectividade sem fio cientes de contexto se atualizem, sobre esses ambientes, como as pessoas se atualizam sobre as notícias ou do previsão do tempo. Para tanto, adotamos uma abordagem publish-subscribe utilizando RSS feeds.

Os dados de contexto de conectividade úteis precisam ser flexíveis em termos de manipulação, personalização e atualização. Para atender esses requisitos, desenvolvemos um sistema de entrega utilizando alimentadores RSS. Esses alimentadores são arquivos XML padronizados para publicar conteúdo de aplicações que são atualizadas com alta frequência e.g., sites de notícias e blogs. As funcionalidades mais interessantes são: combinar conteúdo digital automaticamente, permitir que 
usuários se inscrevam em canais com atualizações temporais, e agregar conteúdo de diversas fontes em um único lugar.

A ideia fundamental, do sistema de entrega, é criar canais para disponibilizar dados de contexto de conectividade sem fio na web e dentro de redes sociais online. A ilustração na Figura 4.6, (1), mostra a estrutura básica de um arquivo RSS. Um canal é definido pela etiqueta $\langle$ channel $>$ que encapsula meta informações sobre autoria, data e conteúdo. O conteúdo pode ser definido em um item com uma referência temporal, etiqueta $<$ item $>$. Em nosso protótipo, o grafo de conectividade é referenciado dentro de um item pela etiqueta $\langle\operatorname{link}\rangle$, que aponta para uma representação textual do grafo, conforme Figura 4.6 (2).

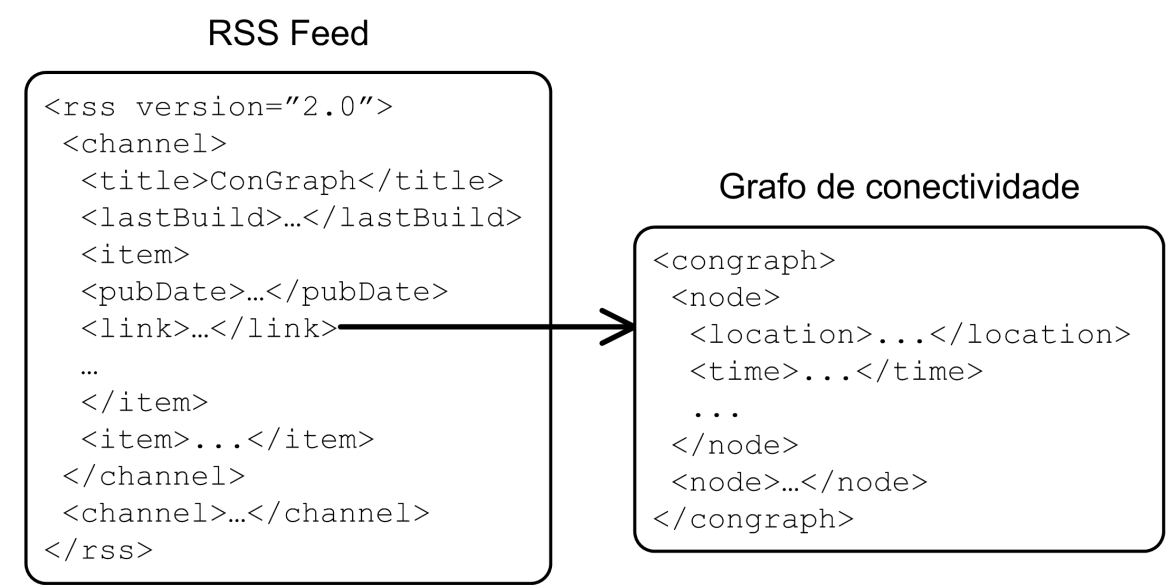

(1)

(2)

Figura 4.6: (1) fragmento de um arquivo RSS. (2) representação textual do grafo de conectividade.

Cada circulo social tem um canal subscrito por todos membros. A etiqueta $<$ lastBuildDate $>$ é usada para verificar se existem atualizações no canal. Essa etiqueta é modificada quando um novo item é adicionado ao canal, o que significa que um grafo de conectividade foi criado ou atualizado. Dessa forma, os usuários podem se atualizar lendo o item mais novo no canal. Adicionalmente, a evolução do grafo conectividade fica armazenada e disponível para todos.

\subsection{Desenvolvimento}

\subsubsection{Comunidade virtual especializada}

O gerenciador de contexto, descrito anteriormente na Seção 4.1, foi implementado em uma aplicação web com o conjunto de métodos previstos. O circulo social é um plugin do Google Friends Connect (hoje chamado de Google $+^{2}$ ) que trás todos amigos virtuais de um usuário para a aplicação web, como ilustrado na Figura 4.7.

\footnotetext{
${ }^{2}$ https://developers.google.com/ +/
} 
Nessa figura, é apresentada uma interface web com os dados pessoais do usuário (1), os RSS feeds subscritos (2), e as pessoas que estão no circulo social (3). Em complemento, é destacado um esquema abstrato de como os feeds podem ser compartilhados entre diferentes comunidades virtuais (5), utilizando um agregador de RSS feeds (4).

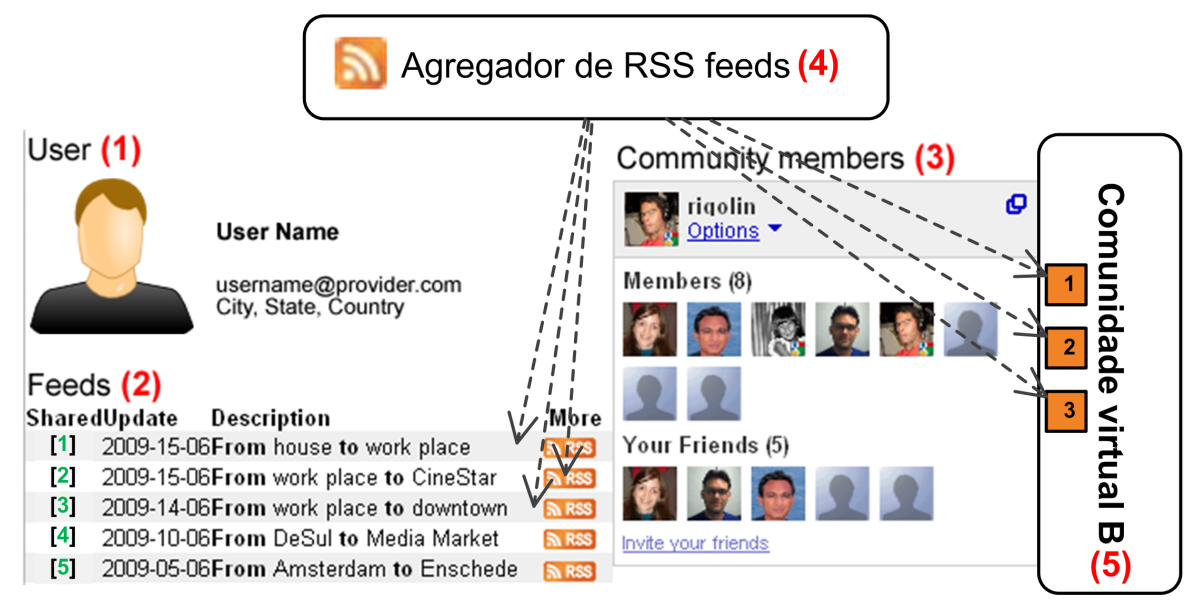

Figura 4.7: Interface web do gerenciador de contexto e uma visão abstrata da aplicação distribuída: (1) dados pessoais (2) feeds subscritos, (3) membros da comunidade, (4) agregador de RSS feeds, e (5) uma comunidade virtual B.

Os feeds com os canais estão disponíveis no agregador na web. Com isso, as aplicações podem criar links comuns para um endereço (do inglês Uniform Resource Locator (URL)) de um canal específico. A solução é composta pela aplicação web, o circulo social online, e uma aplicação no dispositivo móvel. A comunicação entre as partes é feita por meio de requisições get e post do protocolo Hypertext Transfer Protocol (HTTP). Nesse caso o gerenciador de contexto é o responsável em disponibilizar uma interface com o usuário e os serviços essenciais descritos anteriormente na Seção 4.1 .

\subsubsection{Anexando contexto de conectividade a mídias sociais}

Para ilustrar, imaginemos, agora, a Alice em um restaurante com seus colegas de trabalho em uma confraternização. Em um determinado momento ela resolve tirar uma foto com eles utilizando seu telefone. Logo em seguida, ela se conecta a Internet e posta a foto com a sua localização, mais uma descrição do momento e do restaurante.

Alguns dias depois, uma amiga dela, a Beatriz, está em dúvida sobre qual restaurante ir e faz uma busca por comentários de seus conhecidos em uma rede social online. A busca irá retornar um conjunto de comentários sobre restaurantes criados pelas pessoas no círculo social da Beatriz, incluindo a Alice. A presente investigação, propõe que a Alice compartilhe seu contexto de conectividade sem fio no restaurante. Dessa forma, quando a Beatriz ou outra pessoa, no círculo social online de Alice, buscar pelo seu comentário sobre o restaurante, também recebe o seu feedback sobre as opções de conectividade sem fio lá. 
Esta ideia surgiu para o protótipo evoluir de uma abordagem centralizada com a comunidade especializada para uma menos centralizada anexando contexto de conectividade em mídias sociais baseadas em localização. Observamos que as pessoas estão utilizando serviços baseados em localização para compartilhar experiências, em um determinado local, dentro de seus círculos sociais virtuais. Por exemplo, Foursquare ${ }^{3}$ é uma aplicação web e móvel que permite que as pessoas se conectem amigos para compartilhar suas localizações geográfica e experiências nestes lugares $e . g$., fotos, vídeos e comentários.

O propósito dessa aplicação é ajudar as pessoas a explorar sua cidade e descobrir novos lugares interessantes. O sistema utiliza um motor de recomendações sociais que faz recomendações em tempo real, utilizando as sugestões publicadas por pessoas no mesmo circulo social. Na Figura 4.8 é ilustrado um mashup típico compartilhado em redes sociais online. A apresentação é composta por um usuário (1), uma rede social (2), uma mensagem/links (3), e um mapa (4).

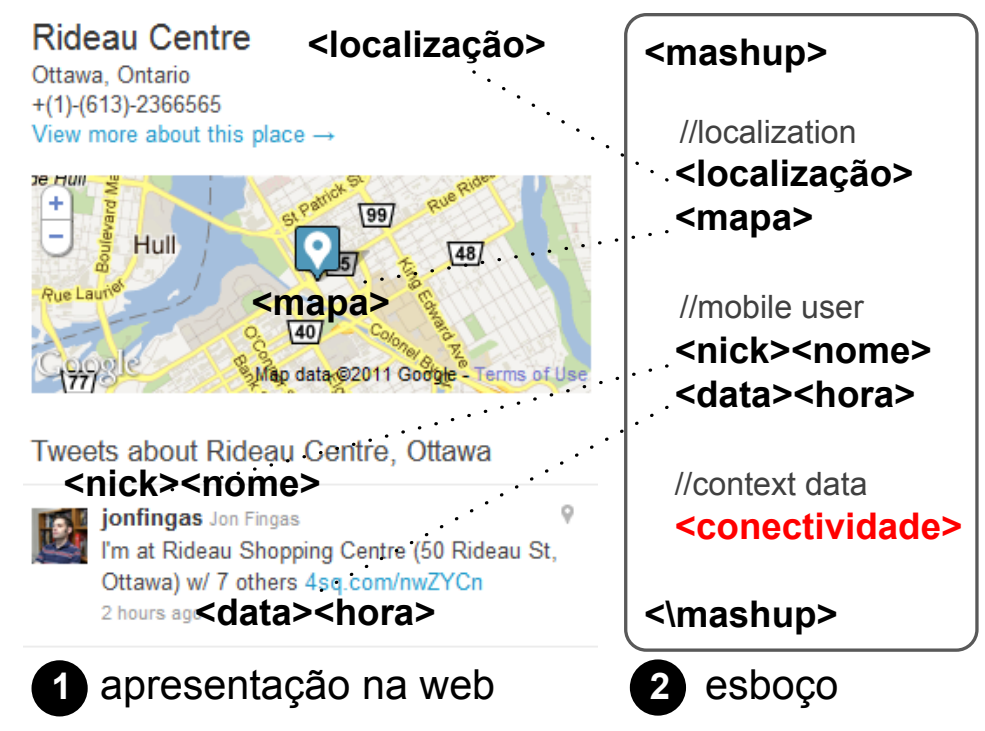

Figura 4.8: Popular mashup na web: (a) interface da rede social online; e (b) uma visão abstrata das principais entidades.

Argumentamos que dados de contexto de conectividade sem fio são mais relevantes quando anexados a esses mashups populares, também chamados de mídias sociais baseadas em localização. O diagrama na Figura 4.8 (b) apresenta uma visão abstrata das partes que compõem o mashup, e adiciona dados de contexto de conectividade.

Para implementar essa solução, identificamos duas formas de interação entre o usuário móvel e serviços baseados em localização, como ilustrado na Figura 4.9. No primeiro caso, o usuário está em um determinado local e decide compartilhar uma experiência em seu circulo social. A entrada é composta pela localização geográfica, uma mensagem/link e os dados de contexto de conectividade. Nesse caso o resultado da interação é um mashup é similar a interface apresentada anteriormente na Figura 4.8 .

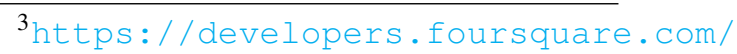




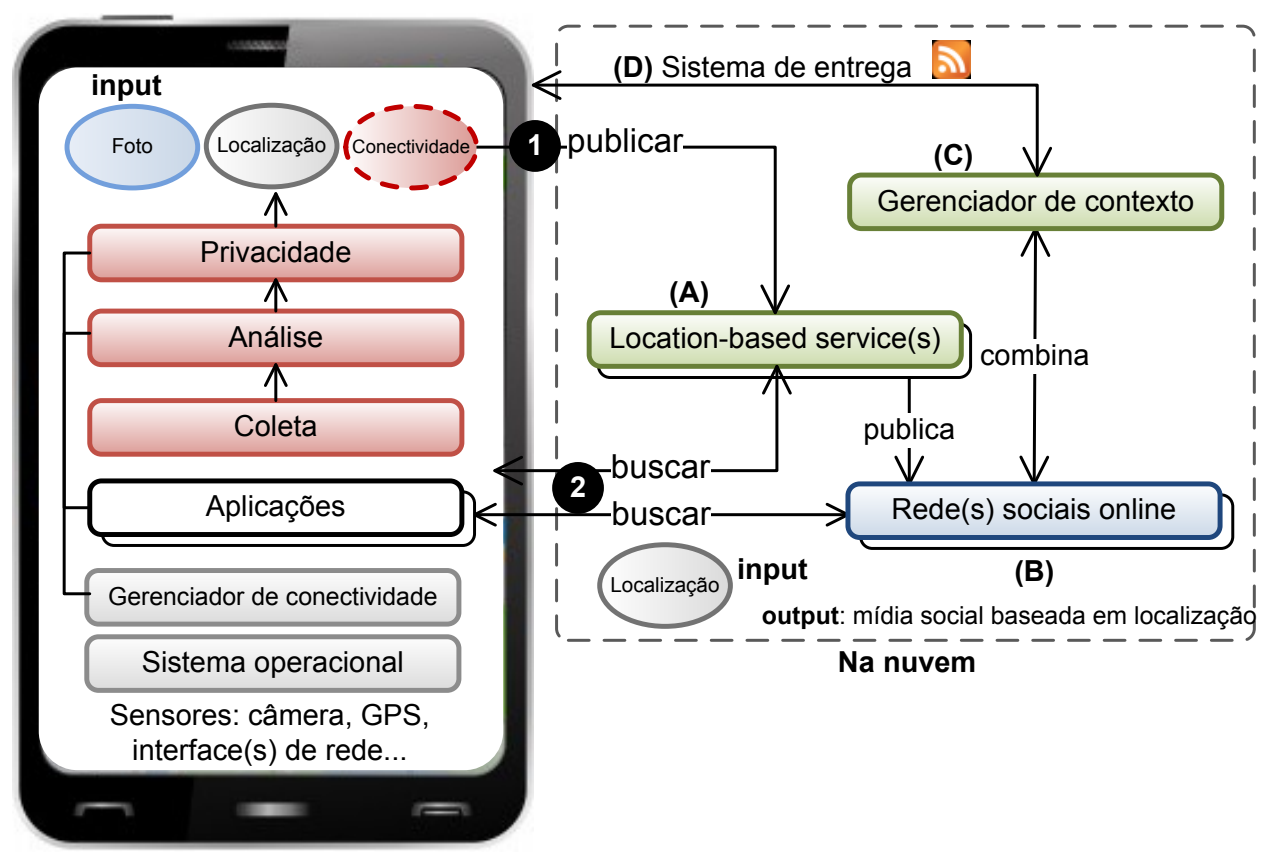

Figura 4.9: Duas formas de interação: (1) compartilhando uma experiência; and (2) buscando por sugestões no circulo social do usuário móvel.

Outra forma de interação, Figura 4.9 (2), ocorre quando o usuário está em um determinado lugar e interessado em buscar sugestões de seus amigos naquele mesmo lugar. Nesse caso, a entrada é a localização atual e o serviço retorna o conjunto de feedbacks publicados no circulo social do usuário. Com essa abordagem os usuários móveis fazem buscas por sugestões significativas e também recebem experiências de conectividade no lugar.

O serviço baseado em localização, Figura 4.9 (A), pode ser qualquer aplicação que publica dados georreferenciados em redes sociais e.g., FourSquare and Google Latitude ${ }^{4}$. A rede social, Figura 4.9 (B), pode ser qualquer rede social online que ofereça interfaces de programação para embarcar aplicações de terceiros.

O gerenciador de contexto, Figura 4.9 (C), implementa os métodos descritos anteriormente na seção 4.1. Esse módulo acessa a rede social online para combinar as experiências de conectividade publicadas no circulo social. A combinação é, também, compartilhada utilizando o sistema de entrega descrito anteriormente na seção 4.1.3.

Esta investigação começou no segundo semestre de 2007 e o conjunto de métodos, descritos na seção 4.1, foi desenvolvido em meados de 2009. Em 2010, surgiu na literatura um artigo propondo utilizar dispositivos móveis com plataforma de sensoriamento de dados, os conceitos básicos foram apresentados no Capítulo 2. Dessa forma, atualizamos a solução para fazer uso deste novo paradigma computacional.

\footnotetext{
${ }^{4}$ http://www.google.com/latitude/intro.html
} 


\subsection{Considerações finais}

Propomos um conjunto de métodos para orquestrar as principais tarefas do gerenciamento de conectividade sem fio ciente de contexto em um laço retroalimentado. Partimos da hipótese que é viável utilizar as redes sociais online para compartilhar dados de contexto de conectividade sem fio e que o laço retroalimentado pode convergir para melhores experiências de conectividade para todos envolvidos.

Discutimos como os dados são coletados, combinados, sumarizados e compartilhados entre os usuários móveis. Examinamos os principais detalhes do protótipo desenvolvido com foco na comunidade virtual especializada e no mashup dos dados de contexto de conectividade com mídias sociais baseadas em localização. O próximo capítulo, 5, descreve os experimentos realizados para avaliar quantitativamente o conjunto de métodos e o protótipo discutidos aqui. 


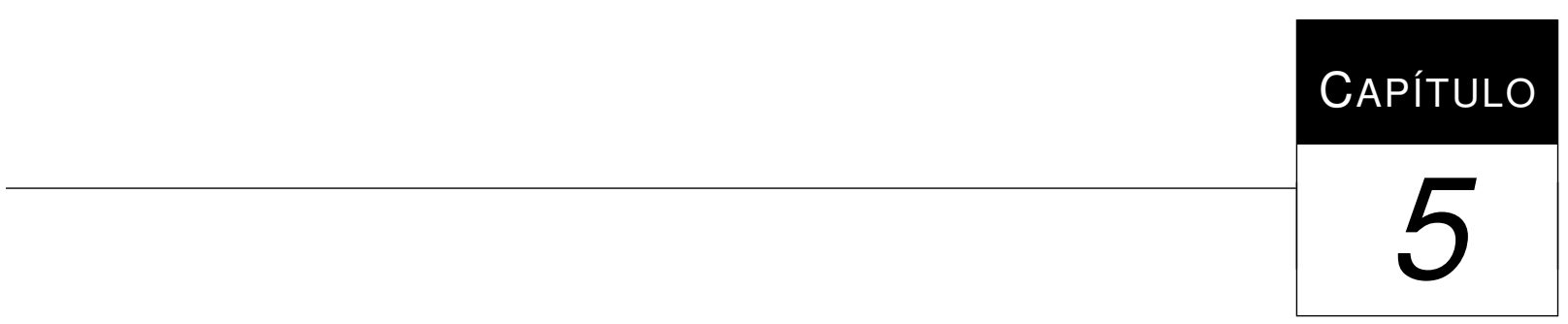

\section{Avaliação quantitativa}

$\mathrm{N}$

este capítulo são apresentados detalhes dos experimentos realizados para avaliar quantitativamente o conjunto de métodos implementados em um protótipo. Primeiro, descrevemos o ambiente de experimentação e os experimentos realizados. Em seguida, analisamos os resultados experimentais de forma comparativa e sob dois pontos de vista: de maneira geral e em caminhos particulares.

Motivados pelos resultados experimentais promissores, realizamos um estudo da eficiência da colaboração na descoberta de ilhas de conectividade sem fio em função do número de usuários, padrões de mobilidade e tamanho da área de interesse. Por fim, discutimos os pontos positivos e negativos da solução proposta na presente investigação.

\subsection{Ambiente de experimentação}

O ambiente de experimentação foi configurado em um prédio com escritórios e laboratórios na universidade, com uma área de aproximadamente $3.200 \mathrm{~m}^{2}$. O ambiente tem excelente cobertura de rede sem fio com seis APs WiFi, IEEE 802.11a/b/g (modelo CISCO Aironet 1200). A localização desses APs no prédio foi utilizada como referência para o sistema de localização desenvolvido, detalhes são apresentados na subseção 5.1.1.

O ambiente computacional é formado por dois servidores, lado servidor, e dispositivos móveis do lado cliente, como ilustrado na Figura 5.1. A carga de processamento durante os experimentos foi dividida entre os dois servidores: um executando o gerenciador de contexto e a comunidade online dentro de um contêiner web e o outro dedicado ao Sistema Gerenciador de Banco de Dados (SGBD) que manipulou todos dados de contexto de conectividade sem fio coletados. 


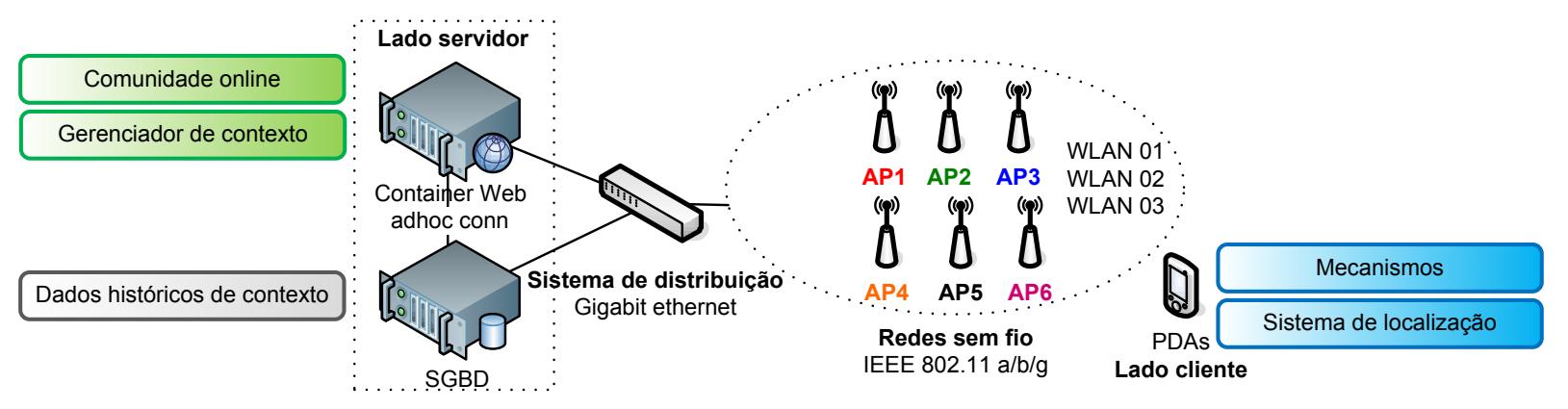

Figura 5.1: Configuração dos servidores, APs e sistema de distribuição no ambiente de experimentação.

A ilustração na Figura 5.1, também, mostra os servidores e os APs interconectados por um sistema de distribuição que é uma Local Area Network (LAN) padrão Gigabit Ethernet (GbE) i.e., vazão de até 1 Gbps. Os usuários utilizaram Personal Digital Assistant (PDA)s (modelo HP iPAQ 214) equipados com interfaces de rede sem fio padrão IEEE $802.11 \mathrm{~b} / \mathrm{g}$ e executando o sistema operacional Windows Mobile $6^{1}$.

Dessa forma, a coleta dos dados de contexto de conectividade sem fio foi feita por meio de APIs específicas deste sistema operacional. Em complemento, as interações entre o dispositivo e o lado servidor é feita por meio de requisições do protocolo HTTP pela interface de rede sem fio.

Os pontos de acesso gerenciam três WLANs diferentes. Configuramos o lado cliente para mudar de rede sem fio toda vez que um handover é necessário. Com isso, garantimos que todos os handovers são feitos entre redes com diferentes domínios IP. Em outros termos, todos os handovers no ambiente de experimentação ocorre entre domínios de rede distintos, o que requer um novo endereço IP e gateway de rede.

No PDA, foram implementados três mecanismos de gerenciamento de conectividade distintos para avaliar nossa solução por comparação, detalhes dos mecanismos são discutidos na Seção 5.2. Os usuários móveis trabalhavam no ambiente descrito aqui e utilizaram os PDAs com os diferentes mecanismos de gerenciamento de conectividade no dia-a-dia.

\subsubsection{Sistema de localização}

A localização do dispositivo móvel é um dado essencial para o modelo de dados, apresentado anteriormente no Capítulo 3, adotado para representar o contexto de conectividade sem fio. Considerando que o ambiente de experimentação é um prédio onde o GPS não funciona, estimamos a localização dos dispositivos móveis pela potência do sinal disponível nos quadros de baliza, também conhecidos como beacons, radiodifundidos pelos APs no prédio.

Para tanto, é preciso saber a localização física de cada AP no ambiente, aplicar um modelo para estimar a distância entre o dispositivo e pelo menos três APs e, finalmente, estimar as coordenadas

\footnotetext{
${ }^{1}$ http://msdn.microsoft.com/en-us/windowsmobile/bb264318.aspx
} 
utilizando triangulação ou multi-lateração (Munoz e Vargas, 2009; Lee e Chen, 2007), conforme ilustração na Figura 5.2.

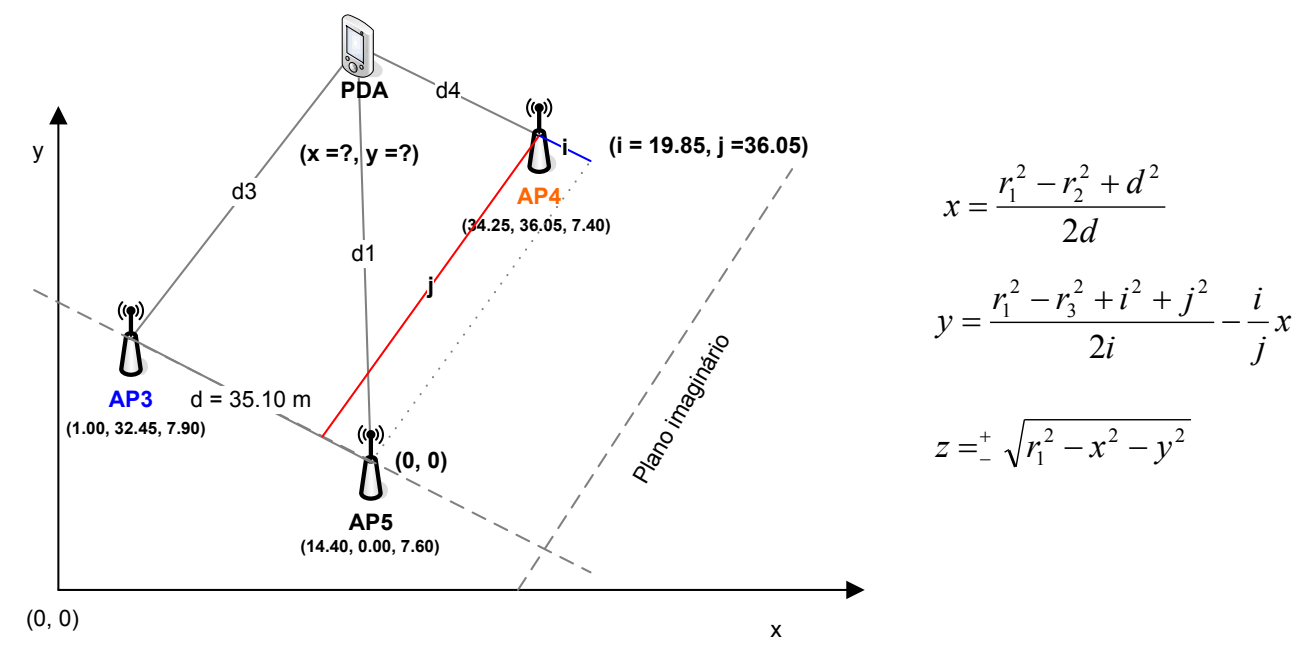

Figura 5.2: Estimando a localização do dispositivo móvel.

Antes de implementar, realizamos um estudo da precisão que o sistema de localização teria no ambiente de experimentação. Primeiro, escolhemos um ponto de referência no prédio para derivar as coordenadas no ambiente. Em seguida, foram definidos 28 pontos diferentes e distribuídos pelo ambiente de experimentação com suas respectivas coordenadas reais. Cada ponto foi visitado para coletar a potência do sinal dos APs conhecidos no prédio, utilizando o mesmo modelo de PDA alocado para os experimentos.

Com esses dados em mãos, calculamos a distância real e a distância estimada entre o dispositivo e os APs, em cada um dos 28 pontos, utilizando o modelo simplificado de Seidel, apresentado na Equação 5.1 (LaMarca et al., 2005b). Onde $d$ é a distância estimada, ss é a potência do sinal (dbm) e $n$ é uma constante que pode variar de 2 a 5 , dependendo das características do ambiente de experimentação.

$$
\mathbf{d}=10^{-(32+\mathbf{s s}) /(10 \mathbf{n})}
$$

Onde:

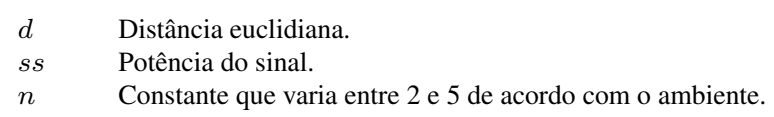

Empregando $n$ igual a 2, 5, como recomendado em (LaMarca et al., 2005b), obtivemos um erro de aproximadamente 12 metros para um AP, o que soma 58 metros de erro total do sistema, como mostra a Tabela 5.1. Esse elevado erro nos motivou a utilizar outras duas técnicas de ajuste (do inglês fitting), nomeadas aqui como: fminsearch e polyfit.

A função fminsearch utiliza otimização linear sem restrições para procurar o valor mínimo de uma função escalar de várias variáveis. Aplicamos esta função para achar o melhor valor para 
a constante do modelo de Seidel, $n$ igual 2,92, com um erro de aproximadamente 5 metros no melhor caso e 18 metros no pior caso.

Em seguida, utilizamos a técnica polyfit que procura os coeficientes de um polinômio, de qualquer grau, que interpola os dados com o menor erro quadrado. Conseguimos um erro de aproximadamente 2,5 metros, com um erro total de 9 metros. O gráfico na Figura 5.3 (1) apresenta as precisões mencionadas a cima para um AP, plotando a distancia em função da potência do sinal.

\begin{tabular}{|l|c|c|c|c|c|}
\hline Técnica & Constante $n$ & Erro (m) & Desvio padrão & Normal & Erro total \\
\hline \hline Estimado & 2,50 & 12,82 & 12,00 & 86,96 & 58,53 \\
fminsearch & 2,92 & 5,30 & 3,66 & 32,01 & 17,90 \\
polyfit & 1,46 & 2,44 & 1,68 & 14,69 & 9,34 \\
\hline
\end{tabular}

Tabela 5.1: Erro dos três modelos aplicados para estimar a localização do dispositivo em função da potência do sinal.

Durante o desenvolvimento do sistema consideramos a hipótese de utilizar APs localizados em outros andares, com objetivo de aumentar o número de referências e, consequentemente a precisão. Contudo, observamos que a atenuação da laje de concreto descaracteriza a distância recuperada em função da potência do sinal com o modelo de Seidel, conforme gráfico na Figura 5.3 (2).

Nessa figura, comparamos a distancia estimada de um AP no mesmo andar do dispositivo móvel com a distância estimada de outro AP em um andar diferente nos 28 pontos definidos anteriormente. Segundo o modelo de Seidel, a distância aumenta quando a potência do sinal diminui e é esse o padrão observado nos dados do AP no mesmo andar do dispositivo móvel. Entretanto, as distâncias estimadas para o AP em outro andar não seguem tal padrão e introduziriam significante erro no sistema de localização.

(1) Ajustes no modelo de Seidel

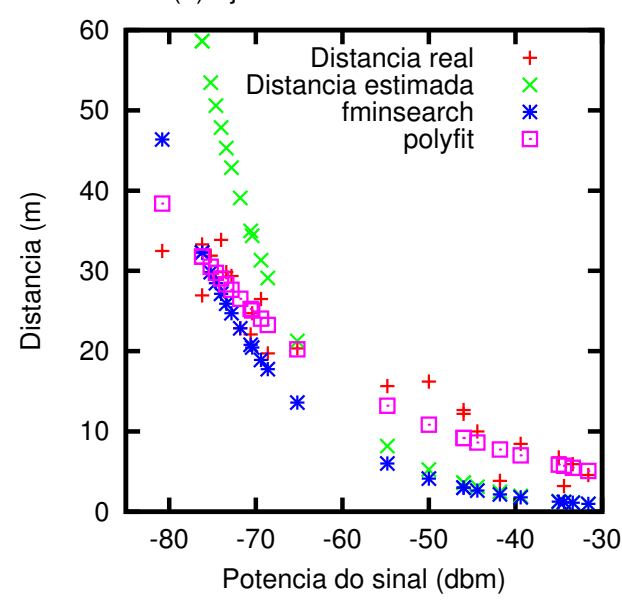

(2) Potencia do sinal em andares distintos

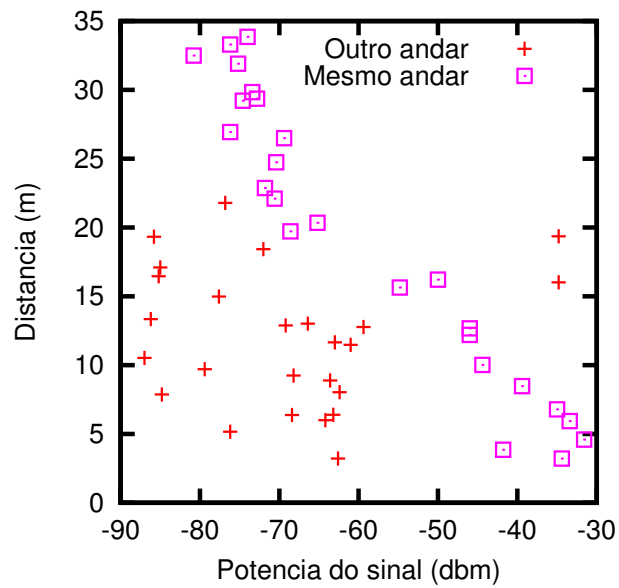

Figura 5.3: 1) Distância em função da potência do sinal nos 28 pontos do prédio. 2) Comparação da distância estimada de 2 APs em diferentes andares.

Existem diversos sistemas de localização publicados na literatura especializada (Munoz e Vargas, 2009). A principal diferença entre eles é a precisão da estimativa que é fortemente relacionada com o volume de conhecimento que o sistema tem sobre a topologia do ambiente. Para ilustrar, 
o PlaceLab (LaMarca et al., 2005a) tem precisão entre 20-30 metros, e o sistema reportado em (Haeberlen et al., 2004) tem erro de menos de 10 metros.

O primeiro utiliza apenas a localização de APs e torres de celular como referências para estimar a localização e pode oferecer cobertura em uma cidade inteira. Por outro lado, o último emprega uma técnica intrusiva para calibrar o sistema com a topologia do ambiente, limitando sua cobertura para um prédio, por exemplo.

O sistema descrito aqui está entre estes dois e acreditamos que serviços de localização serão comuns nos futuros ambientes inteligentes, porque segundo LaMarca et al. (2005) estes sistemas são mais úteis onde trabalhamos e socializamos. O sistema pode evoluir para uma abordagem colaborativa, (Chan et al., 2006; Coronato e Esposito, 2008) ou para utilizar outros sensores do dispositivo móvel e.g., o acelerômetro em (Constandache et al., 2010).

\subsection{Experimentos}

\subsubsection{Descrição}

Realizamos uma avaliação, de desempenho, comparativa entre três mecanismos de gerenciamento de conectividade, chamados: (A) SSS, (B) preditor de mobilidade, e (C) social. O mecanismo SSS é a base para as comparações de desempenho, pois é empregado por sistemas operacionais comuns e.g., Windows Mobile e Android. Nesse mecanismo, o próximo ponto de acesso, a ser utilizado, é aquele que tem melhor qualidade do sinal (ou Received signal strength indication (RSSI)) dada pela razão sinal/ruído (Nicholson e Noble, 2008).

O preditor de mobilidade emprega um modelo de predição de mobilidade que utiliza uma cadeia de Markov de ordem 2, criada com os dados de contexto de conectividade de apenas um usuário móvel, utilizamos como referência o modelo descrito em (Nicholson e Noble, 2008).

Por fim, o mecanismo social emprega o mesmo preditor de mobilidade, contudo, utiliza o grafo de conectividade socializado, detalhado anteriormente no Capítulo 3, para construir o modelo de mobilidade e auxiliar a tomada de decisão de handover (Lopes et al., 2010a).

Em suma, a avaliação comparativa confronta métricas de QoS dos seguintes mecanismos:

(A) SSS: quando a associação com o ponto de acesso atual é desfeita, o SO escolhe o AP disponível com melhor potência do sinal (Nicholson e Noble, 2008);

(B) Preditor de mobilidade: utiliza um preditor de mobilidade, descrito no Capítulo 2, para prever a necessidade de troca de AP;

(C) Social: alimenta o preditor de mobilidade com os dados compartilhados conforme o método descrito no Capítulo 4. Esse é o mecanismo proposto na presente investigação. 
A comparação envolve o monitoramento de métricas de QoS para verificar quantitativamente os benefícios do mecanismo proposto. Executamos nossa solução por aproximadamente quatro meses com três usuários no ambiente de experimentação descrito anteriormente na seção 5.1. As métricas observadas foram: vazão no envio e na recepção de dados, latência e qualidade do sinal.

\subsubsection{Mensurando as métricas de QoS}

Durante os experimentos, os dispositivo móveis fizeram uso intenso da rede sem fio fazendo download e upload de dados utilizando o protocolo HTTP, conforme ilustração na Figura 5.4. A vazão de dados foi recuperada computando o tempo para enviar e receber arquivos no formato HyperText Markup Language (HTML) com tamanho variando entre 30 kbytes e 5 mbytes.

O tamanho do arquivo a ser enviado ou recebido foi definido aleatoriamente, contudo o dispositivo móvel estava constantemente fazendo uso da rede i.e., quando terminava de enviar ou receber um arquivo o processo iniciava novamente em um laço infinito.

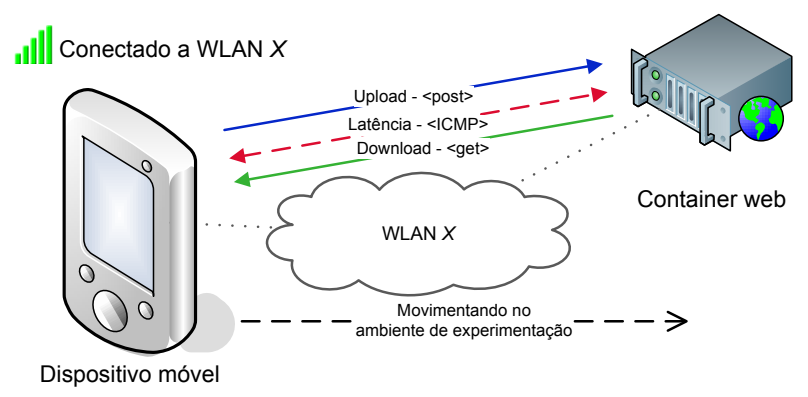

Figura 5.4: Resumo de como as métricas de QoS foram recuperadas.

A implementação utiliza as primitivas get e post para enviar e receber dados de um servidor HTTP dedicado, Figura 5.1, conectado ao sistema de distribuição dos pontos de acesso. A latência entre o dispositivo móvel e o servidor executando o contêiner web foi medida com a ferramenta ping que utiliza o protocolo Internet Control Message Protocol (ICMP) para mensurar o Round Trip Time (RTT) em milissegundos.

Vale destacar que a latência no sistema de distribuição que interliga os APs e os servidores é de aproximadamente 0,43 ms em média. A latência muito baixa no sistema de distribuição garante que o valores de latência recuperados durante os experimentos foram gerados pelo link sem fio.

\subsection{Resultados}

\subsubsection{Visão geral}

Depois de quatro meses o banco de dados tinha oito redes diferentes, 55 APs, e aproximadamente 350.000 tuplas com diferentes timestamps. Analisando os dados de contexto de conectivi- 
dade sem fio recuperados durante este período observamos que durante o primeiro mês, os três mecanismos apresentaram desempenho irregular e praticamente equivalentes.

Nos meses seguintes, observamos uma significante diferença entre o desempenho dos três mecanismos, conforme valores médios apresentados na Figura 5.5. Nessa figura, tem-se os valores médios da qualidade do sinal experimentada pelos três mecanismos durante os quatro meses.

A qualidade do sinal melhorou incrementalmente durante os experimentos até se estabilizar no terceiro mês. O mecanismo social melhorou a qualidade do sinal em $\sim 30$ e $\sim 18 \%$ se comparado com SSS e com o preditor de mobilidade, respectivamente.

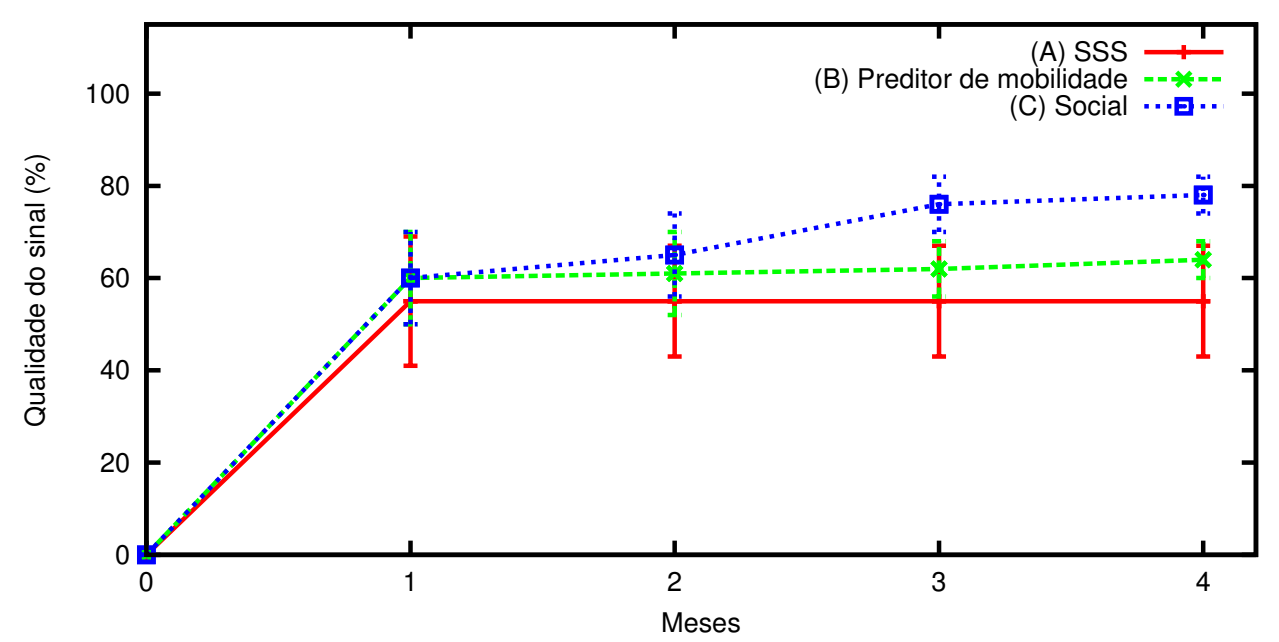

Figura 5.5: Evolução da qualidade do sinal em função do tempo.

Considerando as vazões de dados observadas durante os quatro meses, o mecanismo social obteve resultados superiores em aproximadamente 13 e $23 \%$ aos outros dois mecanismos, SSS e preditor de mobilidade, nessa ordem. Em média, a vazão foi de 3,8 mbps contra 3,3 e 2,9 mbps, para preditor de mobilidade e SSS, respectivamente.

Em complemento, o gráfico na Figura 5.6 apresenta os histogramas e suas respectivas curvas de tendência para cada mecanismo. Para SSS, Figura 5.6 (A), a maioria dos valores estão concentrados abaixo de 3,5 mbps. Por outro lado, para o preditor de mobilidade (B) e mecanismo social (C) concentraram suas vazões acima de 3,0 mbps, com máximo observado de 4,0 mbps.

Comparando o histograma (C), na Figura 5.6, com os outros dois, (A) e (B), é possível concluir que a nossa solução evitou baixas vazões e alta latência no ambiente de experimentação. Isso confirma a possibilidade de obter superiores experiências de conectividade sem fio por meio da melhora da qualidade dos dados de contexto de rede.

Em complemento, o tempo para descobrir um ambiente de rede sem fio pode ser reduzido em função do número de usuários móveis colaborando. Um estudo da colaboração em função do número de usuários e seus padrões de mobilidade é apresentado na seção 5.4. 
(A) SSS

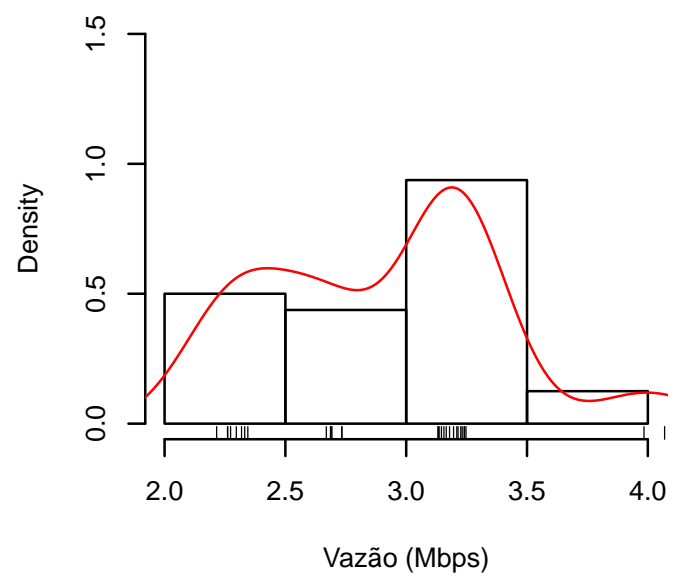

(C) Social

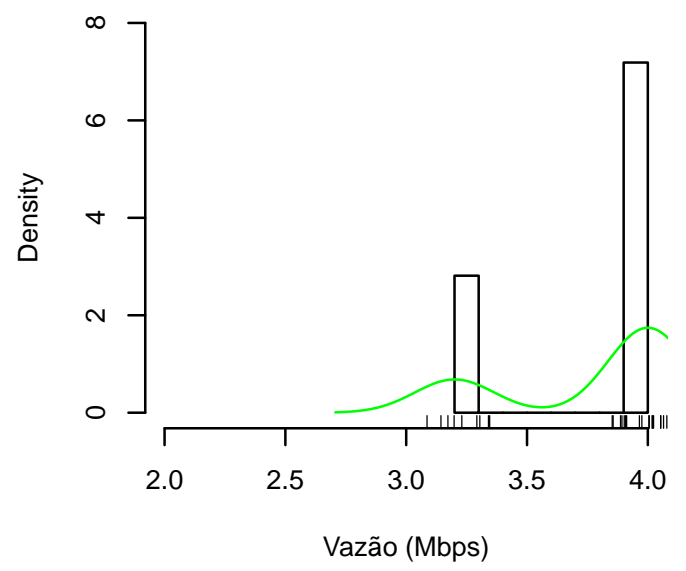

(B) Preditor de mobilidade

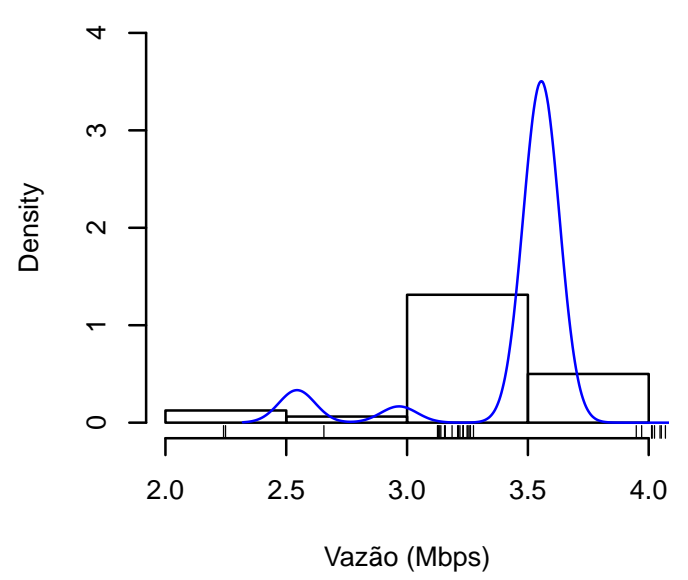

Figura 5.6: Histograma da vazão de dados(rx), durante quatro meses, para: (A) SSS, (B) Preditor de mobilidade, e (C) Social.

\subsubsection{Analisando caminhos particulares}

Nesta subseção descrevemos e discutimos resultados quantitativos observados em dois caminhos no ambiente de experimentação chamados: Alpha-Bravo e Alpha-Charlie. Os resultados obtidos nestes caminhos são apresentados de formas distintas para explorarmos de diferentes ângulos.

Na próxima subseção, 5.3.2, analisamos a métricas de QoS recuperadas no caminho AlphaBravo. Em seguida, na subseção 5.3.2, examinamos o grafo de conectividade e a vazão em função da qualidade do sinal do caminho Alpha-Charlie. 


\section{De Alpha para Bravo}

As principais métricas recuperadas no caminho Alpha-Bravo estão sumarizadas na Tabela 5.2. Esse conjunto de resultados revela quantitativamente que o ambiente de experimentação tem excelente cobertura de rede sem fio. No pior caso, a vazão média é regular e todos os mecanismos de gerenciamento de conectividade alcançaram vazão máxima em algum momento.

\begin{tabular}{|c|c|c|c|c|c|c|c|c|c|c|c|c|}
\hline \multirow[t]{2}{*}{ Métricas } & \multicolumn{4}{|c|}{ (A) SSS } & \multicolumn{4}{|c|}{ (B) Preditor de mobilidade } & \multicolumn{4}{|c|}{ (C) Social } \\
\hline & Min & Avg & $\operatorname{Max}$ & S. Dev. & Min & Avg & $\operatorname{Max}$ & S. Dev. & Min & Avg & $\operatorname{Max}$ & S. Dev. \\
\hline Down (Mbps) & 4.00 & 5.14 & 6.00 & 0.81 & 4.00 & 5.37 & 6.00 & 0.32 & 5.33 & 5.85 & 6.00 & 0.29 \\
\hline Up (Mbps) & 3.20 & 3.56 & 4.00 & 0.39 & 3.20 & 3.82 & 4.00 & 0.22 & 3.50 & 3.92 & 4.00 & 0.14 \\
\hline Latência (ms) & 2.00 & 3.63 & 5.00 & 0.81 & 2.00 & 3.49 & 7.00 & 1.20 & 2.00 & 3.03 & 6.00 & 0.89 \\
\hline Qualidade do sinal (\%) & 40.00 & 73.71 & 100.00 & 27.34 & 40.00 & 82.29 & 100.00 & 22.11 & 60.00 & 91.43 & 100.00 & 13.09 \\
\hline
\end{tabular}

Tabela 5.2: Métricas de QoS observadas no caminho Alpha-Bravo.

Na Figura 5.7 são apresentados os menores valores e os valores médios das três principais métricas de QoS em proporção aos valores máximos observados, ambos estão na Tabela 5.2. Observamos que no pior caso, Figura 5.7 (1), nossa solução tem um desempenho predominantemente superior se comparado aos outros dois mecanismos.

(1) Minimo sobre maximo

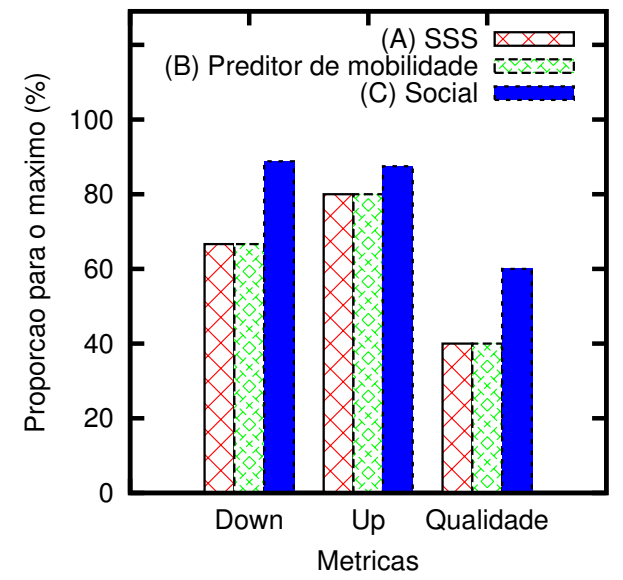

(2) Media sobre maximo

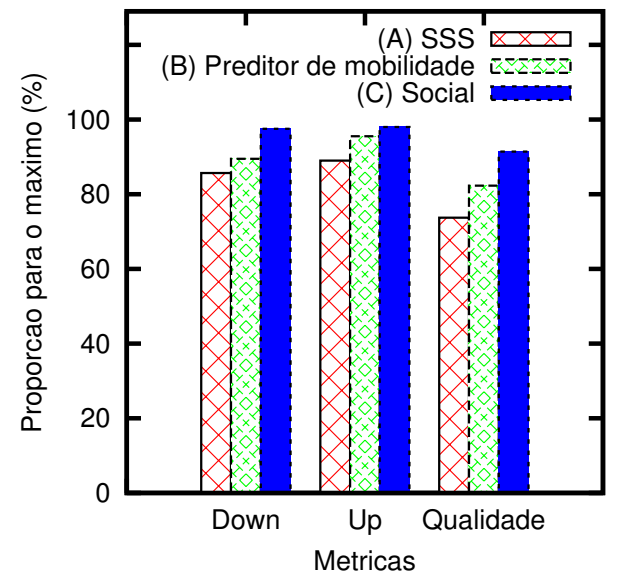

Figura 5.7: Proporção das principais métricas sobre os valores máximos.

Evitamos as piores condições de rede observadas durante os experimentos com desempenho de aproximadamente 25, 9 and $33 \%$, tx down, tx up e qualidade do sinal, nesta sequência. Em média, Figura 5.7 (2), nossa solução teve desempenho marginalmente superior as outras duas técnicas.

\section{De Alpha para Charlie}

O grafo de conectividade gerado pelos três mecanismos de gerenciamento de conectividade handover é apresentado na Figura 5.8, com arestas nomeadas com o seguinte formato: $\langle A P\rangle$, $<\{$ mecanismoGerenciamento $\}>$. Os mecanismos são referenciados como $A, B$ and $C$, para SSS, preditor de mobilidade e social, respectivamente. 
O primeiro, A, fez 3 handovers desnecessários e não fez um necessário para manter uma boa vazão entre Charlie e Alpha, conforme gráfico na Figura 5.9. Mesmo com excelente cobertura de rede o sistema reativo teve desempenho ruim para um ambiente com excelente cobertura de rede. Um dos principais problemas é a aleatoriedade das associações com APs em outros andares ou distantes, mesmo com outros em melhores condições e disponíveis.

O preditor de mobilidade, $B$, fez um handover sem necessidade. Provavelmente, um usuário precisa de mais tempo para descobrir o ambiente de experimentação. Nossa solução, $C$, escolheu a melhor combinação de APs no caminho se comparada as outras duas.

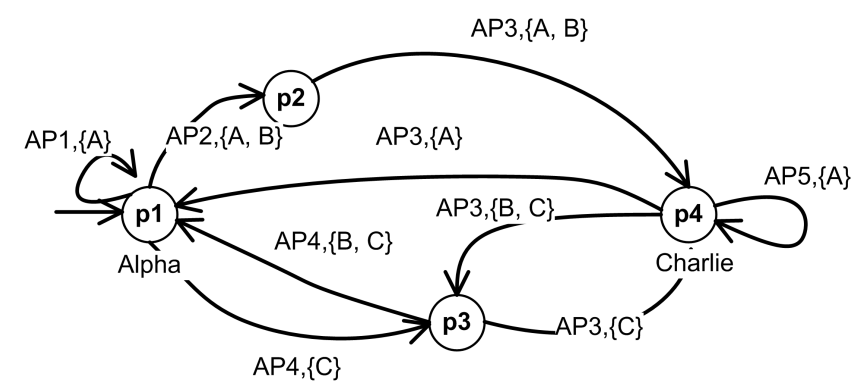

Figura 5.8: Grafo de conectividade para o caminho entre Alpha e Charlie.

Temos que ter em mente que a Figura 5.9 apresenta os resultados entre Alpha e Charlie e viceversa. No início, tempo $0 s$, todos os usuários estão no ponto Alpha e caminhando para Charlie. Segundos depois, no tempo $120 \mathrm{~s}$ eles chegam em Charlie. Então, dão meia volta e começam a retornar para Alpha, chegando lá no tempo $227 \mathrm{~s}$.

A figura mostra a vazão de upload e a qualidade do sinal durante o caminho em função do tempo durante o caminho. Nesse caso, o tempo representa espaço, porque os usuários estavam caminhando no prédio durante todo o experimento. Os resultados mostram que o mecanismo social teve melhor desempenho que os outros dois mecanismos, com comportamento homogêneo nas duas métricas plotadas; vazão de upload e qualidade do sinal.

Entre 50 e 75 segundos, nossa solução teve vazão aproximadamente $25 \%$ menor que os outros dois mecanismos. Entretanto, segundos depois a vazão é 20 e $45 \%$ maior, no melhor e pior caso, respectivamente. Voltando para Alpha, o mecanismo SSS, $A$, veio conectado ao mesmo AP e, por consequência, experimentou as piores condições de QoS observadas.

\subsection{Padrões de mobilidade}

Os promissores resultados experimentais motivaram um estudo de como a colaboração evolui com usuários se deslocando com diferentes padrões de mobilidade. Para tanto, utilizamos um ambiente de simulação para iniciar um estudo sobre a eficiência da colaboração. Pegamos um conjunto de dados coletados para delimitar a cobertura e quantificar o desempenho da rede sem fio em malha, padrão IEEE 802.11x, da cidade de Portland em Oregon, EUA (Phillips e Senior, 2007; Phillips et al., 2008). 


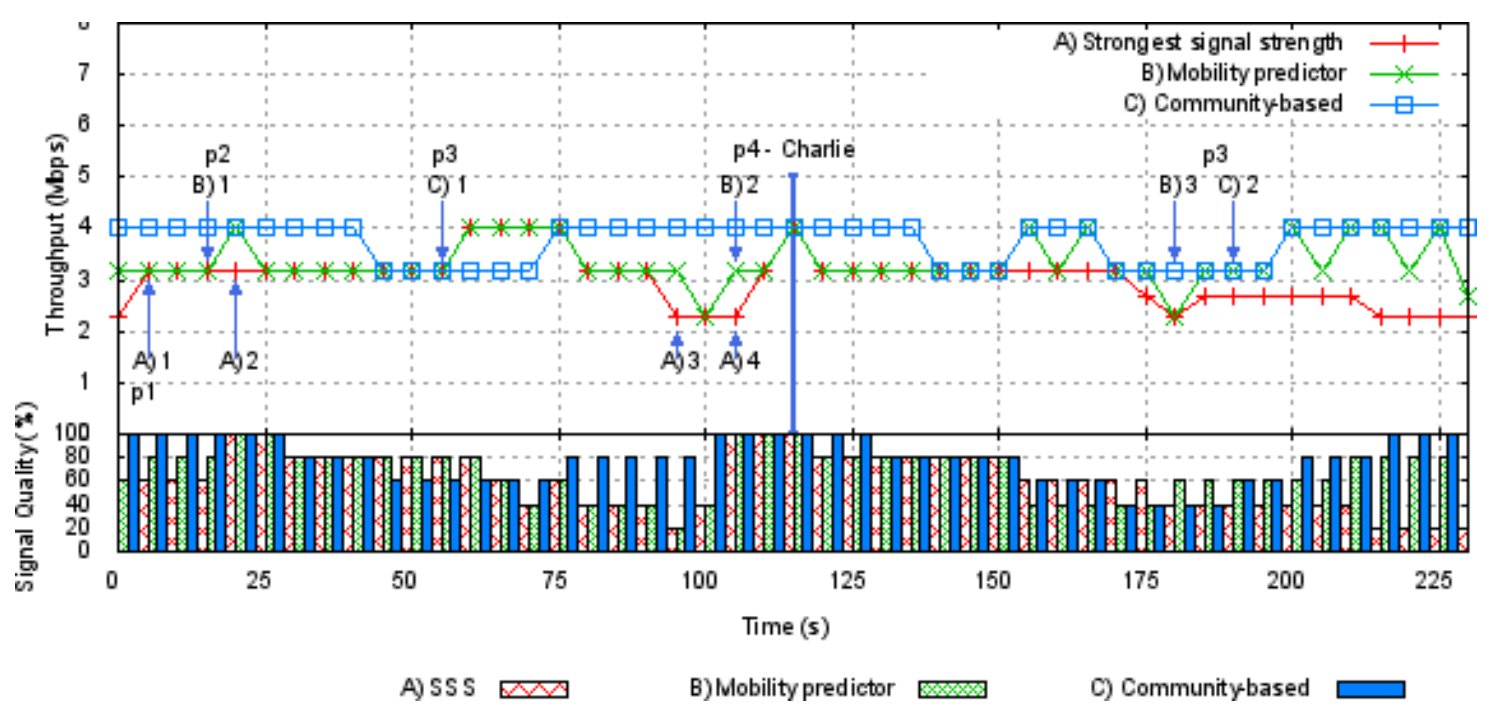

Figura 5.9: Vazão e qualidade do sinal em função do tempo no caminho entre Alpha e Charlie e vice-versa.

Utilizamos dois conjuntos de dados: a localização de todos 72 APs da rede e seus respectivos endereços MAC, conforme gráfico na Figura 5.10a; e outro conjunto de dados com observações do RSSI dos APs coletados por uma extensiva campanha de war-driving na região coberta pela rede municipal, o gráfico na Figura 5.10b.
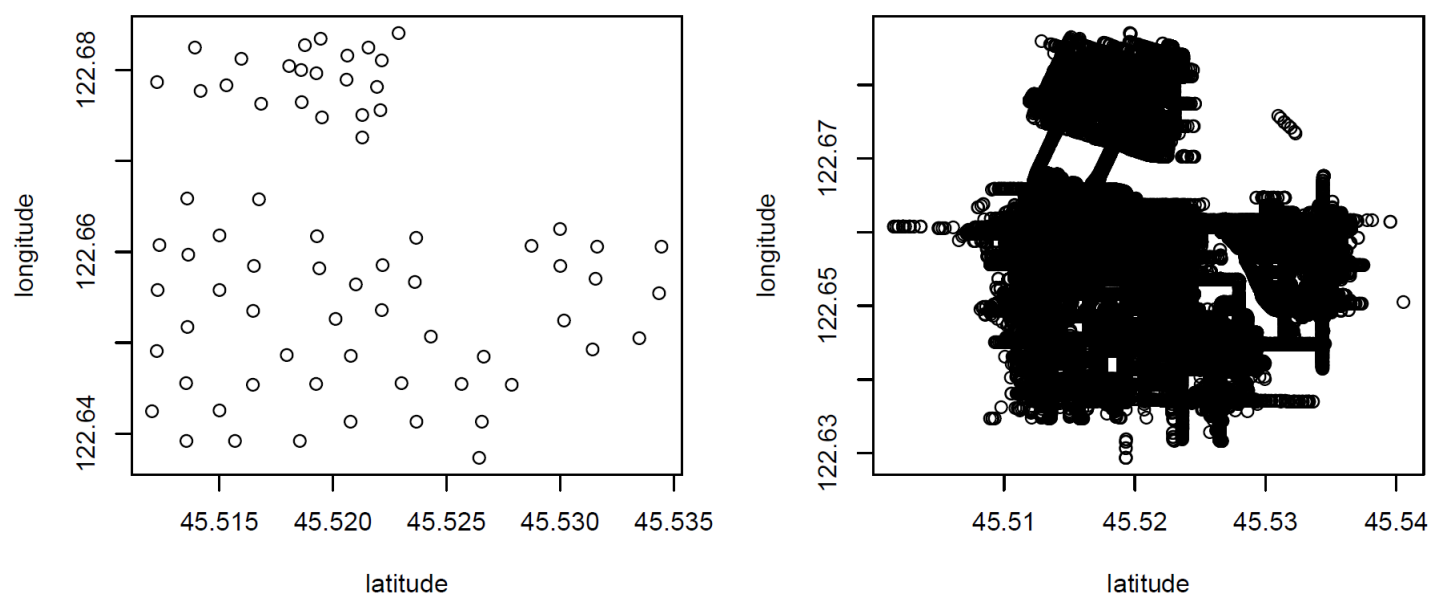

Figura 5.10: (1) Posição dos APs no ambiente. (2) Dados de contexto de conectividade coletados no ambiente.

Esses dados foram coletados com um sniffer no Linux, chamado Kismet ${ }^{2}$, configurado para varrer os 11 canais do padrão IEEE 802.11. A localização dos APs foram recuperadas por meio de triangulação e ajusta com precisão pelos dados de localização geográfica recuperado pelo GPS no dispositivo móvel. Os dados foram coletados passivamente sem acesso especial a rede sem fio.

Para definir as simulações, consideramos que o tempo para a colaboração convergir para melhores experiências de conectividade sem fio depende de quão rápido os usuários são capazes de

2 http://www.kismetwireless.net/ 
descobrir as oportunidades de conectividade no ambiente. Dessa forma, as simulações consistiram em grupos de usuários móveis se movimentando no ambiente de rede, descrito acima, com diferentes padrões de mobilidade: 8,30 e $80 \mathrm{~km} / \mathrm{h}$, para simular uma pessoa andando, usando um veículo em baixa velocidade e em alta velocidade, respectivamente.

O tamanho da área descoberta varia em função do número de usuários colaborando e seus padrões de mobilidade, como mostra o gráfico na Figura 5.11. Nessa figura, é plotado a área descoberta em função do tempo, número de usuários, 10, 20, 30 e 40, e 3 padrões de mobilidade distintos, 8,30 e $80 \mathrm{~km} / \mathrm{h}$.

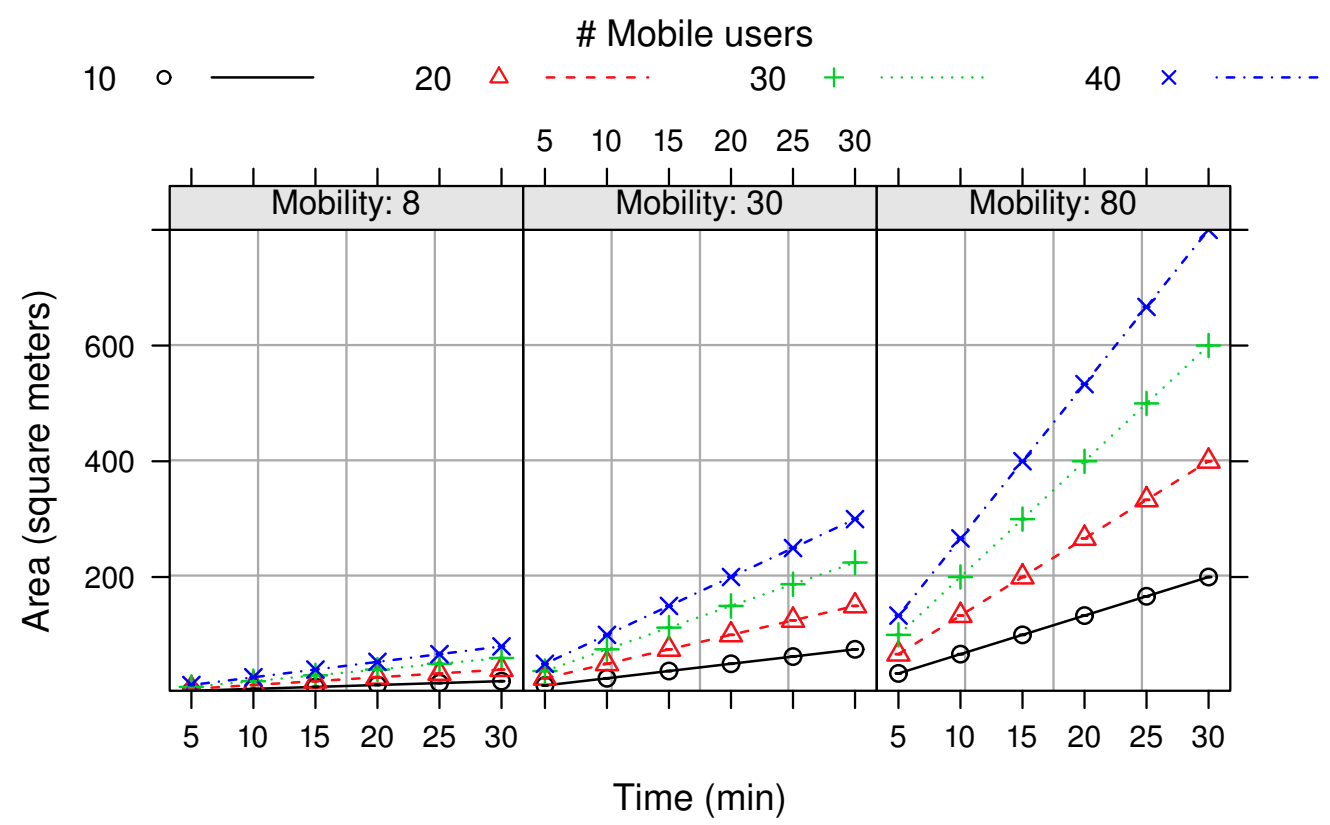

Figura 5.11: Tempo para descobrir ilhas de conectividade em função do número de usuários móveis e seus padrões de mobilidade (Lopes et al., 2012b).

É importante destacar, que nos resultados experimentais todos os usuários estavam envolvidos e colaborando com bastante frequência. A intensidade da colaboração é um problema crítico e de difícil simulação porque está relacionado ao comportamento humano e influência o tempo para descobrir oportunidades de conectividade nos ambientes de rede sem fio.

\subsection{Pontos positivos e negativos}

Nesta subseção discutimos os principais pontos positivos e negativos da solução proposta na presente investigação.

1. Pontos positivos

(a) Solução centrada no usuário sem a necessidade de acesso a serviços administrativos do provedor de acesso; 
(b) A ideia de anexar dados de contexto de conectividade sem fio a mídias sociais baseadas em localização. Isso torna a atualização dos bancos de dados de contexto mais frequente devido a popularidade das mídias sociais baseadas em localização;

(c) Uso das redes sociais como agente de colaboração e compartilhamento de dados;

2. Pontos negativos

(a) Complexidade computacional para manipular grande grafos. As redes sociais online fazem isso com eficiência;

(b) Necessidade de manter o dispositivo atualizado;

(c) Volume de dados históricos e a volatilidade dos ambientes de rede sem fio;

(d) Diferentes precisões nos sistemas de localização.

\subsection{Considerações finais}

O ambiente de experimentação foi configurado para se comportar como um ambiente de rede sem fio coberto por diversos provedores de acesso, próximo do que é esperado nos ambientes NGN. Os resultados dos experimentos, relatados neste capítulo, mostram que a solução proposta é viável e que pode melhorar experiências de conectividade sem fio significativamente.

Apresentamos os principais resultados de forma geral e estudamos dois caminhos particulares no ambiente. Realizamos simulações com traces de um ambiente de rede real com objetivo de verificar a eficiência da colaboração em função do número de usuários e seus padrões de mobilidade. Os resultados de simulação são preliminares e precisam evoluir em profundidade e largura. 



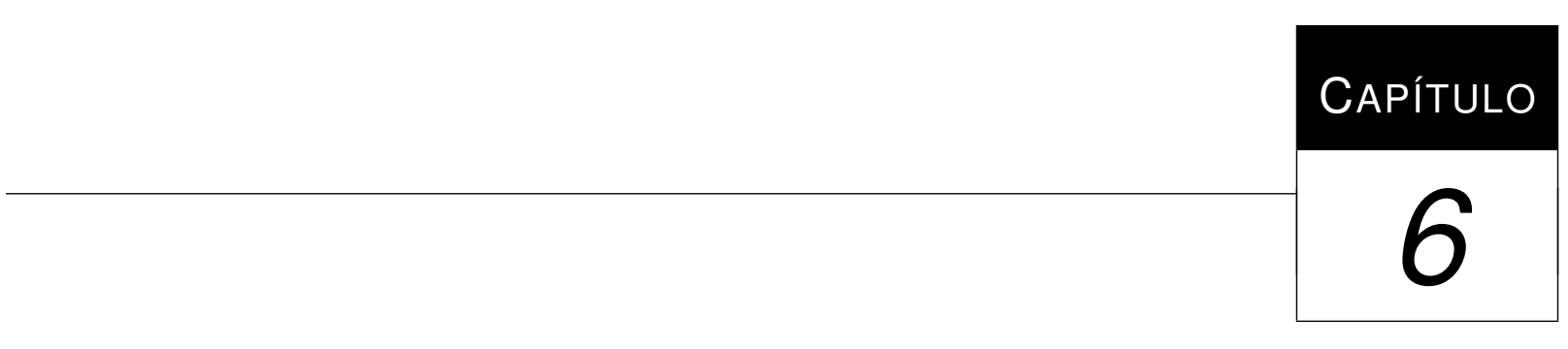

\section{Conclusão e trabalhos futuros}

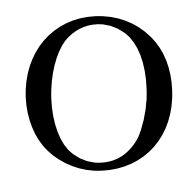

gerenciamento de conectividade sem fio ciente de contexto é o tópico principal de várias pesquisas reportadas na literatura especializada. Algumas dessas pesquisas nos motivaram a projetar um conjunto de métodos para melhorar a qualidade dos dados de contexto de conectividade sem fio recuperados e compartilhados por dispositivos móveis.

Os métodos para gerenciamento de conectividade sem fio ciente de contexto foram orquestrados em um laço retro-alimentado. Trata-se de uma solução centrada no usuário que explora círculos sociais online para compartilhar experiências de conectividade sem fio, com objetivo de permitir a colaboração entre os usuários móveis.

Propusemos um modelo de dados e descrevemos as ferramentas utilizadas para manipular o modelo com objetivo de descobrir áreas com alta densidade de troca de rede, a calcular a interação dos usuários móveis na colaboração e identificar a cobertura das redes sem fio. Nesse modelo, as experiências de conectividade sem fio são um conjunto de dados de contexto de conectividade representados por um dígrafo chamado caminho de conectividade.

Os caminhos de conectividade são combinados em um novo dígrafo chamado grafo de conectividade que sumariza as experiências de conectividade de dois ou mais usuários móveis. Esse grafo é compartilhado entre os usuários móveis para realimentar o sistema. Mostramos como o grafo de conectividade pode ser utilizado para economizar espaço de armazenamento, bateria do dispositivo e melhorar métricas de QoS, enquanto o usuário se movimenta de um lugar para outro.

Um protótipo foi implementado para provar o conceito e experimentos foram realizados para uma avaliação quantitativa. O protótipo foi instalado no prédio da universidade com objetivo de verificar as melhorias nas experiências de conectividade sem fio em termos de métricas de QoS e.g., vazão, qualidade do sinal e latência. Nossos resultados experimentais mostraram que 
as experiências de conectividade sem fio podem ser melhoradas significativamente mesmo em ambientes com boa cobertura de rede.

Essa investigação se desdobrou com o estudo da eficiência da colaboração dos usuários móveis em função do tempo, número de usuários e dos padrões de mobilidade deles. Apresentamos e discutimos resultados encorajadores sobre como a colaboração melhora a qualidade das experiências de conectividade sem fio.

Em suma, na presente investigação discutimos três pontos fundamentais. Primeiro, que existe justificativa para combinar dados de contexto de conectividade sem fio com mídias sociais baseadas em localização. Segundo, que a abordagem proposta pode complementar várias soluções cientes de contexto para gerenciamento de conectividade sem fio publicadas na literatura.

Por fim, que os benefícios da colaboração são interessantes em termos de métricas quantitativas e.g., vazão de dados, qualidade de sinal, economia de energia e de espaço de armazenamento. Essa discussão é embasada por experiências e resultados observados durante o desenvolvimento de um protótipo.

\subsection{Contribuições}

Começamos esta investigação expandindo a visão de Nicholson et. al (2008) que considera as pessoas seres de hábito que tomam decisões similares todos os dias, inclusive a respeito dos caminhos a tomar entre lugares como: casa, trabalho, escola, cinema e etc. Acrescentamos que as pessoas são seres sociais que interagem e colaboram com várias outras pessoas no dia-a-dia.

Delimitamos os principais estados do dispositivo móvel durante a movimentação de um lugar para outro e iniciamos a definição de um modelo de dados para representar os dados de conectividade sem fio (Lopes et al., 2009). Os insights para o projeto do modelo de dados vieram da implementação de um protótipo. No início de 2009 conseguíamos coletar dados de contexto de conectividade e enviar para um banco de dados. Sentimos na prática a dificuldade de manipular tal conjunto de dados que cresce rapidamente.

Nessa época, fui fazer estágio sanduíche no grupo de telemedicina ${ }^{1}$ da Universidade de Twente - Holanda. O principal interesse do grupo era projetar uma comunidade virtual para suporte médico e monitoramento remoto de pacientes. Participei ativamente do projeto da arquitetura e resolvi tentar compartilhar os dados de conectividade sem fio em redes sociais online.

A ideia inicial era manipular os dados de contexto como mídias sociais (Lopes et al., 2010a). O objetivo era projetar um sistema para facilitar a atualização de dados históricos de contexto que é um problema delimitado em (Nicholson et al., 2006). Propomos um conjunto de métodos para coletar, combinar, sumarizar e compartilhar dados de contexto de conectividade sem fio em um laço retroalimentado. Em seguida, fizemos um estudo da viabilidade da solução em termos de sobrecarga de armazenamento e consumo de energia (Lopes et al., 2010b).

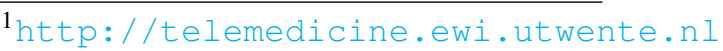


Em 2011, o protótipo chegou em um estágio avançado com o gerenciamento de conectividade sem fio, que chamamos de social, no dispositivo móvel, e funcionalidades de visualização dos dados históricos de contexto de conectividade sem fio no lado servidor (Lopes et al., 2011a). Então, direcionamos os esforços para anexar os dados de contexto de conectividade sem fio as chamadas mídias sociais baseadas em localização (Lopes et al., 2011b).

Em uma visita curta, de 5 semanas, ao grupo DIVA² na Universidade de Ottawa - Canada, iniciamos a investigar como a eficiência colaboração evolui em função do número de usuários e de seus padrões de mobilidade (Lopes et al., 2012b).

Por fim, emergiram na literatura trabalhos propondo transformar os dispositivos móveis modernos em plataformas de sensoriamento. Argumentamos que a coleta de dados de contexto é fundamental para o gerenciamento de conectividade e pode ser projetada como uma aplicação de sensoriamento continuado (Lopes et al., 2012a). As redes sociais online podem disponibilizar dados personalizados, para uma pessoa em particular, ou compartilhar dados com uma comunidade inteira, adicionando escala ao sistema de compartilhamento.

\subsection{Trabalhos futuros}

Em um futuro próximo, será possível acessar e compartilhar mídias sociais de forma transparente entre as aplicações executando no dispositivo móvel simultaneamente. Dispositivos móveis com duas ou mais interfaces de rede sem fio serão capazes de se beneficiar das múltiplas interfaces de rede eficientemente, com mostra a ilustração na Figura 6.1, e.g., WiFi, Long Term Evolution (LTE) e WiMax.

Alavancadas pela maior vazão de dados disponível, as aplicações móveis serão capazes de acessar e compartilhar conteúdo digital de alta qualidade. Como consequência, o dispositivo móvel será capaz de ficar conectado simultaneamente a mais de um sistema multimídia e social na nuvem e.g., Twitter, Facebook e YouTube.

Para ilustrar, a Figura 6.1 mostra uma aplicação de navegação capaz de recuperar experiências de conectividade sem fio enquanto o usuário se movimenta. Os dados de contexto de conectividade estão anexados aos feedbacks relacionados ao lugar sendo visitado, originados de um ou mais círculos sociais online.

Esta investigação pode se desdobrar para atender o cenário supracitado e com foco no uso dos dados de contexto socializados para descobrir o segundo ou $n^{\text {simo }}$ ponto de acesso(s). Em complemento, esforços podem ser direcionados para determinar condições ótimas de localização e QoS para atualizar os dados de contexto compartilhados em arquivos RSS.

O desenvolvimento das arquiteturas para sensoriamento em dispositivos móveis merece uma atenção especial (Lane et al., 2010; Ganti et al., 2011). Tais esforços podem viabilizar a im-

$2_{\text {http: }} / /$ nsercoiva.com/ 


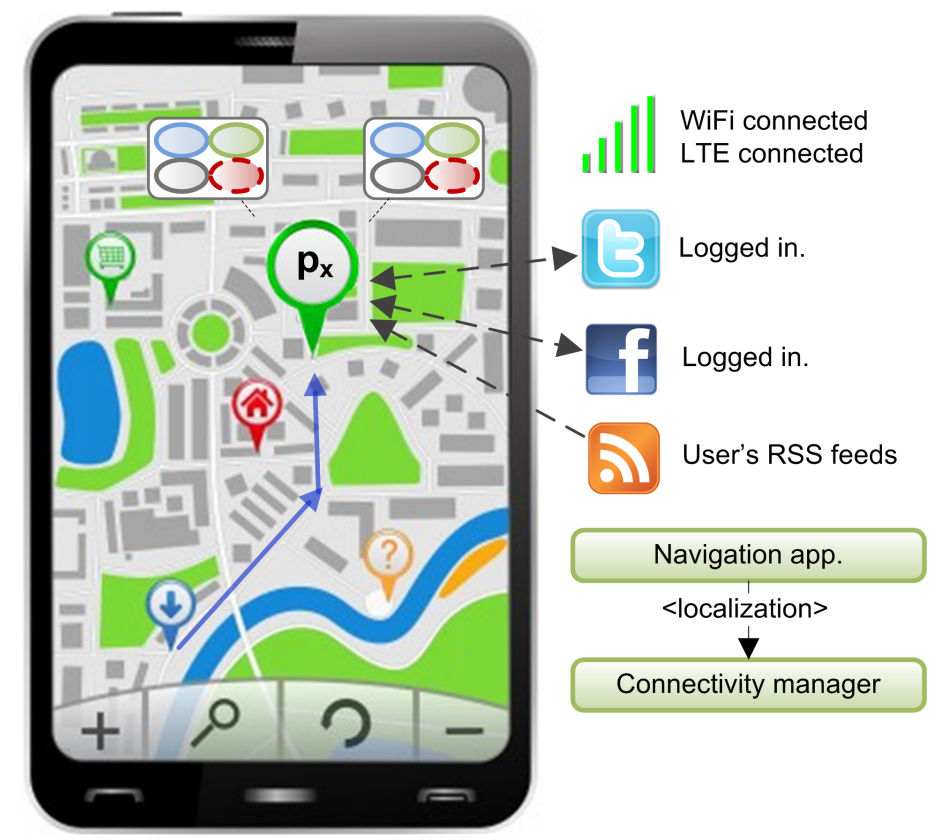

Figura 6.1: Cenário de gerenciamento de conectividade sem fio em um futuro próximo.

plementação de aplicações cientes de contexto auxiliando o projeto de mecanismos de coleta e compartilhamento de dados em larga escala. 


\section{Referências Bibliográficas}

Ahmed, T.; Kyamakya, K.; Ludwig, M. Architecture of a context-aware vertical handover decision model and its performance analysis for GPRS - WiFi handover. In: Proceedings of 11th IEEE Symposium on Computers and Communications (ISCC '06), 2006, p. 795 - 801. Disponível em: http://dx.doi.org/10.1109/ISCC.2006.39

Akyildiz, I.; Xie, J.; Mohanty, S. A survey of mobility management in next-generation all-IP-based wireless systems. IEEE Wireless Communications, v. 11, n. 4, p. 16 - 28, 2004. Disponível em: http://dx.doi.org/10.1109/MWC.2004.1325888

Araujo, G. M.; Kaiser, J.; BeCKer, L. B. An optimized markov model to predict link quality in mobile wireless sensor networks. In: IEEE Symposium on Computers and Communications (ISCC), 2012, p. $307-312$.

Disponível em: http://dx.doi.org/10.1109/ISCC.2012.6249313

BACKSTROM, L.; Sun, E.; MARlOW, C. Find me if you can: improving geographical prediction with social and spatial proximity. In: Proceedings of the 19th international conference on World wide web (WWW'10), New York, NY, USA: ACM, 2010, p. 61-70.

Disponível em: http://doi.acm.org/10.1145/1772690.1772698

Baladron, C.; Aguiar, J.; Carro, B.; Calavia, L.; Cadenas, A.; SanchezESGUEVILlas, A. Framework for intelligent service adaptation to user's context in next generation networks. IEEE Communications Magazine, v. 50, n. 3, p. 18 -25, 2012. Disponível em: http://dx.doi.org/10.1109/MCOM.2012.6163578

BALASUBRAMANIAM, S.; INDULSKA, J. Vertical handover supporting pervasive computing in future wireless networks. Computer Communications, v. 27, n. 8, p. 708 - 719, advances in Future Mobile/Wireless Networks and Services, 2004.

Disponível em: http://dx.doi.org/10.1016/j.comcom.2003.10.010 
Barrat, A.; Barthelemy, M.; Pastor-Satorras, R.; Vespignani, A. The architecture of complex weighted networks. Proceedings of the National Academy of Sciences of the United States of America, v. 101, n. 11, p. 3747, 2004.

Disponível em: http://dx.doi.org/10.1073/pnas.0400087101

Bellavista, P.; Corradi, A.; Foschini, L. Context-aware handoff middleware for transparent service continuity in wireless networks. Pervasive and Mobile Computing, v. 3, n. 4, p. 439 - 466, 2007.

Disponível em: http://dx.doi.org/10.1016/j.pmcj.2007.04.006

BerEzDIVIN, R.; BREINIG, R.; TOPP, R. Next-generation wireless communications concepts and technologies. IEEE Communications Magazine, v. 40, n. 3, p. 108 -116, 2002.

Disponível em: http://dx.doi.org/10.1109/35.989768

Bettini, C.; BrdiczKa, O.; Henricksen, K.; Indulska, J.; Nicklas, D.; RangaNATHAN, A.; RiBOni, D. A survey of context modelling and reasoning techniques. Pervasive and Mobile Computing, v. 6, n. 2, p. 161 - 180, 2010.

Disponível em: http://dx.doi.org/10.1016/j.pmcj.2009.06.002

Chan, J.; Zhou, S.; Seneviratne, A. A QoS adaptive mobility prediction scheme for wireless networks. In: IEEE Global Telecommunications Conference (GLOBECOM 98), 1998, p. $1414-1419$ vol.3.

Disponível em: http://dx.doi.org/10.1109/GLOCOM.1998.776573

Chan, L.-W.; Chiang, J.-R.; Chen, Y.-C.; Ke, C.-N.; Hsu, J.; ChU, H.-H. Collaborative localization: Enhancing WiFi-based position estimation with neighborhood links in clusters. In: Fishrin, K.; Schiele, B.; Nixon, P.; Quigley, A., eds. Pervasive Computing, v. 3968, Springer Berlin / Heidelberg, p. 50-66, 2006.

Disponível em: http://dx.doi.org/10.1007/11748625_4

Chan, P.; SherifF, R.; Hu, Y.; Conforto, P.; Tocci, C. Mobility management incorporating fuzzy logic for heterogeneous a IP environment. IEEE Communications Magazine, v. 39, n. 12 , p. 42-51, 2001.

Disponível em: http://dx.doi.org/10.1109/35.968811

ChAndra, R.; BAHL, P. Multinet: connecting to multiple IEEE 802.11 networks using a single wireless card. In: INFOCOM 2004. Twenty-third AnnualJoint Conference of the IEEE Computer and Communications Societies, 2004, p. 882 - 893 vol.2.

Disponível em: http://dx.doi.org/10.1109/INFCOM.2004.1356976

Chandrasekhar, V.; Andrews, J.; Gatherer, A. Femtocell networks: a survey. IEEE Communications Magazine, v. 46, n. 9, p. 59 -67, 2008.

Disponível em: http://dx.doi.org/10.1109/MCOM.2008.4623708 
Constandache, I.; Choudhury, R.; Rhee, I. Towards mobile phone localization without war-driving. In: Proceedings of IEEE INFOCOM, 2010, p. 1 -9.

Disponível em: http://dx.doi.org/10.1109/INFCOM.2010.5462058

Coronato, A.; Esposito, M. Towards an implementation of smart hospital: A localization system for mobile users and devices. In: Sixth Annual IEEE International Conference on Pervasive Computing and Communications (PerCom 2008), 2008, p. 715 -719.

Disponível em: http://dx.doi.org/10.1109/PERCOM.2008.79

Desset, C.; Ahmed, N.; Dejonghe, A. Energy savings for wireless terminals through smart vertical handover. In: IEEE International Conference on Communications (ICC '09), 2009, p. $1-5$.

Disponível em: http://dx.doi.org/10.1109/ICC.2009.5198995

Eastwood, L.; Migaldi, S.; XIE, Q.; Gupta, V. Mobility using IEEE 802.21 in a heterogeneous IEEE 802.16/802.11-based, IMT-advanced (4G) network. IEEE Wireless Communications, v. 15, n. 2, p. 26-34, 2008.

Disponível em: http://dx.doi.org/10.1109/MWC.2008.4492975

FALAKI, M. H. WLAN interface management on mobile devices. Dissertação de Mestrado, University of Waterloo, Waterloo, Ontario, Canada, 2008.

Disponível em: http://hdl. handle.net/10012/3854

FEI, R.; YANG, K.; CHENG, X. A cooperative social and vehicular network and its dynamic bandwidth allocation algorithms. In: 2011 IEEE Conference on Computer Communications Workshops (INFOCOM WKSHPS), 2011, p. $63-67$.

Disponível em: http://dx.doi.org/10.1109/INFCOMW.2011.5928891

FOdOR, G.; FURUSKAR, A.; LUNDSJO, J. On access selection techniques in always best connected networks. In: ITC Specialist Seminar on Performance Evaluation of Wireless and Mobile Systems, 2004, p. 89-100.

Disponível em: http://130.203.133.150/viewdoc/summary?doi=10.1.1. 60.4690

FURUSKAR, A. Allocation of multiple services in multi-access wireless systems. In: 4th International Workshop on Mobile and Wireless Communications Network, 2002, p. 261 - 265.

Disponível em: http://dx.doi.org/10.1109/MWCN.2002.1045733

FURUsKAR, A.; ZANDER, J. Multiservice allocation for multiaccess wireless systems. IEEE Transactions on Wireless Communications, v. 4, n. 1, p. 174 - 184, 2005.

Disponível em: http://dx.doi.org/10.1109/TWC.2004.840243 
GANTI, R.; Ye, F.; LEI, H. Mobile crowdsensing: current state and future challenges. IEEE Communications Magazine, v. 49, n. 11, p. 32 -39, 2011.

Disponível em: http://dx.doi.org/10.1109/MCOM.2011.6069707

Garton, L.; Haythornthwaite, C.; Wellman, B. Studying online social networks. Journal of Computer-Mediated Communication, v. 3, n. 1, p. 0-0, 1997.

Disponível em: http://dx.doi.org/10.1111/j.1083-6101.1997.tb00062.x

Golaup, A.; Mustapha, M.; Patanapongribul, L. Femtocell access control strategy in UMTS and LTE. IEEE Communications Magazine, v. 47, n. 9, p. 117 -123, 2009.

Disponível em: http://dx.doi.org/10.1109/MCoM.2009.5277464

GuAn, L.; Ke, X.; Song, M.; Song, J. A survey of research on mobile cloud computing. In: IEEE/ACIS 10th International Conference on Computer and Information Science (ICIS), 2011, p. $387-392$.

Disponível em: http://dx.doi.org/10.1109/ICIS.2011.67

Gustafsson, E.; Jonsson, A. Always best connected. IEEE Wireless Communications, v. 10, n. 1, p. $49-55,2003$.

Disponível em: http://dx.doi.org/10.1109/MWC.2003.1182111

Haeberlen, A.; Flannery, E.; Ladd, A. M.; Rudys, A.; Wallach, D. S.; Kavraki, L. E. Practical robust localization over large-scale 802.11 wireless networks. In: MobiCom '04: Proceedings of the 10th annual international conference on Mobile computing and networking, New York, NY, USA: ACM, 2004, p. 70-84.

Disponível em: http://dx.doi.org/10.1145/1023720.1023728

Haibo, X.; Hui, T.; PING, Z. A novel terminal-controlled handover scheme in heterogeneous wireless networks. Computers e Electrical Engineering, v. 36, n. 2, p. 269 - 279, 2010.

Disponível em: http://dx.doi.org/10.1016/j.compeleceng.2009.03.012

Halteren, A.; PAWAR, P. Mobile service platform: A middleware for nomadic mobile service provisioning. In: IEEE International Conference on Wireless and Mobile Computing, Networking and Communications (WiMob'2006), 2006, p. 292 -299.

Disponível em: http://dx.doi.org/10.1109/WIMOB.2006.1696373

Hasswa, A.; NAsser, N.; HAssanein, H. A seamless context-aware architecture for fourth generation wireless networks. Wireless Personal Communications, v. 43, p. 1035-1049, 2007. Disponível em: http://dx.doi.org/10.1007/s11277-007-9262-7

IEEE802.21 IEEE standard for local and metropolitan area networks: Media independent handover services. IEEE, New York, draft standard D9.0, 2009. 
IMIELINSKI, T.; BADRINATH, B. R. Mobile wireless computing: challenges in data management. Commun. ACM, v. 37, n. 10, p. 18-28, 1994.

Disponível em: http://doi.acm.org/10.1145/194313.194317

KAPlan, A. M.; HAEnlein, M. Users of the world, unite! the challenges and opportunities of social media. Business Horizons, v. 53, n. 1, p. 59 - 68, 2010.

Disponível em: http://dx.doi.org/10.1016/j.bushor.2009.09.003

Kassar, M.; Kervella, B.; Pujolle, G. An overview of vertical handover decision strategies in heterogeneous wireless networks. Computer Communications, v. 31, n. 10, p. 2607 2620, 2008.

Disponível em: http://dx.doi.org/10.1016/j.comcom.2008.01.044

KIM, T.-H.; YANG, Q.; LeE, J.-H.; PARK, S.-G.; ShIN, Y.-S. A mobility management technique with simple handover prediction for 3G LTE systems. In: 2007 IEEE 66th Vehicular Technology Conference (VTC-2007 Fall), 2007, p. 259 -263.

Disponível em: http://dx.doi.org/10.1109/VETECF.2007.68

Kimura, B.; Guardia, H.; Santos Moreira, E. Disruption-tolerant sessions for seamless mobility. In: IEEE Wireless Communications and Networking Conference (WCNC), 2012, p. $2412-2417$.

Disponível em: http://dx.doi.org/10.1109/WCNC.2012.6214200

Kimura, B. Y. L.; Yokoyama, R. S.; Lopes, R. R. F.; Guardia, H. C.; Moreira, E. S. Prototyping applications to handle connection disruptions in end-to-end host mobility. In: 2010 SeventhInternational Conference on Wireless On-demand Network Systems and Services (WONS), 2010, p. $1-8$.

Disponível em: http://dx.doi.org/10.1109/WONS.2010.5437141

Klein, A.; Mannweiler, C.; Schneider, J.; Schotten, H. D. Access schemes for mobile cloud computing. In: 2010 Eleventh International Conference Mobile Data Management (MDM), 2010, p. $387-392$.

Disponível em: http://dx.doi.org/10.1109/MDM.2010.79

Kleinrock, L. Nomadic computing an opportunity. SIGCOMM Comput. Commun. Rev., v. 25, n. 1, p. 36-40, 1995.

Disponível em: http://doi.acm.org/10.1145/205447.205450

Kumar, R.; NovaK, J.; TOMKins, A. Structure and evolution of online social networks. In: Yu, P. S. S.; Han, J.; Faloutsos, C., eds. Link Mining: Models, Algorithms, and Applications, Springer New York, p. 337-357, 2010.

Disponível em: http://dx.doi.org/10.1007/978-1-4419-6515-8_13 
Lamarca, A.; Chawathe, Y.; Consolvo, S.; Hightower, J.; Smith, I.; Scott, J.; Sohn, T.; Howard, J.; Hughes, J.; Potter, F.; TAbert, J.; Powledge, P.; BorRIEllo, G.; Schilit, B. Place lab: Device positioning using radio beacons in the wild. In: Pervasive Computing, Springer Berlin / Heidelberg, 2005a, p. 116-133 (Lecture Notes in Computer Science, v.3468).

Disponível em:

http: //www.springerlink.com/content/ p 62lolm7cp $7 \mathrm{rmel1w/}$

LaMarca, A.; Hightower, J.; Smith, I.; Consolvo, S. Self-mapping in 802.11 location systems. In: UbiComp 2005: Ubiquitous Computing, Springer Berlin / Heidelberg, 2005b, p. 87-104 (Lecture Notes in Computer Science, v.3660).

Disponível em: http://dx.doi.org/10.1007/11551201_6

Lane, N.; Miluzzo, E.; Lu, H.; Peebles, D.; Choudhury, T.; Campbell, A. A survey of mobile phone sensing. IEEE Communications Magazine, v. 48, n. 9, p. 140 -150, 2010.

Disponível em: http://dx.doi.org/10.1109/MCOM.2010.5560598

LeE, D. L.; Chen, Q. A model-based WiFi localization method. In: Proceedings of the 2nd international conference on Scalable information systems, InfoScale '07, ICST, Brussels, Belgium, Belgium: ICST (Institute for Computer Sciences, Social-Informatics and Telecommunications Engineering), 2007, p. 40:1-40:7 (InfoScale '07, ).

Disponível em: http://dl.acm.org/citation.cfm?id=1366804.1366856

LI, N.; Chen, G. Analysis of a location-based social network. In: International Conference on Computational Science and Engineering (CSE '09), 2009a, p. 263 -270.

Disponível em: http://dx.doi.org/10.1109/CSE.2009.98

LI, N.; CHEN, G. Multi-layered friendship modeling for location-based mobile social networks. In: Mobile and Ubiquitous Systems: Networking Services, MobiQuitous, 2009. MobiQuitous '09. 6th Annual International, 2009b, p. 1 -10.

Disponível em: http://dx.doi.org/10.4108/ICST.MOBIQUITOUS2009.6828

Lopes, R. R. F.; BeiJnum, B.-J.; MoreIRA, E. S. Managing wireless IP-connectivity experiences as mobile social media. In: 2010 International Congress on Ultra Modern Telecommunications and Control Systems and Workshops (ICUMT), Moscow, Russia, 2010a, p. 154-161. Disponível em: http://dx.doi.org/10.1109/ICUMT.2010.5676643

Lopes, R. R. F.; Boukerche, A.; van Beijnum, B.-J.; Moreira, E. D. S. Online social networks adding community-scale to context-aware wireless connectivity management. Submitted to: IEEE Communications Magazine, 2012a.

Lopes, R. R. F.; Boukerche, A.; van Beijnum, B.-J.; Moreira, E. D. S. Social and location-based collaboration mechanism to manage wireless connectivity context data. In: 2012 
IEEE Wireless Communications and Networking Conference: Mobile and Wireless Networks (IEEE WCNC 2012 Track 3 Mobile \& Wireless), Paris, France, 2012b, p. 2288 -2293.

Disponível em: http://dx.doi.org/10.1109/WCNC.2012.6214175

Lopes, R. R. F.; van Beijnum, B.-J.; Moreira, E. D. S. Community-based approach to handle wireless connectivity context data. In: I2TS 2010, Rio de Janeiro - RJ, Brazil, 2010b. Disponível em: http://Www.i2ts.org/I2TS2010/papers/full_english/ $78470 \_1$. pdf

Lopes, R. R. F.; VAn BeiJnum, B.-J.; Moreira, E. D. S. Community-based tool to manage wireless connectivity. In: SBRC 2011 - Salao de Ferramentas, Campo Grande - MS, Brazil, 2011 a.

Disponível em: http://sbrc2011.facom.ufms.br/files/sf/ST01_5.pdf

Lopes, R. R. F.; van Beijnum, B.-J.; Moreira, E. D. S. Towards a feasible social-based methodology to manage wireless connectivity context data. In: 2011 IEEE 7th International Conference on Wireless and Mobile Computing, Networking and Communications (WiMob'2011), Shanghai, P.R. China, 2011b.

Disponível em: http://dx.doi.org/10.1109/WiMOB.2011.6085398

Lopes, R. R. F.; Yokoyama, R. S.; Kimura, B. Y. L.; Pawar, P.; Beijnum, B. J. F.; MoreIRA, E. S. Exploring user's habits and virtual communities to improve IP-connectivity management. In: Proceedings of 2009 International Conference on Ultra Modern Telecommunications (ICUMT 2009), Saint Petersburg, Russia, IEEE Computer Society, 2009.

Disponível em: http://dx.doi.org/10.1109/ICUMT.2009.5345357

MA, D. Offering RSS feeds: Does it help to gain competitive advantage? In: 42nd Hawaii International Conference on System Sciences (HICSS'09), 2009, p. 1-10.

Mateus, G.; Loureiro, A. Introdução à computação móvel. DCC/IM, COPPE/UFRJ, 1998. Disponível em: http://homepages.dcc.ufmg.br/ loureiro/cm/docs/cm_ livro_le.pdf

Moreira, E.; Cottingham, D.; Crowcroft, J.; Hui, P.; Mapp, G.; Vanni, R. Exploiting contextual handover information for versatile services in NGN environments. In: 2nd International Conference on Digital Information Management (ICDIM '07), 2007, p. 506 -512.

Disponível em: http://dx.doi.org/10.1109/ICDIM.2007.4444273

MORR, C. E.; KAWASH, J. Mobile virtual communities research: a synthesis of current trends and a look at future perspectives. Int. J. Web Based Communities, v. 3, n. 4, p. 386-403, 2007. Disponível em: http://dx.doi.org/10.1504/IJWBC.2007.015865 
Motani, M.; Srinivasan, V.; Nuggehalli, P. S. Peoplenet: engineering a wireless virtual social network. In: Proceedings of the 11th annual international conference on Mobile computing and networking, MobiCom'05, New York, NY, USA: ACM, 2005, p. 243-257 (MobiCom'05, ).

Disponível em: http://doi.acm.org/10.1145/1080829.1080855

Multisilta, J.; Milrad, M. Sharing experiences with social mobile media. In: MobileHCI '09: Proceedings of the 11th International Conference on Human-Computer Interaction with Mobile Devices and Services, New York, NY, USA: ACM, 2009, p. 1-3.

Disponível em: http://dx.doi.org/10.1145/1613858.1613977

Munoz, D.; VArgas, C. Position location techniques and applications. 1st ed. Academic Press, 275 p., 2009.

Disponível em:

http://www.sciencedirect.com/science/book/ 9780123743534

NAZIR, A.; RAZA, S.; ChUAH, C.-N. Unveiling facebook: a measurement study of social network based applications. In: Proceedings of the 8th ACM SIGCOMM conference on Internet measurement, IMC '08, New York, NY, USA: ACM, 2008, p. 43-56 (IMC '08, ).

Disponível em: http://doi.acm.org/10.1145/1452520.1452527

Nicholson, A. J.; Chawathe, Y.; Chen, M. Y.; Noble, B. D.; Wetherall, D. Improved access point selection. In: MobiSys '06: Proceedings of the 4th international conference on Mobile systems, applications and services, New York, NY, USA: ACM, 2006, p. 233-245.

Disponível em: http://doi.acm.org/10.1145/1134680.1134705

Nicholson, A. J.; Noble, B. D. Breadcrumbs: forecasting mobile connectivity. In: Proceedings of the 14th ACM international conference on Mobile computing and networking (MobiCom '08), New York, NY, USA: ACM, 2008, p. 46-57.

Disponível em: http://doi.acm.org/10.1145/1409944.1409952

Nicholson, A. J.; WolchoK, S.; Noble, B. D. Juggler: Virtual networks for fun and profit. IEEE Transactions on Mobile Computing, v. 9, n. 1, p. 31 -43, 2010.

Disponível em: http://dx.doi.org/10.1109/TMC.2009.97

PATANAPOngPibul, L.; MAPP, G. A client-based handoff mechanism for mobile IPv6 wireless networks. In: Eighth IEEE International Symposium on Computers and Communication (ISCC 2003), 2003, p. 563 - 568 vol.1.

Disponível em: http://dx.doi.org/10.1109/ISCC.2003.1214178

Pawar, P.; Wac, K.; Beijnum, B.-J.; Maret, P.; Halteren, A.; Hermens, H. Contextaware middleware architecture for vertical handover support to multi-homed nomadic mobile services. In: Proceedings of the 2008 ACM symposium on Applied computing, SAC '08, New 
York, NY, USA: ACM, 2008, p. 481-488 (SAC '08, ).

Disponível em: http://doi.acm.org/10.1145/1363686.1363806

Phillips, C.; SENIOR, R. Unwire portland proof-of-concept network testing. Relatório Técnico, unwirepdx-watch.org, 2007.

Phillips, C.; Senior, R.; Sicker, D.; Grunwald, D. Robust coverage and performance testing for large area networks. In: AccessNets, 2008.

Disponível em: http://www.unwirepdx-watch.org/files/accessnets08. pdf

Prasad, P.; Agrawal, P. A generic framework for mobility prediction and resource utilization in wireless networks. In: 2010 Second International Conference on Communication Systems and Networks (COMSNETS), 2010, p. 1-10.

Disponível em: http://dx.doi.org/10.1109/COMSNETS.2010.5432004

Prehofer, C.; NAFisi, N.; Wei, Q. A framework for context-aware handover decisions. In: 14th IEEE Proceedings on Personal, Indoor and Mobile Radio Communications (PIMRC 2003), 2003, p. $2794-2798$ vol.3.

Disponível em: http://dx.doi.org/10.1109/PIMRC.2003.1259253

PYUN, J.-Y. Context-aware streaming video system for vertical handover over wireless overlay network. Consumer Electronics, IEEE Transactions on, v. 54, n. 1, p. 71 -79, 2008.

Disponível em: http://dx.doi.org/10.1109/TCE.2008.4470026

Quddus, M. A.; OChiEnG, W. Y.; Noland, R. B. Current map-matching algorithms for transport applications: State-of-the art and future research directions. Transportation Research Part C: Emerging Technologies, v. 15, n. 5, p. 312 - 328, 2007.

Disponível em: http://www.sciencedirect.com/science/article/ B6VGJ-4P2JCX9-1/2/21d1ef73e42329087fc872e39ce78b1b

Rahmati, A.; Zhong, L. Context-for-wireless: context-sensitive energy-efficient wireless data transfer. In: MobiSys '07: Proceedings of the 5th international conference on Mobile systems, applications and services, New York, NY, USA: ACM, 2007, p. 165-178.

Disponível em: http://dx.doi.org/10.1145/1247660.1247681

RidingS, C. M.; GEFEN, D. Virtual community attraction: Why people hang out online. Journal of Computer-Mediated Communication, v. 10, n. 1, p. 00-00, 2004.

Disponível em: http://dx.doi.org/10.1111/j.1083-6101.2004.tb00229.x

SleEM, A.; KumAr, A. Handoff management in wireless data networks using topographyaware mobility prediction. Journal of Parallel and Distributed Computing, v. 65, n. 8, p. 963-982, 2005. 
Disponível em: http://www.sciencedirect.com/science/article/ B6WKJ-4G82Y0M-3/2/f7bcf29447880aeacc2fd07eb92478dd

Smith, M.; Barash, V.; Getoor, L.; LAUW, H. W. Leveraging social context for searching social media. In: SSM '08: Proceeding of the 2008 ACM workshop on Search in social media, New York, NY, USA: ACM, 2008, p. 91-94.

Disponível em: http://dx.doi.org/10.1145/1458583.1458602

SoH, W.-S.; KIM, H. Qos provisioning in cellular networks based on mobility prediction techniques. IEEE Communications Magazine, v. 41, n. 1, p. 86 - 92, 2003.

Disponível em: http://dx.doi.org/10.1109/MCOM.2003.1166661

Song, L.; Deshrande, U.; Kozat, U. C.; Kotz, D.; JaIn, R. Predictability of wlan mobility and its effects on bandwidth provisioning. In: INFOCOM 2006. 25th IEEE International Conference on Computer Communications. Proceedings, 2006, p. 1-13.

Disponível em: http://dx.doi.org/10.1109/INFOCOM.2006.171

Stojanovic, L.; Schneider, J.; Maedche, A.; Libischer, S.; Studer, R.; Lumpp, T.; ABECKER, A.; Breiter, G.; Dinger, J. The role of ontologies in autonomic computing systems. IBM Systems Journal, v. 43, n. 3, p. 598 -616, 2004.

Disponível em: http://dx.doi.org/10.1147/sj.433.0598

Su, W.; LEE, S.-J.; GERLA, M. Mobility prediction in wireless networks. In: MILCOM 2000. 21st Century Military Communications Conference Proceedings, 2000, p. 491 -495 vol.1.

Disponível em: http://dx.doi.org/10.1109/MILCOM.2000.905001

Sun, J.-Z.; SAuvola, J. From mobility management to connectivity management. IEEE Symposium on Computers and Communications, v. 0, p. 307-312, 2005.

Disponível em: http://dx.doi.org/10.1109/ISCC.2005.74

Tlais, M.; WEIS, F. Centralized mobility prediction support in a hierarchical architecture. In: International Conference on Wireless and Mobile Communications (ICWMC '06), 2006, p. 81 -81 .

Disponível em: http://dx.doi.org/10.1109/ICWMC.2006.32

Tragos, E. Z.; Mihovska, A.; Mino-Diaz, E.; Karamolegkos, P.; Vlacheas, P.; LUO, J. Access selection and mobility management in a beyond 3G RAN: The winner approach. Telecommunication Systems, v. 42, n. 3-4, p. 165-177, 2009.

Disponível em: http://www.springerlink.com/content/ $2742582 u 23 j$ ja3571/

TSAO, C.-L.; SivaKumar, R. On effectively exploiting multiple wireless interfaces in mobile hosts. In: CoNEXT '09: Proceedings of the 5th international conference on Emerging networ- 
king experiments and technologies, New York, NY, USA: ACM, 2009, p. 337-348.

Disponível em: http://dx.doi.org/10.1145/1658939.1658977

VAnni, R.; Moreira, E.; Goularte, R. Dohand: An ontology to support building services to exploit handover information in mobile heterogeneous networks. In: I2TS-International Information and Telecommunication Technologies Symposium, Cuiaba, MT, 2006, p. 105-112. Disponível em: http://www.icmc.usp.br/ rporto/DoHand/Paper/ I2TS-2006.pdf

VARShney, U.; JAIn, R. Issues in emerging 4G wireless networks. Computer, v. 34, n. 6, p. 94 -96, 2001.

Disponível em: http://dx.doi.org/10.1109/2.953469

Vidales, P.; Chakravorty, R.; Policroniades, C. Proton: a policy-based solution for future 4G devices. In: Policies for Distributed Systems and Networks, 2004. POLICY 2004. Proceedings. Fifth IEEE International Workshop on, 2004, p. 219 - 222.

Disponível em: http://dx.doi.org/10.1109/POLICY.2004.1309173

Wac, K. E.; Bults, R. G. A.; Beijnum, B. J. F.; Chen, H.; Konstantas, D. Toward mobile web 2.0-based business methods: Collaborative QoS-information sharing for mobile service users. In: HEAD, M.; LI, E., eds. Mobile and Ubiquitous Commerce, v. 4 de Advanced E-Business Methods, UK: Information Science Reference, p. 60-81, 2009.

Disponível em: http://www.igi-global.com/reference/details.asp? ID= 33424

WACK, K. Collaborative sharing of quality of service-information for mobile service users. Tese de Doutoramento, University of Geneva, Geneva, Switzerland, 2009.

Disponível em: http://archive-ouverte.unige.ch/vital/access/ manager/Repository/unige:2454

Wei, Q.; Farkas, K.; Prehofer, C.; Mendes, P.; Plattner, B. Context-aware handover using active network technology. Computer Networks, v. 50, n. 15, p. 2855 - 2872, 2006.

Disponível em: http://dx.doi.org/10.1016/j.comnet.2005.11.002

YAMI, E.; VAKILI, V. Adaptive bandwidth allocation and mobility prediction in mobile cellular networks. In: Third International Conference on Next Generation Mobile Applications, Services and Technologies (NGMAST '09), 2009, p. 343 -348.

Disponível em: http://dx.doi.org/10.1109/NGMAST.2009.13

Yan, X.; Sekercioglu, Y. A.; NARAyanan, S. A survey of vertical handover decision algorithms in fourth generation heterogeneous wireless networks. Computer Networks, v. 54, n. 11 , p. $1848-1863,2010$.

Disponível em: http://dx.doi.org/10.1016/j.comnet.2010.02.006 
Yokota, H.; Idoue, A.; Hasegawa, T.; Kato, T. Link layer assisted mobile ip fast handoff method over wireless lan networks. In: MobiCom '02: Proceedings of the 8th annual international conference on Mobile computing and networking, New York, NY, USA, 2002, p. 131-139. Disponível em: http://doi.acm.org/10.1145/570645.570661

Yu, J.; Benatallah, B.; Casati, F.; Daniel, F. Understanding mashup development. IEEE Internet Computing, v. 12, n. 5, p. 44 -52, 2008.

Disponível em: http://dx.doi.org/10.1109/MIC.2008.114

YU, Z.; FAN, Z. Evaluation method for collaboration degree in knowledge collaboration team. In: 2010 International Conference on Future Information Technology and Management Engineering (FITME), 2010, p. $502-505$.

Disponível em: http://dx.doi.org/10.1109/EITME.2010.5654833

Zeng, D.; Chen, H.; Lusch, R.; Li, S.-H. Social media analytics and intelligence. IEEE Intelligent Systems, v. 25, n. 6, p. 13 -16, 2010.

Disponível em: http://dx.doi.org/10.1109/MIS.2010.151 